Aus der Abteilung Dermatologie, Venerologie und Allergologie

(Prof. Dr. med. M. P. Schön)

im Zentrum Arbeits-, Sozial-, Umweltmedizin und Dermatologie

der Medizinischen Fakultät der Universität Göttingen

\title{
Differenzielle Beeinflussung endothelialer Antigene und dynamischer Endothel-Lymphozyten-Interaktionen durch Dimethylfumarat und Monomethylfumarat
}

\author{
INAUGURAL - DISSERTATION \\ zur Erlangung des Doktorgrades \\ der Medizinischen Fakultät der \\ Georg-August-Universität zu Göttingen
}

\author{
vorgelegt von \\ Nora Drick
}

aus

Berlin 
Dekan: Prof. Dr. med. C. Frömmel

I. Berichterstatter: Prof. Dr. med. M. P. Schön

II. Berichterstatter/in: Prof. Dr. med. K. Schäfer

III. Berichterstatter/in: Prof. Dr. med., Dr. rer. nat. T. Crozier

Tag der mündlichen Prüfung: 18.07.2012 


\section{Inhaltsverzeichnis}

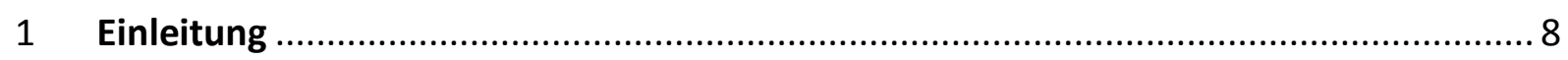

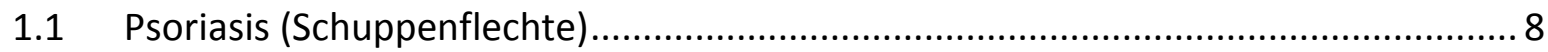

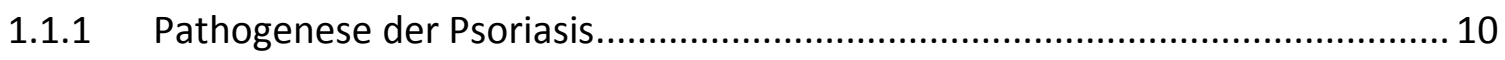

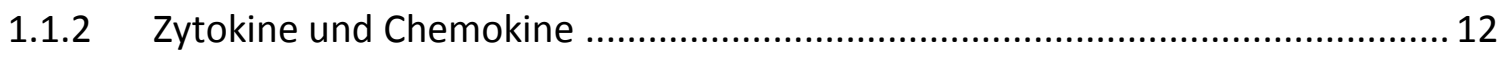

1.1.3 Einwanderung von Leukozyten ................................................................ 13

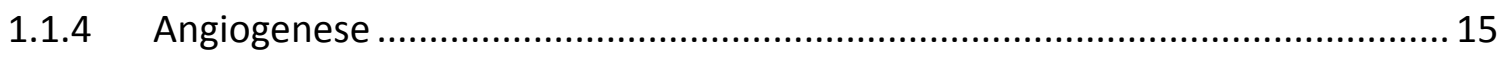

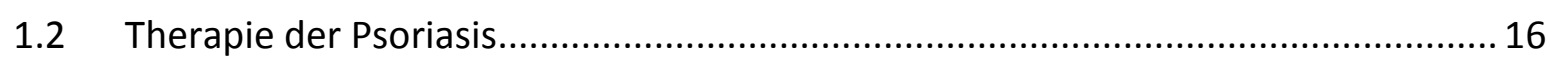

$1.3 \quad$ Fumarsäureester in der Therapie der Psoriasis.................................................... 18

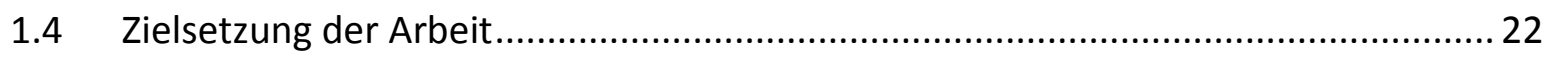

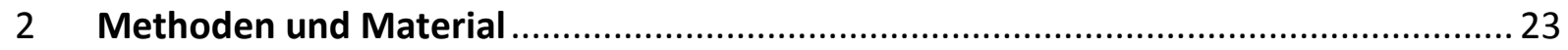

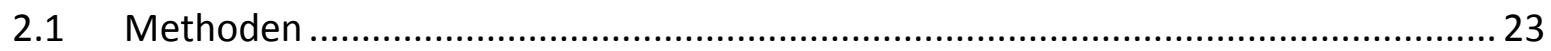

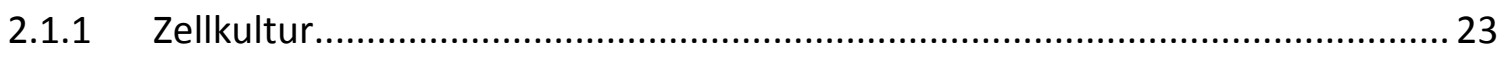

2.1.2 Konzentrationsreihe und Probengewinnung ................................................. 23

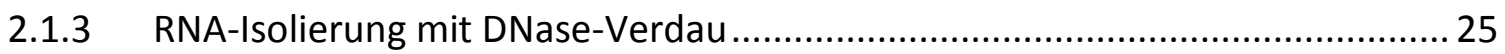

2.1.4 Photometrische Bestimmung der RNA-Konzentration ................................... 26

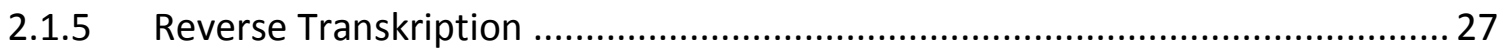

2.1.6 Polymerase-Kettenreaktion (engl. polymerase chain reaction, PCR) ................ 28

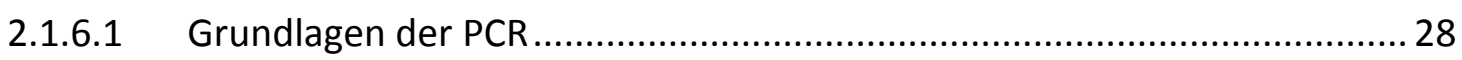

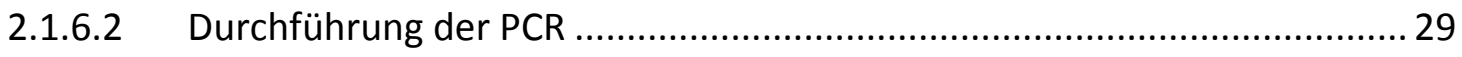

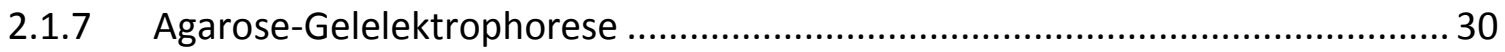

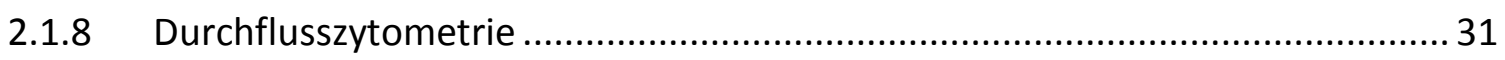

2.1.8.1 Prinzip der Durchflusszytometrie …........................................................ 31

2.1.8.2 Durchführung der Durchflusszytometrie ................................................ 32

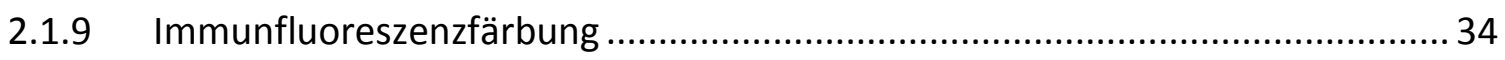

2.1.9.1 Prinzip der Immunfluoreszenzfärbung ..................................................... 34

2.1.9.2 Durchführung der Immunfluoreszenzfärbung ...................................... 34

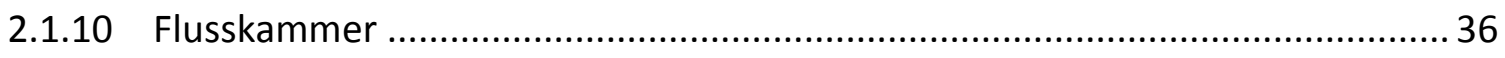

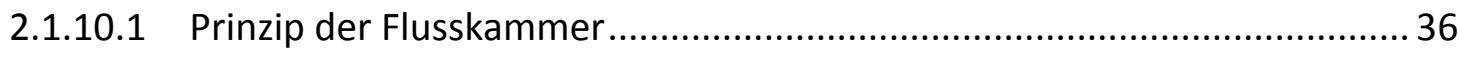

2.1.10.2 Vorbereitung für ein Flusskammerexperiment .................................... 36 


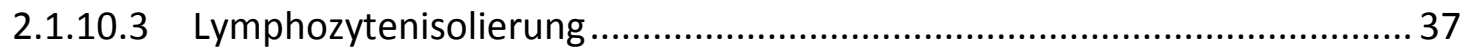

2.1.10.4 Durchführung eines Flusskammerexperiments...................................... 39

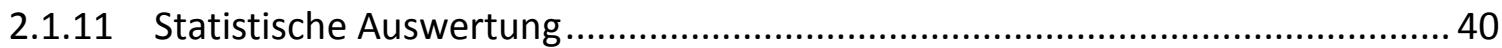

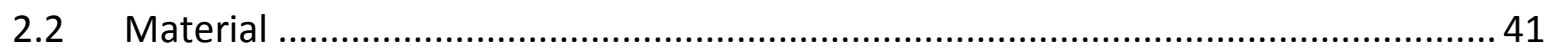

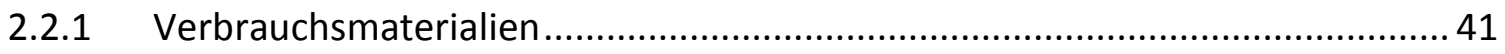

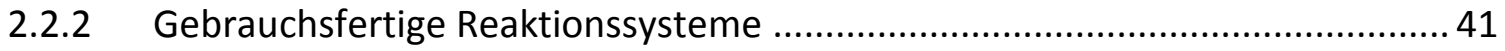

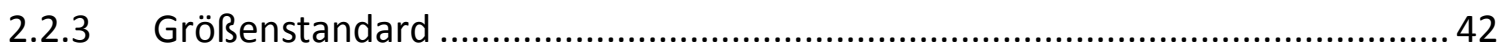

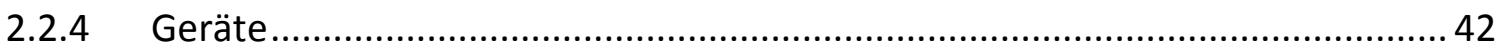

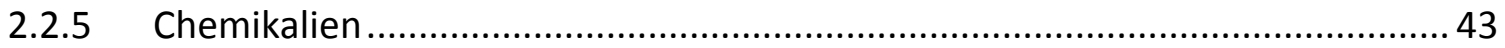

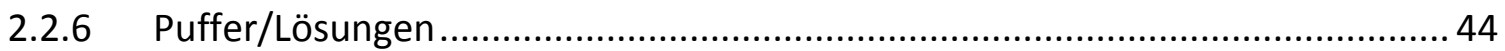

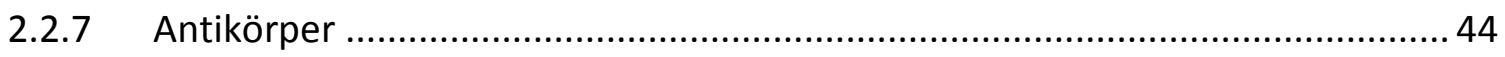

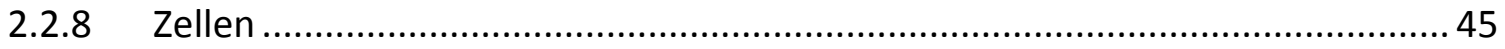

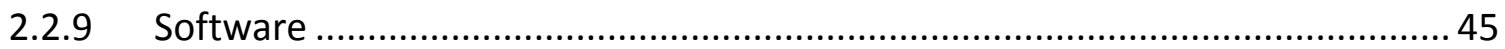

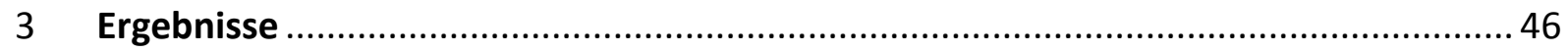

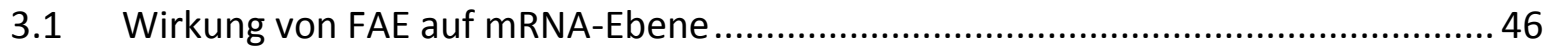

3.1.1 Wirkung von DMF und MMF auf die Zytokintranskription ............................. 46

3.1.2 Wirkung von DMF und MMF auf die VEGF-Transkription ............................... 49

3.1.3 Wirkung von DMF und MMF auf die Adhäsionsproteintranskription ............... 51

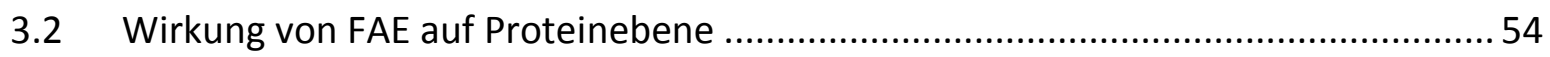

3.2.1 Einfluss von DMF und MMF auf die Expression von E-Selektin .........................55

3.2.2 Einfluss von DMF und MMF auf die Expression von VCAM-1......................... 58

3.2.3 Einfluss von DMF und MMF auf die Expression von ICAM-1 ...........................61

3.3 Wirkung der FAE auf die Interaktion von Endothelzellen und Lymphozyten ........... 63

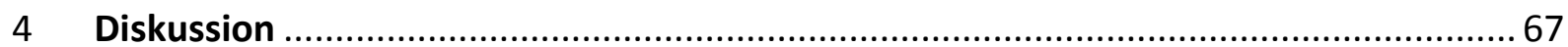

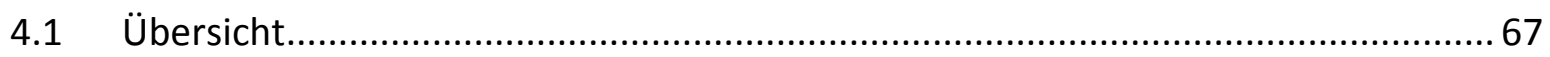

4.2 DMF inhibiert die Expression der Adhäsionsproteine E-Selektin, ICAM-1 und

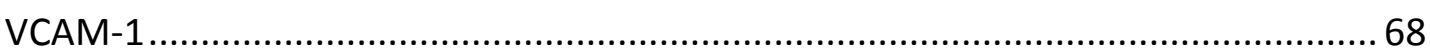

4.2.1 DMF interferiert mit der Wirkung des Transkriptionsfaktors NF-KB ................ 70

4.3 Wirkung von DMF auf die Adhäsionsproteine VE-Cadherin und PECAM-1 ............. 71

4.4 DMF inhibiert die Interaktion von Endothelzellen und Lymphozyten ...................... 72 
4.5 DMF inhibiert die Transkription proinflammatorischer Zytokine ........................... 73

4.6 DMF führt zu einem Anstieg der VEGF-Konzentration auf mRNA-Ebene ................. 75

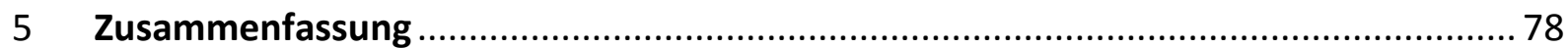

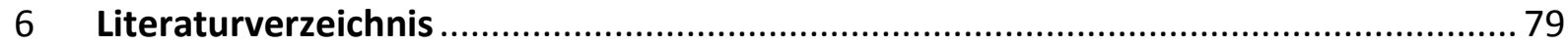

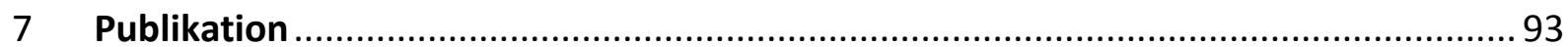




\section{Abkürzungsverzeichnis}

Abb.

AK

bp

BSA

$\mathrm{CaCl}_{2}$

CD

CDNA

CFDA-SE

DAPI

DMF

DMSO

DNA

dNTP

EBM

EGM-MV

FAE

FCS

FITC

GSH

HBSS

$\mathrm{HO}$

ICAM

IFN

$\lg$

IL

LPS

MFI

MMF

MMP
Abbildung

Antikörper

Basenpaar

engl. body surface area

Calciumchlorid

engl. cluster of differentiation

engl. complementary DNA

Carboxyfluorescein-diacetat-succinimidyl-ester

4',6-Diamidin-2-phenylindol

Dimethylfumarat

Dimethylsulfoxid

Desoxyribonukleinsäure

Desoxyribonukleotid-Triphosphat

Basalmedium für Endothelzelln (engl. endothelial cell basal medium)

Wachstumsmedium für mikrovaskuläre Endothelzellen (engl.

endothelial cell growth medium for microvascular vessel)

Fumarsäureester (engl. fumaric acid ester)

fetales Kälberserum (engl. fetal calf serum)

Fluoresceinisothiocyanat

Glutathion

engl. Hank's Buffered Salt Solution

Hämoxygenase

engl. intercellular adhesion molecule

Interferon

Immunglobulin

Interleukin

Lipopolysaccharid

mittlere Fluoreszenzintensität (engl. mean fluorescence intensity)

Monomethylfumarat

Matrixmetalloproteinase 
mRNA

MTX

NAC-DMS

OD

PASI

PBMC

PBS

PCR

PE

RNA

rpm

RT

SCID

$\mathrm{T}_{\mathrm{H}}$

TNF

UV

VCAM

VEGF engl. messenger RNA

Methotrexat

$\mathrm{N}$-acetyl-S-(1,2-dimethoxycarbonylethyl)cystein

optische Dichte

engl. psoriasis area and severity index

Mononukleäre Zellen (engl. peripheral blood mononuclear cells)

engl. phosphate buffered saline

Polymerase-Kettenreaktion (engl. polymerase chain reaction)

Phycoerythrin

Ribonukleinsäure

Umdrehungen pro Minute (engl. rounds per minute)

Raumtemperatur

engl. severe combined immunodeficiency

T-Helferzellen

Tumornekrosefaktor

Ultraviolett

engl. vascular cell adhesion molecule

engl. vascular endothelial growth factor

\section{Einheiten}

${ }^{\circ} \mathrm{C}$

$\mathrm{g}, \mathrm{mg}, \mu \mathrm{g}, \mathrm{ng}$

h, $\min , \mathrm{s}$

$\mathrm{l}, \mathrm{ml}, \mu \mathrm{l}$

$\mathrm{M}, \mathrm{mM}, \mu \mathrm{M}$

$\mathrm{nm}$
Grad Celsius

Gramm, Milligramm, Mikrogramm, Nanogramm

Stunde, Minute, Sekunde

Liter, Milliliter, Mikroliter

Molar, Millimolar, Mikromolar

Nanometer 


\section{Einleitung}

\subsection{Psoriasis (Schuppenflechte)}

Die Psoriasis ist eine gutartige, chronisch schubweise verlaufende entzündliche Erkrankung der Haut, mit scharf begrenzten erythematosquamösen Plaques. Etwa 2 - 3\% der europäischen Bevölkerung, Männer und Frauen gleichermaßen, sind betroffen. Häufig betroffene Körperregionen, so genannte Prädilektionsstellen, sind neben den Streckseiten der Extremitäten die Sakralregion, der behaarte Kopf und die Region um den Bauchnabel. Die scharf begrenzten, erythematosquamösen Plaques sind gekennzeichnet durch eine nicht fest haftende, silbrig-weiße Schuppung.

Die Veranlagung zur Entwicklung einer Psoriasis ist genetisch festgelegt, der Vererbungsmodus allerdings noch unklar. Die Konkordanzrate bei eineiigen Zwillingen liegt bei ca. 70\% (Farber 1972). Neben der erblichen Disposition spielen auch Umwelteinflüsse eine entscheidende Rolle. Auslösende Faktoren für einen Ausbruch oder eine Exazerbation der Erkrankung können Infektionen, insbesondere der oberen Atemwege, Medikamente, das Klima oder psychische Faktoren sein. Mechanische Reizungen der Haut können zur Entstehung eines Psoriasisherdes an der dem unspezifischen Reiz ausgesetzten und zuvor nicht betroffenen Hautstelle führen, dem Köbner-Phänomen.

Die häufigste Form der Psoriasis ist mit ca. 90\% die Psoriasis vulgaris, die auch als Psoriasis vom Plaque-Typ bezeichnet wird. Es kommt zur Ausprägung einzelner, später oft konfluierender Plaques, bevorzugt an den Prädilektionsstellen. Es werden zwei Typen unterschieden. Der häufiger auftretende Typ I zeichnet sich durch eine frühe Manifestation, mit einem Altersgipfel zwischen 15 und 22 Jahren und eine hohe familiäre Belastung aus. In einer Studie wiesen $71 \%$ der Patienten mit Psoriasis vulgaris Typ I eine positive Familienanamnese auf (Morris et al. 2001). Die klinischen Verläufe sind häufig schwerer und neigen zur Generalisation. Zudem konnte eine Assoziation mit verschiedenen HLA-Allelen gezeigt werden. Das Allel HLA-Cw6 konnte in einer Untersuchung bei 54\% der Patienten mit Typ-I-Psoriasis nachgewiesen werden (Mallon et al. 1997). Bei der Psoriasis vulgaris Typ II hingegen liegt der Erkrankungsgipfel zwischen 57 und 60 Jahren. Es zeigt sich keine familiäre Häufung und die Erkrankung ist oft weniger stark ausgeprägt als bei der Psoriasis Typ I 
(Henseler und Christophers 1985). Grundsätzlich kann sich die Psoriasis aber in jedem Lebensalter erstmals manifestieren.

Die Psoriasis guttata verläuft oft akut exanthematisch. Häufig tritt sie als Erstmanifestation im Jugendalter und bevorzugt nach Streptokokkeninfektionen auf. Ein Übergang in eine Psoriasis vulgaris ist möglich.

Die Psoriasis inversa zeichnet sich durch Hautveränderungen in den intertriginösen Arealen der Haut aus und zeigt klassischerweise keine oder wenig Schuppung.

Die Psoriasis pustulosa ist durch Pustelbildung auf stark geröteten erythematösen Arealen gekennzeichnet. Es werden mehrere klinische Varianten unterschieden. Die Psoriasis pustulosa generalisata (Typ von Zumbusch) geht zunächst mit einzeln stehenden, später meist konfluierenden Pusteln, Fieber und einem starken Krankheitsgefühl einher. Bei der Psoriasis pustulosa palmoplantaris (Typ Barber-Königsbeck) sind nur die Handflächen und Fußsohlen befallen. Sowohl die Psoriasis vulgaris als auch die Psoriasis pustulosa können in eine psoriatische Erythrodermie übergehen. Bei dieser Maximalform ist der gesamte Körper betroffen.

Bei 20 - 30\% der Psoriasis-Patienten kommt es (oftmals nach Jahren) zusätzlich zu einer Gelenkbeteiligung (Psoriasis arthropathica). Die Ausprägung der Gelenkveränderungen erfolgt unabhängig von der Erkrankung der Haut (Amherd-Hoekstra et al. 2010).

Obwohl die Psoriasis sich in erster Linie an der Haut manifestiert, ist sie eine entzündliche Systemerkrankung, die gehäuft mit anderen Erkrankungen assoziiert ist (so genannte Komorbidität). Gerade in den letzten Jahren sind klinische und pathogenetische Zusammenhänge zwischen Psoriasis und anderen Erkrankungen in den Mittelpunkt des wissenschaftlichen Interesses gerückt. Zu den häufig mit Psoriasis assoziierten Erkrankungen gehören kardiovaskuläre Erkrankungen, das metabolische Syndrom sowie psychiatrische Erkrankungen aus dem Formenkreis der Depression (Boehncke et al. 2010).

Zur Messung des Schweregrades der Psoriasis wird häufig der „psoriasis area and severity index" (PASI) verwendet, der Werte zwischen 0 und 72 annehmen kann. Dabei wird die Ausprägung des Erythems, der Infiltration und der Schuppung sowie das Ausmaß der von diesen Symptomen betroffenen Körperoberfläche berücksichtigt. Die einfache Abschätzung über die Ausdehnung der Läsionen in Bezug auf die Körperoberfläche ist mit der „body surface area" (BSA) möglich. PASI und BSA sind u.a. für Therapieentscheidungen von Bedeutung. Ab einem PASI $>10$ und einer BSA > 10 spricht man von einer mittelschweren bis 
schweren Form der Psoriasis. Diese Definition wird auch in der S3-Leitlinie zur Therapie der Psoriasis verwendet (Nast et al. 2011).

\subsubsection{Pathogenese der Psoriasis}

Der Erkrankung liegt vermutlich ein Immunprozess zugrunde, bei dem es durch eine T-Zellvermittelte kutane Entzündungsreaktion zu epidermaler Hyperproliferation kommt. Über ein bisher unbekanntes Antigen kommt es zur Aktivierung von dendritischen Zellen (LangerhansZellen) in der Haut, die dann wiederum über die Interaktion mit T-Lymphozyten in Lymphknoten zur Auslösung einer $\mathrm{T}_{H} 1$-vermittelten Entzündung führen (Lebwohl 2003). T-Helferzellen ( $T_{\mathrm{H}}$-Zellen) treten in zwei Subpopulationen auf. $T_{\mathrm{H}}$ 1-Zellen produzieren vorwiegend die Zytokine Interleukin-2 (IL-2), Interferon- $\gamma$ (IFN- $\gamma$ ) und Tumornekrosefaktor- $\alpha$ (TNF $\alpha$ ) und induzieren so eine zelluläre Immunantwort. $T_{H} 2$-Zellen hingegen produzieren hauptsächlich IL-3, IL-4, IL-5, IL-9, IL-10 und IL-13 und sorgen so für eine Antikörperabhängige Immunantwort. Bei der Psoriasis ist das Gleichgewicht zwischen $T_{H} 1$ - und $\mathrm{T}_{\mathrm{H}}$ 2-Antwort verschoben, die $\mathrm{T}_{\mathrm{H}}$ 1-vermittelte Immunantwort überwiegt. Die $\mathrm{T}_{H}$ 1-Zytokine INF- $\gamma$, IL-2 und TNF $\alpha$ fördern die Reifung der Keratinozyten und begünstigen vaskuläre Veränderungen (Lew et al. 2004). Histologisch findet man als Korrelat der Entzündungsreaktion eine Ansammlung von Leukozyten. In der neueren Forschung hat man darüber hinaus auch die besondere Relevanz der erst kürzlich beschriebenen $T_{H}$ 17-Zellen bei der Pathogenese der Psoriasis erkannt. $\mathrm{T}_{H} 17$ Zellen sind durch die Produktion des Zytokins IL-17 gekennzeichnet und spielen wichtige Rollen bei der Pathogenese verschiedener Autoimmunerkrankungen, beispielsweise Multiple Sklerose, Rheumatoide Arthritis, Morbus Crohn oder Diabetes Typ I (Steinman 2007; Harrington et al. 2005). Das Spektrum der T-Zellen, das den psoriatischen Krankheitsprozess vermittelt, unterscheidet sich teilweise deutlich von demjenigen in anderen chronisch entzündlichen Hauterkrankungen, beispielsweise der atopischen Dermatitis (Eyerich et al. 2011).

An der Ausprägung psoriatischer Läsionen sind viele der in der Haut auftretenden Zellgruppen beteiligt. Die Teilungsrate der basalen Keratinozyten ist bis zu 50-fach gesteigert. Um durch die Epidermis bis zum Stratum corneum zu gelangen, brauchen die Keratinozyten in psoriatischer Haut lediglich 3 - 5 Tage, anstatt der normalen 28 - 30 Tage (Schön und Boehncke 2005). Es kommt zu einer verbreiterten Epidermis (Akanthose). Die 
rasch proliferierenden Keratinozyten reifen nicht aus und besitzen bei Erreichen des Stratum corneum noch ihre Zellkerne (Parakeratose).

Auch Endothelzellen sind an der Pathogenese der Psoriasis beteiligt. Die dermalen Blutgefäße sind dilatiert, vermehrt gewunden und reichen in den dermalen Papillen bis an die Epidermis heran (Micali et al. 2010). Bei Psoriasis-Patienten zeigen die Gefäße der papillären Dermis in betroffener Haut eine vierfach vergrößerte Endothelzelloberfläche im Vergleich zu nicht betroffener Haut (Creamer et al. 1997). Die Endothelzellen in psoriatischer Haut exprimieren verstärkt die Adhäsionsproteine E-Selektin (CD62E), VCAM-1 (CD106) und ICAM-1 (CD54), die für die Adhäsion von Leukozyten an der Gefäßinnenwand essentiell sind. T-Helferzellen (CD4-positive Lymphozyten) und zytotoxische T-Zellen (CD8-positive Lymphozyten) verlassen die Zirkulation und infiltrieren sowohl die Epidermis als auch die Dermis. Dort bilden sie proinflammatorische Zytokine und sind somit an der Aufrechterhaltung des Entzündungsgeschehens maßgeblich beteiligt. Einwandernde neutrophile Granulozyten, eine weitere Leukozytenpopulation, sammeln sich in der Epidermis und bilden Munro-Mikroabszesse. In einer Studie konnte gezeigt werden, dass die Injektion von CD4 ${ }^{+}$-T-Lymphozyten ausreicht, um in SCID (severe combined immunodeficiency) Mäusen einen Phänotyp hervorzurufen, welcher der Psoriasis

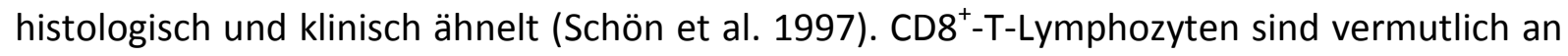
der Aufrechterhaltung der Läsionen maßgeblich beteiligt (Robert und Kupper 1999).

T-Lymphozyten spielen somit in der Pathogenese der Psoriasis eine entscheidende Rolle. Obwohl der Pathomechanismus der Psoriasisentstehung noch nicht restlos aufgeklärt wurde, wird von einem primär T-Zell-vermittelten Geschehen ausgegangen. Das Ansprechen auf die Behandlung mit Cyclosporin A gab einen ersten Hinweis auf die Beteiligung von T-Lymphozyten am Krankheitsgeschehen (Mueller und Herrmann 1979). Cyclosporin A unterdrückt die Immunabwehr durch Hemmung des Enzyms Calcineurin, welches in T-Lymphozyten für die Phosphorylierung mehrerer Transkriptionsfaktoren zuständig ist. In einer weiteren Studie konnte gezeigt werden, dass sich durch Gabe eines Fusionsproteins aus humanem Interleukin-2 und Fragmenten des Diphterietoxins (DAB $\left.{ }_{389} / L-2\right)$, das sich speziell gegen T-Zell-Funktionen richtet, eine Besserung der Symptomatik erzielen lässt (Gottlieb et al. 1995). Gestützt wird die Annahme, dass T-Lymphozyten eine Schlüsselrolle in der Pathogenese der Psoriasis spielen, auch noch durch weitere Versuche. So konnte gezeigt werden, dass die Injektion aktivierter T-Zellen in gesunde Haut von Psoriasis-Patienten, die 
zuvor auf SCID-Mäuse transplantiert worden war, zur Ausbildung psoriatischer Veränderungen führte (Wrone-Smith und Nickoloff 1996). Auch die Assoziation der Psoriasis mit bestimmten MHC-Allelen (Bowcock 2005) sowie die Induktion Psoriasis-artiger Hautläsionen durch dysregulierte T-Zellen in einem Modell des immunologischen adoptiven Transfers (Schön et al. 1997) sprechen für eine T-Zell-vermittelte Immunpathogenese der Psoriasis.

\subsubsection{Zytokine und Chemokine}

Eine zentrale Rolle in der Pathogenese der Psoriasis spielen verschiedene Chemokine und Zytokine. Diese bilden ein komplexes Netzwerk und werden sowohl von Keratinozyten, mesenchymalen Zellen, beispielsweise Endothelzellen, sowie verschiedenen Zellen des Immunsystems sezerniert. Durch das Zusammenspiel der proinflammatorischen Chemokine und Zytokine und der an der Pathogenese beteiligten Zellgruppen lassen sich viele Merkmale der Psoriasis, wie die Hyperproliferation der Keratinozyten, die verstärkte Vaskularisierung der Haut und die Entzündungsreaktion erklären.

Zytokine dienen als interzelluläre Mediatoren und modulieren die Aktivität einzelner Zellen oder Gewebe (Stadnyk 1994). Zu den Zytokinen zählen u.a. Tumornekrosefaktoren, Interleukine, die der Kommunikation von Leukozyten dienen, und Chemokine, die chemotaktisch auf Zellen des Immunsystems wirken.

In der Pathogenese der Psoriasis spielen insbesondere die proinflammatorischen $T_{H}$ 1-Zytokine IL-2, IFN- $\gamma$ und TNF $\alpha$ eine zentrale Rolle. Sie induzieren die Expression von Adhäsionsproteinen auf Endothelzellen und Keratinozyten und ermöglichen dadurch Interaktionen mit Leukozyten. T-Lymphozyten werden durch chemotaktische Chemokine, u.a. CCL27 (cutaneous T-cell-attracting chemokine), welches von Keratinozyten sezerniert wird, an den Ort der Entzündung rekrutiert (Homey et al. 2002). Das Chemokin MCP-1 (monocyte chemotactic protein-1) wird ebenfalls von Keratinozyten produziert und wirkt chemotaktisch auf Monozyten (Vestergaard et al. 2004). Durch das Chemokin CXCL1 (GRO- $\alpha$ ), welches von Endothelzellen und Keratinozyten sezerniert wird, werden neutrophile Granulozyten an den Ort der Entzündung gelockt.

Die aktivierten Leukozyten bilden ihrerseits vermehrt Adhäsionsproteine, verlassen die Blutbahn und bilden Infiltrate in Dermis und Epidermis. Dort sezernieren sie verschiedene 
Mediatoren, bespielsweise IFN- $\gamma$ und TNF $\alpha$, und üben somit wiederum proinflammatorische Wirkungen auf die Endothelzellen und Keratinozyten aus. Das Zytokinmilieu führt zu einer gesteigerten Angiogenese. Die Keratinozyten werden zur Proliferation angeregt und sezernieren ihrerseits Wachstumsfaktoren und Zytokine, u.a. IL-6, IL-8, IL-12 und TNFa. Somit entsteht ein Netzwerk, in dem sich die einzelnen Zellgruppen gegenseitig stimulieren und die Sekretion von Entzündungsmediatoren dauerhaft gefördert wird. Die Zunahme der proinflammatorischen Mediatoren und das Überwiegen der $T_{H} 1$-Zytokine geht mit einem Ungleichgewicht zu Ungunsten der antiinflammatorischen Zytokine IL-10 und IL-4 einher (Austin et al. 1999). Der IL-10-Rezeptor wird in psoriatischer Haut ebenfalls reduziert exprimiert (Michel et al. 1997).

TNF $\alpha$ wird von verschiedenen Zellgruppen sezerniert und nimmt mit seinen zahlreichen Wirkungen unter den Entzündungsmediatoren eine zentrale Rolle ein (Boyman et al. 2004). In mehreren Studien konnte gezeigt werden, dass gegen TNFa gerichtete Antikörper in der Therapie der Psoriasis äußerst wirksam sind (Schopf et al. 2002; Leonardi et al. 2003) und TNF $\alpha$ eine regulierende Schlüsselrolle in der komplexen Entzündungskaskade einnimmt.

\subsubsection{Einwanderung von Leukozyten}

Der erste Schritt der Leukozyteninfiltration aus dem Blutstrom ins Gewebe ist das Rollen der Leukozyten entlang der Gefäßwand (Abb. 1). Diese kurzen, adhäsiven Interaktionen werden durch Selektine, auf endothelialer Seite hauptsächlich E-Selektin (CD62E) und P-Selektin (CD62P), vermittelt. Selektine sind einkettige Membranproteine, die Lektin-artige Bindungen mit Zuckerstrukturen eingehen können. Mit dem Hauptteil ihrer Transmembranhelix ragen sie in den perizellulären Raum und können dort Glykopeptide und Glykoproteine auf der Zelloberfläche von Leukozyten binden (Tedder et al. 1995). Ein drittes Selektin, L-Selektin (CD62L), wird auf Leukozyten exprimiert und ist besonders wichtig für die Interaktion mit Endothelzellen in lymphatischem Gewebe (Kansas 1996).

E- und P-Selektin werden auf aktivierten Endothelzellen verstärkt exprimiert. Während PSelektin intrazellulär in Weibel-Palade-Körperchen gespeichert und auf einen Reiz hin schnell auf die Zelloberfläche transloziert werden kann, wird E-Selektin nach Aktivierung der Zelle transkriptionell reguliert. Die wichtige Funktion der Selektine bei der Leukozytenadhäsion konnte in zahlreichen Studien belegt werden (Schön et al. 2002; Todderud et al. 1997). 
An das kurzzeitige lymphozytäre Rollen schließen sich die Aktivierung der Lymphozyten und nachfolgend die feste Adhäsion an. Die Aktivierung von Leukozyten und Endothelzellen unter dem Einfluss von Entzündungsmediatoren führt zu einer vermehrten Expression von Adhäsionsmolekülen auf beiden Zelltypen. Die Leukozyten binden infolgedessen fester an das Endothel. Von der Endothelzellseite aus wird diese Bindung durch ICAM-1 (intercellular adhesion molecule-1, CD54) und VCAM-1 (vascular cell adhesion molecule-1, CD106) aus der Immunglobulin-Superfamilie vermittelt. Aktivierte Lymphozyten binden über $\beta_{2}$-Integrine (LFA-1: lymphocyte function-associated antigen-1, CD11a/CD18; MAC-1: magrophage-1 antigen, $\mathrm{CD} 11 \mathrm{~b} / \mathrm{CD} 18$ ) an ICAM-1, über $\beta_{1}$-Integrine (VLA-4: very late antigen-4, CD49d/CD29) erfolgt die feste Bindung an VCAM-1 (Schön et al. 2003). Gleichzeitig flachen sich die Leukozyten ab und entziehen sich dadurch weitgehend den mechanischen Kräften des Blutstroms.

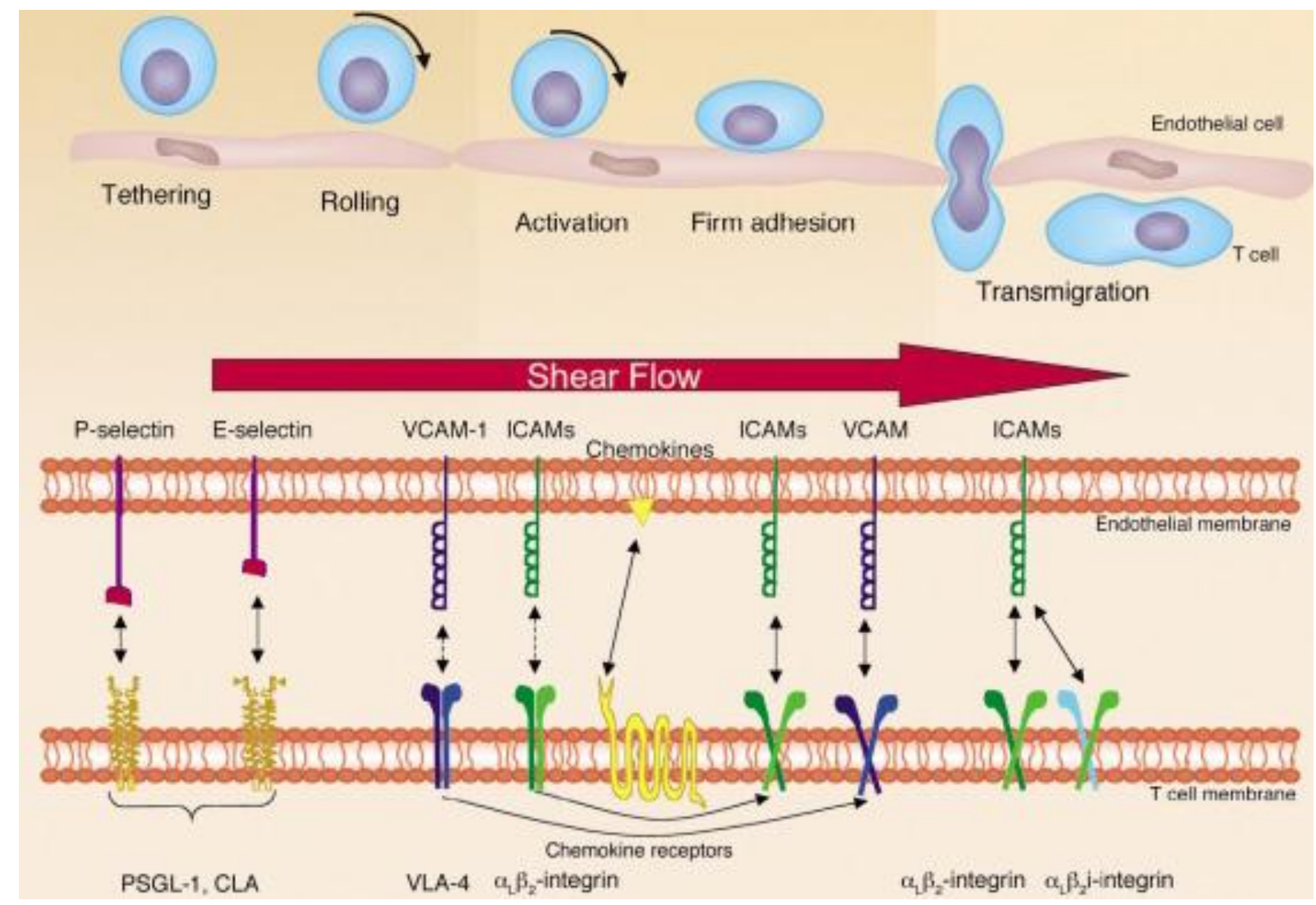

Abb. 1 Das lockere Anhaften und das kurzzeitige Rollen der Lymphozyten entlang der Gefäßwand wird auf Seiten der Endothelzellen durch E-Selektin und P-Selektin vermittelt. Die darauffolgende feste Adhäsion erfolgt durch die Bindung an die Adhäsionsproteine VCAM-1 und ICAM-1. An die feste Adhäsion schließt sich die Transmigration der Zellen durch den Endothelzellverbund an. (Zollner und Asadullah 2003, S. 981) 
Nach der Adhäsion an das Endothel gelangen die Leukozyten durch amöboide Bewegungen zum nächsten interendothelialen Spalt, durch den sie in das interstitielle Gewebe auswandern. Für die transendotheliale Migration konnten die Adhäsionsproteine PECAM-1 (platelet endothelial cell adhesion molecule 1, CD31), MIC2 (CD99), VE-cadherin (vascular endothelial cadherin, CD144) und die Proteine JAM-A, -B, -C (junctional adhesion molecules) als wichtige Moleküle identifiziert werden (Schön und Ludwig 2005). Sie sind an den lateralen Zellgrenzen der Endothelzellen lokalisiert und ermöglichen so die Migration der Leukozyten. Die Leukozyten binden, nachdem sie den Blutstrom verlassen haben, über $\beta_{1^{-}}$ Integrine an verschiedene Komponenten der extrazellulären Matrix, u.a. an Kollagenfasern, Fibronektin, Laminin oder Hyaluronsäure, und können sich so durch das Gewebe bewegen (Konter et al. 1989). Über die sich anschließende Migration der Leukozyten durch das epitheliale Gewebe ist bisher nur sehr wenig bekannt (Schön et al. 2003).

\subsubsection{Angiogenese}

Neben den Lymphozyteninfiltraten in Dermis und Epidermis sowie der Hyperproliferation der Keratinozyten lässt sich in psoriatischer Haut auch eine dysregulierte Angiogenese beobachten. Das verstärkte Auswachsen von Blutgefäßen in die Dermis zusammen mit morphologischen und funktionalen Veränderungen der Kapillargefäße ist Kennzeichen von chronisch entzündlichen Hauterkrankungen wie der Psoriasis (Detmar et al. 1994). Die Psoriasis geht mit verlängerten, verstärkt gewundenen und hyperpermeablen dermalen Gefäßen einher (Braverman und Yen 1977). Die Angiogenese, das Aussprossen neuer Blutgefäße aus bereits vorhandenen, wird durch proangiogene Faktoren wie VEGF (vascular endothelial growth factor), HIF (hypoxia-inducible factor), TNF $\alpha$ und IL-8 (CXCL8) gefördert. VEGF, ein Glykoprotein, stellt mit sieben verschiedenen Faktoren, VEGF A - F und PGF (placental growth factor), eine eigene Gruppe unter den Wachstumsfaktoren dar. VEGF induziert die Angiogenese und wird bei Verletzungen der Dermis sowie bei Hypoxie verstärkt von Keratinozyten exprimiert. Des Weiteren erhöht VEGF die endotheliale Permeabilität (Ferrara und Davis-Smyth 1997). Diese Destabilisierung bereits existierender Blutgefäße stellt einen essentiellen Schritt in der Angiogenese dar. VEGF wirkt mitogen auf mikro- und makrovaskuläre Endothelzellen (Thomas 1996) und trägt dazu bei, die Homöostase der epidermalen Barriere aufrecht $\mathrm{zu}$ erhalten. Zudem ist es in der Lage, die 
Keratinozytenproliferation zu stimulieren (Elias et al. 2008). Seine zahlreichen Wirkungen ruft VEGF über eine Bindung an die Tyrosinkinaserezeptoren VEGFR1 und VEGFR2 hervor. Die Expression von VEGF ist in den Keratinozyten psoriatischer Plaques gesteigert. Zudem werden die Rezeptoren VEGFR1 und -2 verstärkt in den Gefäßen der dermalen Papillen exprimiert (Detmar et al. 1994). Auch im Serum von Psoriasis-Patienten konnten gesteigerte VEGF-Konzentrationen gemessen werden. Die Menge des Serum-VEGF korreliert zudem mit der Schwere der Erkrankung (Nielsen et al. 2002). Ein Einzel-Nukleotid-Polymorphismus innerhalb des VEGF-kodierenden Gens ist mit einer frühen und gleichzeitig schweren Form der Psoriasis assoziiert (Young et al. 2004).

In einer kürzlich veröffentlichten Studie führte die Behandlung eines kolorektalen Karzinoms mit Bevacizumab, einem monoklonalen Antikörper gegen VEGF, bei einem zusätzlich an Psoriasis erkrankten Patienten zu einer vollständigen Remission der Psoriasis (Akman et al. 2009). In einer anderen Studie konnte gezeigt werden, dass VEGF-transgene Mäuse, die VEGF in ihrer Epidermis überexprimieren, spontan einen Psoriasis-ähnlichen Phänotyp entwickeln (Xia et al. 2003). Diese beiden Ergebnisse unterstützen die Annahme, dass VEGF in der Pathogenese der Psoriasis eine entscheidende Rolle spielt. Kürzlich konnte gezeigt werden, dass eine direkte Hemmung der Angiogenese, beispielsweise durch anti-angiogene somatische Gentherapie, die Psoriasis im Tiermodell bessern kann (Zibert et al. 2011).

\subsection{Therapie der Psoriasis}

Die Auswahl der optimalen Therapie der Psoriasis-Patienten richtet sich nach verschiedenen Kriterien. Zu Beginn sollte mit Hilfe klinischer Bewertungsskalen (so genannten Scores), wie dem PASI oder der BSA, eine Beurteilung des Schweregrades erfolgen. Für eine milde Psoriasis kommt in der Regel eine topische Behandlung in Betracht, eventuell in Kombination mit einer UV-B-Therapie. Beim Vorliegen einer mittelschweren bis schweren Psoriasis muss meist eine systemische Therapie und/oder eine Phototherapie gewählt werden.

Entsprechend ihrer Bedeutung für die Auslösung von Krankheitsschüben sollten zu Beginn der Therapie auch die Provokationsfaktoren der Psoriasis eliminiert werden. Dazu gehören in erster Linie Infekte, Stress, Medikamente und mangelnde Hautpflege. 
Am Anfang jeder Psoriasisbehandlung steht zudem die Entfernung der Hautschuppen (Keratolyse) durch lokale Anwendungen mit Salicylsäure $(5-10 \%)$ in Vaseline oder Harnstoffsalben. Sobald sich die parakeratotische Hornschicht wieder ausgebildet hat, muss die Keratolyse wiederholt werden. An die Keratolyse schließt sich die Therapie mit differenten Lokaltherapeutika an. Topische Glukokortikosteroide zählen zu den häufig angewendeten Lokaltherapeutika bei Psoriasis. Ihre gute Wirksamkeit konnte in zahlreichen Studien belegt werden (Mason et al. 2002). Des Weiteren werden Vitamin- $D_{3}$-Analoga (z.B. Calcipotriol, Tacalcitol, Calcitriol), lokale Retinoide (Vitamin-A-Analoga, z.B. Tazaroten, das in Deutschland allerdings vom Markt genommen wurde) und Dithranol (Cignolin), ein synthetisches Teerderivat, erfolgreich angewendet. Bei ca. $70-80 \%$ der Psoriasis-Patienten reicht eine adäquate topische Therapie zur Behandlung der Erkrankung aus.

Führt die Lokaltherapie allein nicht zu dem gewünschten Behandlungserfolg, kann sie mit der äußerst wirksamen Ultraviolett-Phototherapie kombiniert werden. Bei leichteren Fällen verwendet man UV-B, in schwereren aufgrund der größeren Eindringtiefe UV-A, meist in Kombination mit dem Wirkverstärker Psoralen (PUVA).

Systemische Therapien sind bei mittelschweren bis schweren Fällen von Psoriasis, die mittels lokaler Maßnahmen und Phototherapie nicht hinreichend kontrolliert werden können, indiziert. Neben ihrer Wirkung als Lokaltherapeutikum zeigen Retinoide auch in der systemischen Therapie einen positiven Effekt. Sie werden auch bei pustulösen Formen der Psoriasis und der psoriatischen Erythrodermie eingesetzt und meist mit einer Phototherapie kombiniert. Die Retinoide wirken auf Keratinozyten und führen zur Normalisierung der Proliferationsrate und der Ausdifferenzierung (Pang et al. 2008). Bei schwereren PsoriasisFällen stellt die systemische Behandlung mit Immunsuppressiva wie Methotrexat (MTX) oder Cyclosporin A eine gute Therapieoption dar (Heydendael et al. 2003). MTX inhibiert als Folsäure-Antagonist das Enzym Dihydrofolatreduktase und wirkt dadurch antiproliferativ und antiinflammatorisch. Cyclosporin A wirkt einerseits über die Inhibierung der TZellaktivierung und hat andererseits eine antiproliferative Wirkung auf Keratinozyten (Reynolds und Al-Daraji 2002). In Deutschland sind zudem die Fumarsäureester (FAE) für die systemische Therapie der Psoriasis zugelassen. Sie weisen eine gute klinische Wirksamkeit und eine große Langzeitsicherheit auf. Die Verträglichkeit wird jedoch durch gastrointestinale Nebenwirkungen eingeschränkt (Kolbach und Nieboer 1992). 
Die klassischen systemischen Therapien führen bei vielen Patienten zu dem gewünschten Behandlungserfolg. Allerdings rufen sie auch unerwünschte Nebenwirkungen hervor, sie sind bei einigen Patienten kontraindiziert (Kinderwunsch bei MTX), weisen eine kumulative Toxizität auf (MTX, Cyclosporin A) oder sind für die Dauertherapie nicht geeignet, wie zum Beispiel Cyclosporin A (Boehncke et al. 2003). In den letzten Jahren haben daher Biologika einen immer größer werdenden Stellenwert in der Therapie der schweren und therapieresistenten Psoriasis eingenommen. Bei den Biologika handelt es sich um biotechnologisch hergestellte Proteine, die aus lebendem Material wie Mikroorganismen, Pflanzen, menschlichen oder tierischen Zellen gewonnen werden und natürlich vorkommende, funktionale Membranstrukturen hemmen oder imitieren (Kupper 2003). Für die Behandlung der Psoriasis von großer Bedeutung sind Antikörper und Fusionsproteine, die entweder proinflammatorische Mediatoren antagonisieren oder die Funktionen von T-Zellen inhibieren. Die Wirksamkeit der Biologika ist häufig sehr gut. Zurzeit für die Therapie der Psoriasis vulgaris zugelassen sind die TNF $\alpha$-Antagonisten Infliximab (Remicade ${ }^{\circledR}$; chimärer monoklonaler Antikörper), Adalimumab (Humira ${ }^{\circledR}$; humaner monoklonaler Antikörper) und Etanercept (Enbrel ${ }^{\circledR}$; humanes Fusionsprotein eines TNF $\alpha$-Rezeptors). Efalizumab, ein T-Zellaktivierungsinhibitor, wurde 2009 aufgrund eines erhöhten Risikos für die Entwicklung einer progressiven multifokalen Leukenzephalopathie (PML) vom Markt genommen. Ustekinumab (Stelara ${ }^{\circledR}$; humaner monoklonaler Antikörper), ein p40-Antagonist, der die Wirkungen der Zytokine IL-12 und IL-23 hemmt, wurde ebenfalls zur Behandlung von Psoriasis-Patienten zugelassen und weist eine sehr gute Wirksamkeit und Verträglichkeit auf (Griffiths et al. 2010). Weitere Biologika, beispielsweise IL-17-Inhibitoren, befinden sich in späten Phasen der klinischen Entwicklung.

\subsection{Fumarsäureester in der Therapie der Psoriasis}

Bereits 1959 entdeckte der deutsche Chemiker Schweckendiek die antipsoriatische Wirkung der Fumarsäureester (FAE). Seit 1994 ist Fumaderm $^{\circledR}$, ein Mischpräparat aus Dimethylfumarat (DMF) und drei Salzen von Monoethylfumarat (MEF), für die Therapie der schweren Psoriasis vulgaris und seit 2008 auch zur Behandlung der mittelschweren Psoriasis in Deutschland zugelassen (Mrowietz et al. 2009). Fumaderm ${ }^{\circledR}$ ist eines der wichtigsten 
Medikamente in der systemischen „First-Line“-Therapie. Die S3-Leitlinie zur Behandlung der Psoriasis bescheinigt dem Medikament sowohl eine gute Wirksamkeit in der Induktions- und der Langzeittherapie als auch eine gute Langzeitsicherheit (Nast et al. 2011). In einer doppelblinden klinischen Studie mit 100 Patienten zeigte sich nach 16 Wochen Therapie mit Fumaderm $^{\circledR}$ eine wesentliche Besserung der Symptomatik (entspricht einer Besserung des PASI um mindestens $75 \%$ ) bei $54 \%$ der Patienten (Altmeyer et al. 1994). In einer multizentrischen, prospektiven Studie an 101 Patienten mit schwerer Psoriasis konnte nach 16 Wochen eine mittlere Reduktion des PASI um 80\% erreicht werden (Mrowietz et al. 1998).

Der pleiotrope Wirkmechanismus der FAE ist noch nicht vollständig geklärt und auch die Frage, welche Einzelsubstanz der FAE für den antipsoriatischen Effekt von Fumaderm ${ }^{\circledR}$ verantwortlich ist, konnte bislang noch nicht abschließend beantwortet werden. Hierfür kommt neben den Inhaltsstoffen von Fumaderm ${ }^{\circledR}$, DMF und MEF, auch Monomethylfumarat (MMF), ein Metabolit von DMF in Frage.

In einer Doppelblindstudie mit 45 Patienten zeigten sich keine Unterschiede im Behandlungserfolg zwischen einer Monotherapie mit DMF und einer Kombinationsbehandlung mit DMF und MEF (Nieboer et al. 1990). In einer weiteren Studie konnte gezeigt werden, dass eine Monotherapie mit MEF einer Plazebobehandlung nicht überlegen ist (Nieboer et al. 1989). Die Wirksamkeit von Fumaderm ${ }^{\circledR}$ scheint somit auf der Gabe von DMF zu beruhen.

Mit Hilfe von in-vitro-Experimenten konnten zahlreiche Wirkungen von DMF in definierten Systemen nachgewiesen werden. DMF ist in der Lage, die Umwandlung von Monozyten in dendritische Zellen, die für die Immunreaktion bei der Psoriasis bedeutend sind, zu unterdrücken (Zhu und Mrowietz 2001). Zudem moduliert es die Zytokinproduktion in Keratinozyten und T-Lymphozyten. Unter dem Einfluss von DMF verschiebt sich das Zytokinprofil weg von den dominierenden $T_{H}$ 1-Zytokinen hin zu den $T_{H}$ 2-Zytokinen. In humanen T-Lymphozyten konnte unter DMF-Behandlung eine absinkende Sekretion von IFN- $\gamma$ und eine ansteigende Konzentration des antiinflammatorischen IL-10 beobachtet werden (Ockenfels et al. 1998). Somit wirkt DMF dem $\mathrm{T}_{H} 1-\mathrm{T}_{H} 2$-Ungleichgewicht, das bei der Psoriasis vorliegt, entgegen. Eine weitere Eigenschaft von DMF in höheren Konzentrationen $(20 \mu \mathrm{g} / \mathrm{ml})$ ist die Induktion von Apoptose in humanen T-Lymphozyten. Aktivierte T-Zellen reagieren hierbei besonders empfindlich auf die Behandlung (Treumer et al. 2003). In vivo 
konnte außerdem gezeigt werden, dass DMF die Interaktion von Lymphozyten und Endothelzellen durch eine Reduktion der Expression lymphozytärer Adhäsionsmoleküle hemmt (Rubant et al. 2008). Des Weiteren inhibiert DMF die Proliferation von Keratinozyten, vermutlich über einen Anstieg des Calcium-Einstroms in die Zelle (Thio et al. 1994).

Die Ergebnisse der zahlreichen in-vitro-Versuche sprechen dafür, dass DMF (zumindest in Bezug auf die Behandlung der Psoriasis) der Hauptwirkstoff der verabreichten FAE ist. Allerdings konnte DMF im Blut gesunder Probanden nach oraler Einnahme von Fumaderm ${ }^{\circledR}$ bisher nicht nachgewiesen werden. Stattdessen wurde MMF in steigenden Konzentrationen gemessen (Litjens et al. 2004c), was schließlich zu der Annahme führte, dass es sich bei MMF um den Hauptwirkstoff unter den FAE handeln könnte.

Da Fumaderm ${ }^{\circledast}$ als magensaftresistente Tablette eingenommen wird, erfolgt die Freisetzung der Inhaltstoffe erst im Dünndarm. Hier kann DMF unter Abspaltung einer Methylgruppe schnell zu MMF verstoffwechselt werden (Abb. 2). Das legt die Vermutung nahe, dass nach Einnahme von Fumaderm ${ }^{\circledR}$ die Umwandlung von DMF in MMF bereits vollständig im Dünndarm erfolgen und MMF die aktive Substanz im Körper darstellen könnte. Mit Hilfe verschiedener in-vitro-Experimente konnte eine inhibitorische Wirkung von MMF auf den Differenzierungsvorgang von Monozyten zu dendritischen Zellen nachgewiesen werden (Litjens et al. 2006). T-Lymphozyten, die in Kokultur mit dendritischen Zellen inkubiert wurden, produzierten unter MMF-Einfluss weniger IFN- $\gamma$ (Litjens et al. 2004b). Zudem steigerte MMF die Produktion der $\mathrm{T}_{\mathrm{H}}$ 2-Zytokine IL-4 und IL-5. Ein Effekt auf die für die Psoriasis relevante $T_{H} 1$-Sekretion blieb allerdings aus (de Jong et al. 1996). 
<smiles>COC(=O)/C=C/C(=O)OC</smiles>

Dimethylfumarate

Monomethylfumarate

\begin{abstract}
Abb. 2 Die Abbildung zeigt die Strukturformeln der Fumarsäureester Dimethylfumarat (DMF) und Monomethylfumarat (MMF). DMF, ein Inhaltsstoff des Medikaments Fumaderm ${ }^{\circledR}$, lässt sich durch Abspaltung einer Methylgruppe in MMF umwandeln. (Rostami-Yazdi et al. 2010, S. 532)
\end{abstract}

In einer unlängst veröffentlichten Studie gelang nun der Nachweis eines Metaboliten von DMF im Urin von Psoriasis-Patienten (Rostami-Yazdi et al. 2009). Es handelt sich dabei um Acetylcystein, welches entsteht, wenn Arzneistoffe im Körper an Glutathion (GSH) gebunden werden. GSH ist für Entgiftungsprozesse und das Redox-Gleichgewicht in Zellen essentiell. Zuvor konnte bereits gezeigt werden, dass DMF unter physiologischen Bedingungen innerhalb kürzester Zeit eine kovalente Bindung mit GSH eingeht (Schmidt et al. 2007). Somit führt der aktuelle Stand der Forschung zu der Annahme, dass nur ein geringer Teil des oral aufgenommenen DMFs zu MMF hydrolysiert wird. Der größere Teil wird aus dem Duodenum in den Pfortaderkreislauf und dort in Zellen des Blutes aufgenommen und geht intrazellulär Verbindungen mit GSH ein.

In einer weiteren Studie führte der gesteigerte GSH-Verbrauch nach DMF-Behandlung in aktivierten mononukleären Zellen (peripheral blood mononuclear cells, PBMC) zur Induktion des antiinflammatorisch wirksamen Enzyms Hämoxygenase-1 (HO-1). Über den Anstieg der HO-1 werden in den Zellen entzündungshemmende Prozesse in Gang gesetzt, u.a. die Reduktion der Expression einiger Zytokine (Lehmann et al. 2007). Somit erklärt die Beobachtung, dass DMF intrazellulär mit GSH reagiert, nicht nur die fehlenden DMF-Spiegel im Blut, sondern trägt auch einen Teil dazu bei, die entzündungshemmende Wirkung von DMF aufzuklären. 


\subsection{Zielsetzung der Arbeit}

Bereits 1959 wurden die Fumarsäureester das erste Mal zur Behandlung der Psoriasis eingesetzt. Obwohl sie mittlerweile einen festen Stellenwert in der systemischen Therapie der Psoriasis eingenommen haben, ist ihr genauer Wirkmechanismus immer noch nicht bekannt. In dieser Arbeit sollen die Wirkungen der beiden Fumarsäureester DMF und MMF auf funktionelle Parameter humaner Endothelzellen untersucht werden.

Ziel ist es, in erster Linie einen Einfluss der FAE auf die Interaktion von Endothelzellen und Lymphozyten aufzudecken. Lymphozyten bilden bei der Psoriasis entzündliche Infiltrate in Epidermis und Dermis und spielen eine Hauptrolle in der Pathogenese der Psoriasis. Aus diesem Grund werden die Zell-Zell-Interaktionen mit Hilfe einer Flusskammer, einem experimentellen Modell für den essentiellen ersten Schritt der Lymphozyten-Rekrutierung, direkt beobachtet. Zusätzlich wird die Expression von Adhäsionsproteinen auf der Endothelzelloberfläche, die für die Infiltration der Lymphozyten in die Haut essentiell sind, untersucht. Da auch Chemokine in der Pathogenese der Psoriasis eine wichtige Rolle spielen, werden zudem die Veränderungen in der Chemokinexpression unter FAE-Einfluss beobachtet.

Von Interesse ist außerdem, welche der beiden untersuchten Substanzen einen Effekt auf die Endothelzellen ausübt, denn obwohl sich die Hinweise auf DMF als Hauptwirkstoff verdichten, ist zurzeit immer noch nicht klar, ob DMF, einer der Inhaltsstoffe von Fumaderm $^{\circledR}$, oder MMF, sein Hauptmetabolit, für die antipsoriatische Wirkung von Fumaderm ${ }^{\circledR}$ verantwortlich ist. 


\section{Methoden und Material}

\subsection{Methoden}

\subsubsection{Zellkultur}

Die Versuche wurden mit den humanen Endothelzellreihen HUVEC (human umbilical vein endothelial cells) und HPEC-A2 (immortalized human placental microvascular endothelial cells) (Schütz et al. 1997; Oostingh et al. 2007) durchgeführt. Für die Kultivierung wurden die Zellen aus dem flüssigen Stickstoff entnommen und die vorgesehene Zellmenge $\mathbf{1 . 0 0 0 . 0 0 0}$ Zellen) im Wasserbad aufgetaut. Im Anschluss wurden die Endothelzellen in $75 \mathrm{~cm}^{2}\left(T_{75}\right)$ großen Kulturflaschen ausgesät und bei $37^{\circ} \mathrm{C}, 5 \% \mathrm{CO}_{2}$ und einer Luftfeuchtigkeit von $95 \%$ kultiviert. Für HUVEC wurde Wachstumsmedium für Endothelzellen (EGM, endothelial growth medium) verwendet, HPEC-A2 wurden in Wachstumsmedium für mikrovaskuläre Endothelzellen (EGM-MV, endothelial growth medium for microvascular cells) kultiviert. Eine konfluente Zellschicht war abhängig von der jeweiligen Zellpassage nach 4 bis 6 Tagen erreicht. Die dicht gewachsenen Zellen konnten nun für ein Experiment genutzt oder passagiert werden. Zum Passagieren der Zellen wurde das Medium abgesaugt und der konfluente Zellrasen für ca. $30 \mathrm{~s}$ mit $10 \mathrm{ml}$ PBS gewaschen, um im Medium enthaltene Proteinaseinhibitoren zu entfernen. Im Anschluss erfolgten die Zugabe von $1 \mathrm{ml}$ Trypsin und die Inkubation im Brutschrank bei $37^{\circ} \mathrm{C}, 5 \% \mathrm{CO}_{2}$ und einer Luftfeuchtigkeit von $95 \%$ für 2 min. Unter dem Mikroskop wurde kontrolliert, dass sich die Zellen komplett vom Kulturflaschenboden abgelöst hatten. Anschließend wurde die Trypsinreaktion durch Zugabe des Mediums gestoppt, denn der Serumzusatz im Medium bewirkt eine sofortige Inaktivierung des Trypsins. Zellverklumpungen wurden durch mehrmaliges Resuspendieren aufgelöst und die Zellen abhängig von der gewünschten Zellzahl auf neue Kulturflaschen aufgeteilt.

\subsubsection{Konzentrationsreihe und Probengewinnung}

Um die Wirkung der Fumarsäureester DMF und MMF auf mRNA-Ebene zu untersuchen, wurden die beiden humanen Endothelzellreihen HUVEC und HPEC-A2 mit den sechs nachfolgenden Konzentrationen von DMF und MMF behandelt: 5, 15, 25, 50, 100 oder 
200 M. DMSO (Dimethylsulfoxid) diente als Lösungsmittel. Im Anschluss an die Behandlung wurden Proben für die mRNA-Analyse gewonnen. Dafür wurden HUVEC und HPEC-A2 so lange kultiviert, bis von jeder Zellreihe genügend Zellen (jeweils 16 Kulturflaschen zu je 25 $\mathrm{cm}^{2}, \mathrm{~T}_{25}$ ) vorhanden waren. Etwa $24 \mathrm{~h}$ vor der geplanten Behandlung mit den zu untersuchenden Fumarsäureestern wurde das spezielle Endothelzellmedium abgenommen, um eventuell auftretende Interaktionen zwischen im Medium enthaltenen Supplementfaktoren und den Endothelzellen zu unterbinden. Für die letzten $24 \mathrm{~h}$ wurden die Zellen in Basalmedium für Endothelzellen (EBM, endothelial basal medium), dem 10\% FCS zugesetzt war, kultiviert.

$\mathrm{Zu}$ Beginn der FAE-Behandlung wurde das Medium erneut abgenommen und alle Kulturflaschen mit 4 ml EBM-Medium gefüllt. Anschließend wurden 16 Reaktionsgefäße mit jeweils $1 \mathrm{ml}$, d.h. der gewünschten Menge an DMF/MMF-Lösung und EBM-Medium, gefüllt und anschließend in die 16 Kulturflaschen überführt. Im Anschluss wurden die Zellen für $1 \mathrm{~h}$ im Brutschrank inkubiert. Nun folgte die Stimulation mit $125 \mathrm{ng}$ TNF $\alpha(25 \mathrm{ng} / \mathrm{ml})$ für $4 \mathrm{~h}$. Vier der Kulturflaschen dienten als Kontrollen. Diese wurden entweder mit dem Lösungsmittel DMSO oder mit EBM versetzt oder blieben unbehandelt. Nach der insgesamt 5-stündigen Inkubation wurde das Medium abgesaugt und die Zellen wurden mit PBS gewaschen. Es folgte die Zugabe von $400 \mu \mathrm{l}$ Trypsin und eine Inkubation im Brutschrank für 2 min bei $37^{\circ} \mathrm{C}$, $5 \% \mathrm{CO}_{2}$ und einer Luftfeuchtigkeit von 95\%, um die Zellen vom Kulturflaschenboden abzulösen. Im Anschluss wurden die Zellen unter dem Mikroskop mit einer NeubauerZählkammer gezählt. Mit Hilfe der Zellzahlen war es möglich, die richtige Menge an LysePuffer, in dem die Zellen für die anschließende RNA-Isolierung aufgenommen werden sollten, zu ermitteln. Nach dem Zählen der Zellen wurden die Inhalte der Kulturflaschen mit jeweils $5 \mathrm{ml}$ Medium in Zentrifugen-Röhrchen überführt und bei $500 \times \mathrm{g}$ für $5 \mathrm{~min}$ zentrifugiert. Der Überstand wurde abgesaugt und das verbleibende Zellsediment in der zuvor ermittelten Menge an Lyse-Puffer resuspendiert und in ein 1-ml-Reaktionsgefäß überführt. Nun konnten die gewonnenen Zellproben direkt für die mRNA-Isolierung weiterverwendet oder bei $-20^{\circ} \mathrm{C}$ gelagert werden. 
Nachfolgend findet sich das Pipettierschema mit allen 16 Ansätzen:

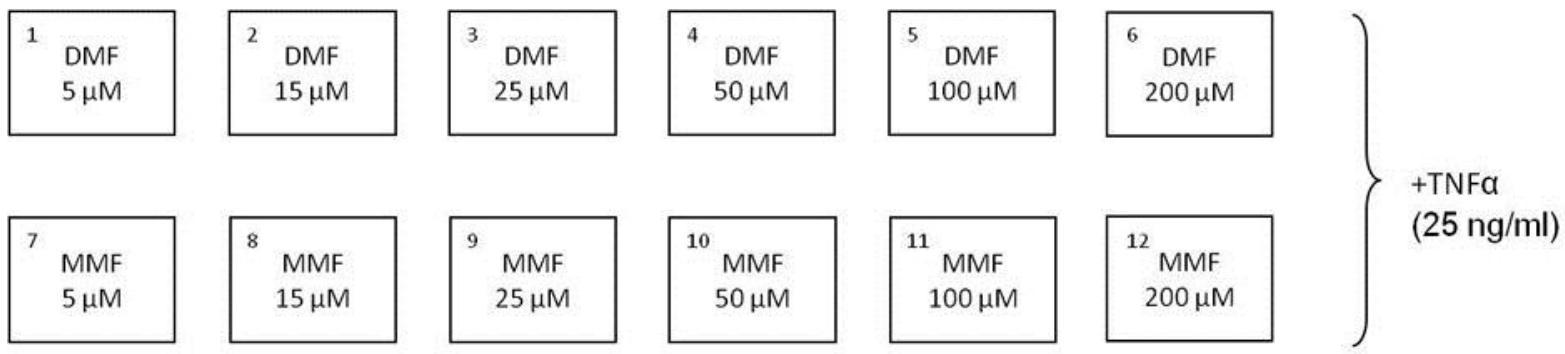

Kontrollen
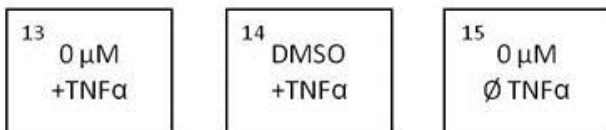

$160 \mu \mathrm{M}$
$\varnothing \mathrm{TNFa}$
EBM+Suppl.

Abb. 3 Die humanen Endothelzellen wurden mit DMF oder MMF in sechs verschiedenen Konzentrationen behandelt und mit TNF $\alpha$ stimuliert. Als Kontrolle dienten Ansätze, die entweder unbehandelt und stimuliert, unbehandelt und unstimuliert, mit dem Lösungsmittel DMSO behandelt und stimuliert oder unbehandelt, unstimuliert und mit Medium (einschließlich Zusätzen) behandelt wurden.

\subsubsection{RNA-Isolierung mit DNase-Verdau}

Die mRNA-Isolierung wurde mit dem Total RNA Kit von E.Z.N.A. ${ }^{\text {TM }}$, der DNase-Verdau mit dem RNase-Free DNase Set von OMEGA durchgeführt. Die RNA-Isolierung basiert auf der reversiblen Bindung von RNA an eine Silika-Gel-Membran. Zellrückstände und Verunreinigungen wurden durch zahlreiche Waschschritte mit anschließender Zentrifugation reduziert. Durch die Zugabe von DNase werden vorhandene DNA-Kontaminationen beseitigt. Im letzten Schritt wurde die RNA durch die Zugabe von RNase-freiem Wasser und der dadurch entstehenden $\mathrm{pH}-$ Wert-Änderung aus der Membran gelöst.

Nachfolgend findet sich eine Auflistung der einzelnen Arbeitsschritte:

Alle Angaben in $\mu \mathrm{l}$ beziehen sich jeweils auf eine Probe.

1) Die zu verarbeitenden Zellen wurden in TRK Lyse-Puffer aufgenommen. Bis zu einer Zellzahl von $5 \times 10^{6}$ Zellen erfolgte eine Aufnahme in $350 \mu \mathrm{l}$, bei einer Zellzahl zwischen $5 \times 10^{6}$ und $1 \times 10^{7}$ mussten $700 \mu$ hinzugegeben werden. Vor der Anwendung wurde der Lyse-Puffer noch mit 2\% $\beta$-Mercaptoethanol versetzt.

2) Das so gewonnene Gemisch wurde im Verhältnis 1:1 mit 70-prozentigem Ethanol gemischt und gevortext. Im Anschluss wurde das Lysat auf eine Säule pipettiert 
(enthält eine Silika-Gel-Membran), diese in ein 2-ml-Reaktionsgefäß platziert und für $60 \mathrm{~s}$ bei $10.000 \times \mathrm{g}$ zentrifugiert.

3) Anschließend wurde die Säule mit $250 \mu \mathrm{l}$ Waschpuffer I gewaschen und erneut für $60 \mathrm{~s}$ bei $10.000 \times \mathrm{g}$ zentrifugiert.

4) Danach erfolgte die Zugabe von $75 \mu \mathrm{l}$ DNase-Verdau-Lösung, bestehend aus 73,5 $\mu \mathrm{l}$ DNase-Verdau-Puffer und 1,5 $\mu \mathrm{l}$ RNase-freier DNase, direkt auf die Silika-GelMembran mit anschließender Inkubation bei Raumtemperatur für 15 min.

5) Nun wurden $500 \mu \mathrm{l}$ Waschpuffer I auf die Säule gegeben. Nach einer Inkubation bei Raumtemperatur für 2 min wurden die Proben für $60 \mathrm{~s}$ bei 10.000 x g zentrifugiert.

6) Im Anschluss wurden erneut $500 \mu$ l Waschpuffer II hinzupipettiert und es folgte eine Zentrifugation bei $10.000 \times \mathrm{g}$ für $60 \mathrm{~s}$. Dieser Arbeitsschritt wurde zweimal hintereinander durchgeführt.

7) Um letzte Flüssigkeitsrückstände zu entfernen, wurde die Säule noch einmal bei maximaler Geschwindigkeit für 2 min zentrifugiert.

8) Die Säule wurde nun in ein 1,5-ml-Reaktionsgefäß platziert. Abhängig von der erwarteten RNA-Menge wurden 40 - $70 \mu$ l RNase-freies Wasser hinzugegeben. Es folgten eine 1-minütige Inkubation bei Raumtemperatur und eine 2-minütige Zentrifugation bei $10.000 \times \mathrm{g}$, um die RNA zu lösen.

Die so gewonnene RNA konnte direkt weiterverarbeitet oder bei $-70^{\circ} \mathrm{C}$ gelagert werden.

\subsubsection{Photometrische Bestimmung der RNA-Konzentration}

Die RNA-Konzentration jeder Probe in $\mu \mathrm{g} / \mathrm{ml}$ wurde mithilfe eines Spektralphotometers bestimmt. Um möglichst geringe Mengen der RNA für die Konzentrationsbestimmung zu verbrauchen, wurde der 0,2 $\mathrm{mm}$ TrayCell-Einsatz für Spektralphotometer von Hellma verwendet, mit dem es möglich ist, die RNA-Konzentration in $1 \mu$ l Flüssigkeit genau zu bestimmen. Durch den TrayCell-Einsatz werden ein 0,2 mm breiter Strahlengang und dadurch eine virtuelle Verdünnung von 1:50 erzeugt.

Nachdem $1 \mu \mathrm{l}$ der RNA-Lösung auf den TrayCell-Einsatz pipettiert wurde, konnte die RNAKonzentration bei einer Wellenlänge von $260 \mathrm{~nm}$ gemessen werden. Zur Bestimmung des Reinheitsgrades der Probe, wurde zusätzlich die optische Dichte (OD) bei $280 \mathrm{~nm}$ bestimmt. 
Der Quotient aus OD $260 \mathrm{~nm}$ / OD $280 \mathrm{~nm}$ gibt Aufschluss über eventuelle Proteinverunreinigungen der Probe und sollte zwischen 1,8 und 2,0 liegen. Im Anschluss an die photometrische Quantifizierung der RNA-Konzentration, konnten die für die reverse Transkription einzusetzenden RNA-Mengen berechnet werden.

\subsubsection{Reverse Transkription}

Unter der reversen Transkription versteht man die mRNA-abhängige DNA-Synthese. Mit Hilfe der Reversen Transkriptase, einer RNA-abhängigen DNA-Polymerase, entsteht aus RNA die sogenannte cDNA (complementary DNA). Da die Matrize für die cDNA-Synthese eine prozessierte RNA ist, d.h. die posttranskriptionale Modifizierung hat bereits stattgefunden, besteht die cDNA nur aus kodierenden Abschnitten, den so genannten Exons.

Für die reverse Transkription wurden jeweils $2 \mu \mathrm{g}$ RNA eingesetzt. Die einzusetzende RNAMenge in $\mu \mathrm{l}$ wurde errechnet und RNase-freies Wasser bis zu einer Gesamtmenge von $10 \mu \mathrm{l}$ hinzugegeben. Außerdem wurde $1 \mu$ l oligo $(\mathrm{dt})_{18}$ Primer hinzupipettiert. Es folgte eine kurze Zentrifugation mit anschließender 5-minütiger Inkubation bei $65^{\circ} \mathrm{C}$. Danach wurde die Probe auf Eis gekühlt und noch einmal kurz zentrifugiert. Anschließend erfolgte die Zugabe folgender Substanzen in angegebener Reihenfolge:

$\begin{array}{lr}\text { RNA mit oligo }(\mathrm{dt})_{18} \text { Primer } & 11 \mu \mathrm{l} \\ \text { Reaktionspuffer } & 4 \mu \mathrm{l} \\ \text { RiboLock RNase Inhibitor } & 1 \mu \mathrm{l} \\ 10 \mathrm{mM} \text { dNTP mix } & 2 \mu \mathrm{l} \\ \text { Reverse Transkriptase } & 2 \mu \mathrm{l} \\ & 20 \mu \mathrm{l}\end{array}$

Im Anschluss wurde der Versuchsansatz sorgfältig gemischt und zentrifugiert. Dann wurde die Probe für $60 \mathrm{~min}$ bei $37^{\circ} \mathrm{C}$ inkubiert. Durch die darauffolgende Inkubation für 5 min bei $70^{\circ} \mathrm{C}$ wurde das Enzym inhibiert und die Reaktion gestoppt. Die cDNA wurde entweder direkt weiterverwendet oder bei $-20^{\circ} \mathrm{C}$ gelagert. 


\subsubsection{Polymerase-Kettenreaktion (engl. polymerase chain reaction, PCR)}

\subsubsection{Grundlagen der PCR}

Die Polymerase-Kettenreaktion ermöglicht es, spezifische DNA-Abschnitte mit Hilfe der hitzestabilen Taq-Polymerase zu amplifizieren. Bei der Taq-Polymerase handelt es sich um eine hitzebeständige DNA-Polymerase, die ursprünglich aus dem Bakterium Thermus aquaticus isoliert wurde. Durch die zyklische Wiederholung bestimmter Reaktionsschritte ist bei der PCR eine exponentielle Vermehrung von DNA-Strängen möglich, da neu synthetisierte Stränge im nächsten Zyklus als Vorlage für weitere Vervielfältigungen dienen. Die Amplifikation basiert auf der wiederholten Abfolge von drei Reaktionsschritten:

1. Denaturierung: Durch Temperaturen zwischen $92^{\circ} \mathrm{C}$ und $94^{\circ} \mathrm{C}$ werden die Wasserstoffbrückenbindungen innerhalb der DNA gespalten und die DNA in zwei Einzelstränge aufgetrennt. Die Hitzedenaturierung ermöglicht im nächsten Reaktionsschritt das Anlagern der Primer (Oligonukleotide) an die DNA. Es werden Primer-Paare benötigt, da die Primer jeweils komplementär zu einem DNA-Strang sein müssen.

2. Annealing: Die Temperatur wird reduziert und auf einer Temperatur gehalten, die eine spezifische Anlagerung der Primer an die DNA erlaubt.

3. Elongation: Ausgehend von den Primern lagert die Polymerase Nukleotide an und füllt die neuen Einzelstränge auf. Die Synthese der neuen Stränge erfolgt in 5'-3'Richtung. Dieser Reaktionsschritt erfolgt bei $72^{\circ} \mathrm{C}$, dem Temperaturoptimum der TaqPolymerase. Die Taq-Polymerase kann in der Regel ca. 1000 bp/min amplifizieren. Die Dauer der Elongation richtet sich daher nach der Größe des zu amplifizierenden Fragments.

Der Reaktionszyklus wird je nach Reaktion 25 bis 40 Mal wiederholt. Die Primer sollten im Überschuss vorliegen und eine minimale Länge von 12 Basen besitzen. Zudem sollte gewährleistet sein, dass die zu amplifizierende Sequenz nur einmal in der DNA vorhanden ist. Allerdings sollte auch eine maximale Primerlänge von 35 Basen nicht überschritten werden, um die Hybridisierungstemperatur nicht zu stark zu erhöhen. Dadurch sinkt die Gefahr, dass selbst homologe Sequenzen nicht binden. 


\subsubsection{Durchführung der PCR}

Zur Durchführung einer PCR wurde ein genau definiertes Gemisch aus sämtlichen benötigten Substanzen (so genannter Mastermix) hergestellt und auf die Reaktionsgefäße verteilt. In die Reaktionsgefäße wurden dann die jeweiligen Proben hinzugegeben. Die Taq-Polymerase wurde zuletzt hinzu pipettiert.

Der Mastermix enthielt folgende Substanzen:

\begin{tabular}{lr} 
Vorwärtsprimer (for) & $1 \mu \mathrm{l}$ \\
Rückwärtsprimer (rev) & $1 \mu \mathrm{l}$ \\
dNTP $10 \mathrm{mM}$ & $1 \mu \mathrm{l}$ \\
10x Puffer & $2,5 \mu \mathrm{l}$ \\
Taq-Polymerase & $0,2 \mu \mathrm{l}$ \\
Aqua dest. & $18,3 \mu \mathrm{l}$ \\
\cline { 2 - 2 } & $24 \mu \mathrm{l}$
\end{tabular}

$\mathrm{Zu}$ jedem Mastermix-Ansatz wurde noch $1 \mu \mathrm{l}$ der zu amplifizierenden cDNA gegeben. Außerdem wurde für jede PCR eine Negativ-Kontrolle erstellt, d.h. das Volumen der Probe wurde durch Aqua dest. ersetzt.

Die Reaktionsbedingungen für die PCR sahen wie folgt aus:

$\left.\begin{array}{lll}\text { Initiale Denaturierung } & 94^{\circ} \mathrm{C} & 3 \mathrm{~min} \\ \text { Denaturierung } & 94^{\circ} \mathrm{C} & 30 \mathrm{~s} \\ \text { Annealing } & 56^{\circ} \mathrm{C}-62^{\circ} \mathrm{C} & 30 \mathrm{~s} \\ \text { Elongation } & 72^{\circ} \mathrm{C} & 30-60 \mathrm{~s}\end{array}\right\} 25-40$ Zyklen


Nachfolgend finden sich die Primersequenzen und die Versuchsbedingungen der durchgeführten PCR-Reaktionen.

\begin{tabular}{|c|c|c|}
\hline Gen & Primersequenz & $\begin{array}{l}\text { Annealingtemperatur/ Anzahl der } \\
\text { Zyklen/ Produktgröße }\end{array}$ \\
\hline CD31 & $\begin{array}{l}\text { for 5'- AATGCTCTCCCAGCCCAG - 3' } \\
\text { rev 5'- TCTCCAGACTCCACCACC - 3' }\end{array}$ & $\begin{array}{c}56^{\circ} \mathrm{C} / 26 \text { Zyklen } \\
333 \mathrm{bp}\end{array}$ \\
\hline CD54 & $\begin{array}{l}\text { for 5' - TGACCAGCCCAAGTTGTTGG - 3' } \\
\text { rev 5' - ATCTCTCCTCACCAGCACCG - 3' }\end{array}$ & $\begin{array}{l}55^{\circ} \mathrm{C} / 26 \text { Zyklen } \\
379 \mathrm{bp}\end{array}$ \\
\hline CD62P & $\begin{array}{l}\text { for 5' - AGGCATCATCCGGGAACC - 3' } \\
\text { rev 5' - CCCCAGAGGTTGGAGCAG - 3' }\end{array}$ & $\begin{array}{c}56^{\circ} \mathrm{C} / 26 \text { Zyklen } \\
200 \mathrm{bp} \\
\end{array}$ \\
\hline CD62E & $\begin{array}{l}\text { for 5' - AAGCCTGGCAGTTCCGGG - 3' } \\
\text { rev 5' - GGCTTTGGCAGCTGCTGG - 3' }\end{array}$ & $\begin{array}{l}56^{\circ} \mathrm{C} / 26 \text { Zyklen } \\
308 \mathrm{bp}\end{array}$ \\
\hline CD106 & $\begin{array}{l}\text { for 5' - CCAGAATCTAGATATCTTGCTC - 3' } \\
\text { rev 5' - CAGCCTGTCAAATGGGTATAC - 3' }\end{array}$ & $\begin{array}{l}58^{\circ} \mathrm{C} / 30 \text { Zyklen } \\
355 \mathrm{bp}\end{array}$ \\
\hline CD144 & $\begin{array}{l}\text { for 5' - GCCCCGGAGTTTGCCAAG - 3' } \\
\text { rev 5' - CTCCCGGTCAAACTGCCC - 3' }\end{array}$ & $\begin{array}{l}58^{\circ} \mathrm{C} / 26 \text { Zyklen } \\
223 \mathrm{bp}\end{array}$ \\
\hline CXCL1 & $\begin{array}{l}\text { for 5' - ATGGCCCGCGCTGCTCTCTCC - 3' } \\
\text { rev 5' - CTTAACTATGGGGGATGCAGG - 3' }\end{array}$ & $\begin{array}{l}58^{\circ} \mathrm{C} / 26 \text { Zyklen } \\
282 \mathrm{bp}\end{array}$ \\
\hline VEGFR1 & $\begin{array}{l}\text { for 5' - GTCACAGAAGAGGATGAAGGTGTCTA - 3' } \\
\text { rev 5' - CACAGTCCGGCACGTAGGTGATT - 3' }\end{array}$ & $\begin{array}{l}62^{\circ} \mathrm{C} / 33 \text { Zyklen } \\
414 \mathrm{bp}\end{array}$ \\
\hline VEGFR2 & $\begin{array}{l}\text { for 5' - CTGGCATGGTCTTCTGTGAAGCA - 3' } \\
\text { rev 5' - AATACCAGTGGATGTGATGCGG - 3' }\end{array}$ & $\begin{array}{c}60^{\circ} \mathrm{C} / 26 \text { Zyklen } \\
795 \mathrm{bp} \\
\end{array}$ \\
\hline GAPDH & $\begin{array}{l}\text { for 5' - CTTTGGTATCGTGGAAGGACTC - 3' } \\
\text { rev 5' - TTCGTTGTCATACCAGGAAATG - 3' }\end{array}$ & $\begin{array}{l}58^{\circ} \mathrm{C} / 26 \text { Zyklen } \\
451 \mathrm{bp}\end{array}$ \\
\hline IL-6 & $\begin{array}{l}\text { for 5' - ATGAACTCCTTCTCCACAAGCGC - 3' } \\
\text { rev 5' - GAAGAGCCCTCAGGCTGGACTG - 3' }\end{array}$ & $\begin{array}{l}60^{\circ} \mathrm{C} / 26 \text { Zyklen } \\
628 \mathrm{bp}\end{array}$ \\
\hline IL-6R & $\begin{array}{l}\text { for 5' - CATTGCCATTGTTCTGAGGTT C - 3' } \\
\text { rev 5' - AGTAGTCTGTATTGCTGATGTC - 3' }\end{array}$ & $\begin{array}{l}56^{\circ} \mathrm{C} / 33 \text { Zyklen } \\
251 \mathrm{bp}\end{array}$ \\
\hline IL-8 & $\begin{array}{l}\text { for 5' - ACAAGCTTCTAGGACAAGAGCCAGGAAG - 3' } \\
\text { rev 5' - GTGAATTCAGTGTGGTCCACTCTCAATC - 3' }\end{array}$ & $\begin{array}{l}62^{\circ} \mathrm{C} / 26 \text { Zyklen } \\
253 \mathrm{bp}\end{array}$ \\
\hline MCP-1 & $\begin{array}{l}\text { for 5' - GCTCATAGCAGCCACCTTCATTC - 3' } \\
\text { rev 5' - TGCAGATTCTTGGGTTGTGGAG - 3' }\end{array}$ & $\begin{array}{l}58^{\circ} \mathrm{C} / 26 \text { Zyklen } \\
297 \mathrm{bp}\end{array}$ \\
\hline MMP-2 & $\begin{array}{l}\text { for 5' - GGCCTCTCCTGACATTGACCTT - 3' } \\
\text { rev 5' - GGCCTCGTATACCGCATCAAT - 3' }\end{array}$ & $\begin{array}{c}60^{\circ} \mathrm{C} / 26 \text { Zyklen } \\
241 \mathrm{bp} \\
\end{array}$ \\
\hline VEGF & $\begin{array}{l}\text { for 5' - CGAAGTGGTGAAGTTCATGGA - 3' } \\
\text { rev 5' - TTCTGTATCAGTCTTTCCTGGT - 3' }\end{array}$ & $\begin{array}{l}55^{\circ} \mathrm{C} / 30 \text { Zyklen } \\
469 \mathrm{bp}\end{array}$ \\
\hline
\end{tabular}

\subsubsection{Agarose-Gelelektrophorese}

Mit Hilfe der Agarose-Gelelektrophorese können Nukleinsäuren, unter Ausnutzung ihrer negativen Ladung, der Größe nach aufgetrennt und ihre Größe durch Vergleich mit Strängen bekannter Größe bestimmt werden. Lange Fäden aus Agarosepolymeren werden zu einem Gel vernetzt, wobei die Poren umso kleiner sind, je höher die Agarose konzentriert ist. Das 
Anlegen eines elektrischen Feldes bewirkt, dass die Nukleinsäuren aufgrund ihrer Ladung durch das Gel wandern. Kleine Moleküle bewegen sich schneller durch die Poren des Gels als größere. Im Anschluss können die Nukleinsäuren mit Hilfe von GelRed ${ }^{\mathrm{TM}}$, einem DNAinterkalierenden Fluoreszenzfarbstoff, unter UV-Licht sichtbar gemacht werden.

Die Lösung der Agarose erfolgte in 1 x TBE-Puffer. Für die Herstellung eines 1-prozentigen Agarosegels wurde $1 \mathrm{~g}$ Agarose in $100 \mathrm{ml} 1$ x TBE-Puffer gelöst. Dafür musste das Gemisch aus Agarose und TBE-Puffer für $4 \mathrm{~min}$ bei 600 Watt in der Mikrowelle erhitzt werden. Anschließend wurden $3 \mu \mathrm{l} \mathrm{GelRed}{ }^{\mathrm{TM}} / 100 \mathrm{ml}$ Agarose-Lösung hinzupipettiert. Nach einer kurzen Abkühlphase wurde das Gel in die vorbereitete Gelkammer gegossen, in die zuvor 2 4 Kämme zur Taschenbildung eingelegt wurden. Nachdem das Gel fest geworden war, konnten die zu untersuchenden Proben aufgetragen werden. Dafür wurden $10 \mu \mathrm{l}$ des PCRProdukts mit $2 \mu$ l DNA-Probenpuffer versetzt und davon jeweils $10 \mu \mathrm{l}$ in eine Geltasche pipettiert. Zur Größenbeurteilung des DNA-Produkts wurden außerdem 2,5 $\mu$ l eines Basenpaar-Markers, einer Mischung aus DNA-Fragmenten bekannter Länge, in eine Geltasche pipettiert. Für 60 min wurde eine Spannung von $100 \mathrm{~V}$ angelegt. Anschließend konnten die Banden unter UV-Licht sichtbar gemacht werden.

\subsubsection{Durchflusszytometrie}

\subsubsection{Prinzip der Durchflusszytometrie}

Die Durchflusszytometrie beschreibt ein Verfahren, mit dem es möglich ist, in Suspension vorliegende Zellen in Bezug auf ihre Größe und Granularität genauer zu untersuchen. In einem Durchflusszytometer werden die Zellen durch eine Kapillare gesaugt und passieren einzeln einen Laserstrahl. Trifft der Laserstrahl auf eine Zelle, wird ein Teil des Lichts gestreut und mittels eines Detektors nachgewiesen. Das sogenannte Vorwärtsstreulicht (engl. forward scatter, FSC) gibt Auskunft über die Größe, das Seitwärtsstreulicht (engl. side scatter, SSC) ist ein Maß für die Granularität der Zelle. Mit Hilfe fluoreszenzmarkierter Antikörper, die gegen Oberflächenproteine der zu untersuchenden Zellen gerichtet sind, lassen sich die Expressionsmuster dieser Proteine genauer untersuchen. Trifft der Laserstrahl auf einen am jeweiligen Antikörper gekoppelten Farbstoff, wird dieser angeregt. Die charakteristische Lichtemission des verwendeten Farbstoffs wird nach Wellenlängen 
aufgetrennt und durch Detektoren gemessen. Die Durchflusszytometrie ermöglicht eine Abschätzung des Expressionsgrades der Oberflächenproteine, da die Intensität der Emission proportional zu der Anzahl der gebundenen fluoreszenzmarkierten Antikörper ist.

\subsubsection{Durchführung der Durchflusszytometrie}

Die durchflusszytometrische Messung wurde mit dem FACSCanto II (BD) durchgeführt. HUVEC wurden in Kulturplatten mit jeweils 12 Vertiefungen für die Zellkultur (so genannte 12-well-Platten), mit 100.000 Zellen pro „well“ in 1 ml EBM-Medium + 10\% FCS ausgesät und für $36 \mathrm{~h}$ bei $37^{\circ} \mathrm{C}, 5 \% \mathrm{CO}_{2}$ und einer Luftfeuchtigkeit von $95 \%$ im Brutschrank inkubiert. Im Anschluss an die Inkubation wurden die Zellen für $1 \mathrm{~h}$ mit DMF oder MMF behandelt. Es wurden 5 Konzentrationen zwischen $5 \mu \mathrm{M}$ und $200 \mu \mathrm{M}(5,15,25,50,200 \mu \mathrm{M})$ ausgewählt. Als Lösungsmittel für DMF und MMF diente DMSO. Unbehandelte Zellen dienten als Kontrolle. Nach der 1-stündigen Inkubation mit DMF oder MMF wurde zusätzlich TNF $\alpha$ (25 $\mathrm{ng} / \mathrm{ml}$ ) auf die Zellen gegeben und es folgte eine Inkubation für weitere 4 Stunden. Auch hier dienten unstimulierte Zellen als Kontrolle. Erst nach der insgesamt 5-stündigen Inkubation wurde das Medium abgenommen und jedes „well“ mit $1 \mathrm{ml}$ PBS gewaschen. Es folgte die Zugabe von $200 \mu \mathrm{l}$ Trypsin zu jedem „well“. Die Zellen wurden für 3 min im Brutschrank inkubiert. Anschließend wurde die Reaktion durch Zugabe von $800 \mu \mathrm{PBS}+\mathrm{Ca}^{2+}+\mathrm{Mg}^{2+} \mathrm{mit} 5 \%$ humanem AB-Serum gestoppt und die Zellen in Reaktionsröhrchen überführt. Die Röhrchen wurden für $7 \mathrm{~min}$ bei 1300 rpm (292 x g) zentrifugiert und der Überstand abgenommen. Nun erfolgte die Zugabe von $1 \mu$ ldes monoklonalen Primärantikörpers (1. AK), gerichtet gegen ICAM-1, VCAM-1 oder E-Selektin. Die Zellen wurden mit dem Primärantikörper für 30 min bei $4^{\circ} \mathrm{C}$ inkubiert. Nach erneutem Waschen mit PBS und erneuter Zentrifugation wurden $3 \mu \mathrm{l}$ des PE (Phycoerythrin) - konjugierten Sekundärantikörpers hinzugegeben. Die Zugabe eines Sekundärantikörpers (2. AK) dient der Signalverstärkung, da mehrere Sekundärantikörper an einen Primärantikörper binden können. Die Zellen wurden für $30 \mathrm{~min}$ bei $4^{\circ} \mathrm{C}$ inkubiert. Es folgte ein letzter Waschschritt mit PBS. Zum Schluss wurden die Zellen in $500 \mu \mathrm{l}$ PBS resuspendiert.

Die mittlere Fluoreszenzintensität (engl. mean fluorescence intensity, MFI) und die Anzahl der positiven Zellen in Prozent, d.h. die Anzahl der Zellen, die das zu untersuchende Oberflächenprotein exprimieren, wurden unmittelbar danach in einem Durchflusszytometer 
bestimmt. Die Expression der Oberflächenproteine E-Selektin, ICAM-1 und VCAM-1 wurde gemessen und mit Hilfe der FACSDiva Software ausgewertet.

Nachfolgend findet sich eine Auflistung aller 60 Ansätze:

\begin{tabular}{|c|c|c|c|c|}
\hline 1) & Kein 1. AK & kein 2. AK & kein TNF $\alpha$ & kein DMF/MMF \\
\hline 2) & Kein 1. AK & $+2 . A K$ & kein TNF $\alpha$ & kein DMF/MMF \\
\hline 3) & PE-Isotyp, IgG & kein 2. AK & kein TNF $\alpha$ & kein DMF/MMF \\
\hline 4) & 1. AK E-Selektin & $+2 . A K$ & kein TNF $\alpha$ & kein DMF/MMF \\
\hline 5) & 1. AK VCAM-1 & $+2 . A K$ & kein TNF $\alpha$ & kein DMF/MMF \\
\hline 6) & 1. AK ICAM-1 & $+2 . A K$ & kein TNF $\alpha$ & kein DMF/MMF \\
\hline 7) & 1. AK E-Selektin & $+2 . A K$ & $+\mathrm{TNF} \alpha$ & kein DMF/MMF \\
\hline 8) & 1. AK VCAM-1 & $+2 . A K$ & $+\mathrm{TNF} \alpha$ & kein DMF/MMF \\
\hline 9) & 1. AK ICAM-1 & $+2 . A K$ & $+\mathrm{TNF} \alpha$ & kein DMF/MMF \\
\hline 10) & 1. AK E-Selektin & $+2 . A K$ & $+\mathrm{TNF} \alpha$ & $+5 \mu \mathrm{M}$ DMF \\
\hline 11) & 1. AK E-Selektin & $+2 . A K$ & $+\mathrm{TNF} \alpha$ & $+15 \mu \mathrm{M}$ DMF \\
\hline 12) & 1. AK E-Selektin & $+2 . A K$ & $+\mathrm{TNF} \alpha$ & $+25 \mu \mathrm{M}$ DMF \\
\hline 13) & 1. AK E-Selektin & $+2 . A K$ & $+\mathrm{TNF} \alpha$ & $+50 \mu \mathrm{M}$ DMF \\
\hline 14) & 1. AK E-Selektin & $+2 . A K$ & $+\mathrm{TNF} \alpha$ & $+200 \mu \mathrm{M}$ DMF \\
\hline 15) & 1. AK E-Selektin & $+2 . A K$ & $+\mathrm{TNF} \alpha$ & $+5 \mu \mathrm{M} M M F$ \\
\hline 16) & 1. AK E-Selektin & $+2 . A K$ & $+\mathrm{TNF} \alpha$ & $+15 \mu \mathrm{M}$ MMF \\
\hline 17) & 1. AK E-Selektin & $+2 . A K$ & $+\mathrm{TNF} \alpha$ & $+25 \mu \mathrm{M}$ MMF \\
\hline 18) & 1. AK E-Selektin & $+2 . A K$ & $+\mathrm{TNF} \alpha$ & $+50 \mu \mathrm{M} M M F$ \\
\hline 19) & 1. AK E-Selektin & $+2 . A K$ & $+\mathrm{TNF} \alpha$ & $+200 \mu \mathrm{M}$ MMF \\
\hline 20) - 29) & 1. AK VCAM-1 & $+2 . A K$ & $+\mathrm{TNF} \alpha$ & $+5-200 \mu \mathrm{M}$ DMF \\
\hline 30) - 39) & 1. AK VCAM-1 & $+2 . A K$ & $+\mathrm{TNF} \alpha$ & $+5-200 \mu \mathrm{M} M M F$ \\
\hline 40) - 49) & 1. AK ICAM-1 & $+2 . A K$ & $+\mathrm{TNF} \alpha$ & $+5-200 \mu \mathrm{M}$ DMF \\
\hline 50) - 59) & 1. AK ICAM-1 & $+2 . A K$ & $+\mathrm{TNF} \alpha$ & $+5-200 \mu \mathrm{M}$ MMF \\
\hline
\end{tabular}

60) Lösungsmittelkontrolle: DMSO 


\subsubsection{Immunfluoreszenzfärbung}

\subsubsection{Prinzip der Immunfluoreszenzfärbung}

Die Immunfluoreszenzfärbung beruht auf der Detektion spezifischer Antigene mittels Antikörpern. Meist handelt es sich um Oberflächenproteine, die mit dieser Methode durch farbliche Markierung erkannt werden können. Somit lassen sich Proteine lokalisieren und auch eine Zunahme oder Abnahme der Expression ist oft erkennbar. Die Antikörper sind entweder direkt mit einem Farbstoff markiert oder werden erst in einem nachfolgenden Schritt mit einem zweiten Antikörper fluoreszenzmarkiert.

\subsubsection{Durchführung der Immunfluoreszenzfärbung}

HUVEC wurden auf Objektträger mit aufgesetzten Zellkultur-Kammern (so genannte „chamber slides“) mit 30.000 Zellen pro Kammer in jeweils $300 \mu$ l EBM-Medium ausgesät und für $36 \mathrm{~h}$ bei $37^{\circ} \mathrm{C}, 5 \% \mathrm{CO}_{2}$ und einer Luftfeuchtigkeit von $95 \%$ im Brutschrank inkubiert. Im Anschluss an die Inkubation wurden die Zellen für $1 \mathrm{~h}$ mit DMF oder MMF behandelt. Die Behandlung erfolgte mit Konzentrationen von $50 \mu \mathrm{M}$ oder $200 \mu \mathrm{M}$. Unbehandelte Zellen dienten als Kontrolle. Der Inkubation mit DMF oder MMF für 1 Stunde folgte eine Inkubation mit TNFa (25 ng/ml) für 4 Stunden. Auch hier dienten unstimulierte Zellen als Kontrolle. Nach der insgesamt 5-stündigen Inkubation wurde das Medium abgenommen und jede Kammer mit $500 \mu \mathrm{l}$ PBS gewaschen. Zum Fixieren der Zellen wurden $500 \mu$ l Methanol $\left(-20^{\circ} \mathrm{C}\right)$ in jede Kammer gegeben und die "chamber slides" im Anschluss für 5 min bei $-20^{\circ} \mathrm{C}$ inkubiert. Das Methanol wurde gründlich entfernt und die Zellen erneut zweimal mit PBS gewaschen. Es folgte die Zugabe von $500 \mu \mathrm{l}$ PBS mit 5\% FCS (zum Absättigen unspezifischer Protein-Bindungsstellen) und eine Inkubation bei RT auf dem Schüttler für $1 \mathrm{~h}$. Nach Entfernung der PBS/FCS-Lösung folgte die Zugabe des Primärantikörpers (1. AK) in einer Konzentration von $10 \mu \mathrm{g} / \mathrm{ml}$. Der Antikörper wurde in der AK-Grundlösung (2,5\% FCS in PBS) gelöst und $300 \mu \mathrm{l}$ der Lösung wurden in jede Kammer pipettiert. Die Inkubation erfolgte bei RT für 30 min auf dem Schüttler und anschließend bei $4^{\circ} \mathrm{C}$ über Nacht. Am nächsten Morgen wurde der 1. AK durch dreimaliges Waschen für je 10 min mit PBS entfernt. Der nächste Schritt war die Zugabe des Sekundärantikörpers (2. AK). $1 \mu \mathrm{l}$ des 2. AK wurde in $300 \mu \mathrm{l}$ der AK-Grundlösung gelöst und in jede Kammer gegeben. Die „chamber slides“ wurden bei RT 
für $1 \mathrm{~h}$ auf dem Schüttler inkubiert. Da der 2. AK fluoreszenzmarkiert und somit lichtsensitiv war, mussten die "chamber slides“ mit Alufolie abgedeckt werden, um eine vorzeitige Abschwächung des Fluoreszenzsignals zu verhindern. Anschließend wurden die Zellen dreimal gründlich für 5 min und zweimal für 10 min mit PBS gewaschen. Nun wurden die Plastikkammern der „chamber slides“ abgenommen und die Objektträger mit den fixierten Zellen an der Luft getrocknet. Danach wurden die Zellen mit Einbett-Medium, dem vor der Anwendung DAPI (4',6-Diamidin-2-phenylindol) in einer Verdünnung von 1:200 zugesetzt wurde, eingedeckt. Bei DAPI handelt es sich um einen interkalierenden Fluoreszenzfarbstoff, der zur Markierung von DNA eingesetzt werden kann. Zuletzt wurde der Objektträger mit einem Deckglas bedeckt und die Ränder mit Klarlack abgedichtet. Die Aufnahmen wurden mit dem Fluoreszenzmikroskop Axiolmager M1 (Zeiss) gemacht. Als Software wurde AxioVision (Zeiss) verwendet.

Nachfolgend findet sich eine Auflistung der 15 Ansätze:

1)

2)

3)

4)

5)

6)

7)

8)

9)

10)

11)

12)

13)

14)

15)
Kein 1. AK

Kein 1. AK

PE-Isotyp, IgG

1. AK E-Selektin

1. AK E-Selektin

1. AK E-Selektin

1. AK E-Selektin

1. AK E-Selektin

1. AK E-Selektin

1. AK VCAM-1

1. AK VCAM-1

1. AK VCAM-1

1. AK VCAM-1

1. AK VCAM-1

1. AK VCAM-1 kein 2. AK

+2. AK

kein 2. AK

+2 . AK

+2. AK

+2 . AK

+2 . AK

+2. AK

+2 . AK

+2. AK

+2 . AK

+2 . AK

+2 . AK

+2 . AK

+2 . AK kein TNF $\alpha$ kein TNF $\alpha$

kein TNF $\alpha$

kein TNF $\alpha$

+ TNF $\alpha$

+ TNF $\alpha$

+ TNF $\alpha$

+ TNF $\alpha$

$+\mathrm{TNF} \alpha$, kein TNF $\alpha$

+ TNF $\alpha$

$+\mathrm{TNF} \alpha$,

$+\mathrm{TNF} \alpha$,

$+\mathrm{TNF} \alpha$,

$+\mathrm{TNF} \alpha$, kein DMF/MMF

kein DMF/MMF

kein DMF/MMF

kein DMF/MMF

kein DMF/MMF

$+50 \mu \mathrm{M}$ DMF

$+200 \mu \mathrm{M}$ DMF

$+50 \mu \mathrm{M} M M F$

$+200 \mu \mathrm{M}$ MMF

kein DMF/MMF

kein DMF/MMF

$+50 \mu \mathrm{M} \mathrm{DMF}$

$+200 \mu \mathrm{M}$ DMF

$+50 \mu \mathrm{M} M M F$

$+200 \mu \mathrm{M} M M F$ 


\subsubsection{Flusskammer}

\subsubsection{Prinzip der Flusskammer}

Die Flusskammer (Abb. 4) wurde entwickelt, um die physikalischen Bedingungen, die im fließenden Blut vorherrschen, nachzustellen. Mit ihrer Hilfe lassen sich Interaktionen zwischen Endothelzellen und Lymphozyten, wie das lymphozytäre Rollen und die feste Adhäsion auf den Endothelzellen, untersuchen. Die Flusskammer besteht aus einem Acrylquader und einem Metallgestell mit zwei Schraubvorrichtungen. Ein mit Endothelzellen beschichteter Thermanox ${ }^{\mathrm{TM}}$-Objektträger wird mit der beschichteten Seite nach oben in das Metallgestell eingelegt. Der Acrylquader wird exakt auf den Objektträger gelegt und mit den beiden Schrauben fixiert. Der Acrylquader besitzt in der Mitte eine 0,5 cm breite, 3,5 cm lange und $50 \mu \mathrm{m}$ tiefe gefräste Rinne (Aussparung). In dieser Aussparung findet die Interaktion zwischen Endothel- und Blutzellen statt. Zwei dünne Röhrchen im Acrylquader, an denen jeweils ein Schlauch befestigt ist, dienen als Zu- bzw. Abfluss für die Lymphozytensuspension.
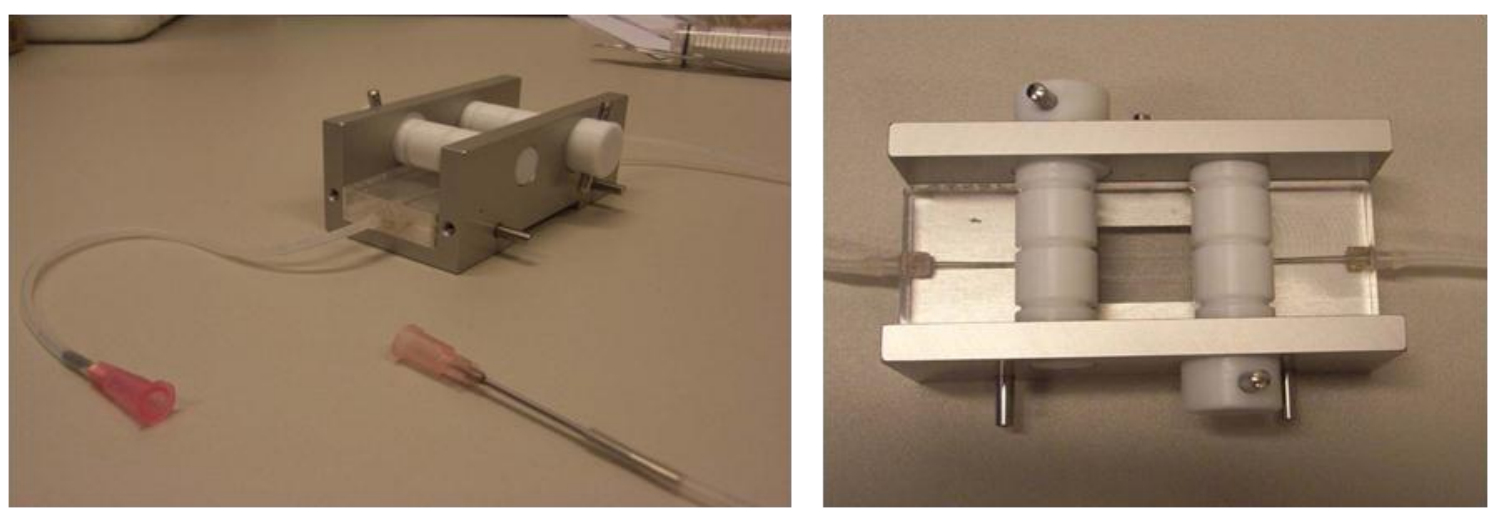

Abb. 4 Die Flusskammer besteht aus einem Acrylquader und einer Haltevorrichtung aus Metall mit zwei Schraubvorrichtungen. Der mit Endothelzellen beschichtete Objektträger wird zwischen Metallgestell und Acrylquader gelegt. Die Lymphozyten werden durch ein Schlauchsystem zu- und abgeführt. In der Mitte des Acrylquaders befindet sich die Aussparung, in der die Zell-Zell-Interaktionen stattfinden können

\subsubsection{Vorbereitung für ein Flusskammerexperiment}

Für ein Flusskammerexperiment wurden 6 beschichtete Objektträger verwendet. Auf jedem Objektträger wurden 50.000 HUVEC in $1 \mathrm{ml}$ EBM ausgesät und diese wiederum in Petrischalen platziert. Nach $6 \mathrm{~h}$ Inkubationszeit hafteten die Endothelzellen bereits locker 
am Objektträger und es wurden noch einmal $7 \mathrm{ml}$ EBM vorsichtig in jede Petrischale pipettiert. Um genügend Zeit zum Anwachsen zu garantieren, wurden die Zellen insgesamt für $36 \mathrm{~h}$ bei $37^{\circ} \mathrm{C}, 5 \% \mathrm{CO}_{2}$ und einer Luftfeuchtigkeit von $95 \%$ im Brutschrank inkubiert. Nach abgelaufener Inkubationszeit wurden die HUVEC wie schon bei der Durchflusszytometrie und der Immunfluoreszenzfärbung für $1 \mathrm{~h}$ mit DMF oder MMF (50 $\mu \mathrm{M}$ oder $200 \mu \mathrm{M}$ ) und für 4 h mit $200 \mathrm{ng}$ TNF $\alpha(25 \mathrm{ng} / \mathrm{ml})$ stimuliert. Anschließend wurde das Medium abgenommen und die Objektträger wurden für die funktionelle Untersuchung der Interaktion zwischen Lymphozyten und Endothelzellen nacheinander in die Flusskammer gelegt.

Nachfolgend findet sich eine Auflistung der 6 Ansätze:
1) kein TNF $\alpha$ Kein DMF/MMF,
2) $\quad+$ TNF $\alpha \quad$ Kein DMF/MMF
3) $\quad+\mathrm{TNF} \alpha \quad 50 \mu \mathrm{MDMF}$
4) $\quad+$ TNF $\alpha \quad 200 \mu \mathrm{M}$ DMF
5) $\quad+\mathrm{TNF} \alpha \quad 50 \mu \mathrm{MMMF}$
6) $\quad+\mathrm{TNF} \alpha \quad 200 \mu \mathrm{M} \mathrm{MMF}$

\subsubsection{Lymphozytenisolierung}

Die Experimente mit humanen Zellen wurden von der Ethik-Kommission der Medizinischen Fakultät der Georg August Universität Göttingen genehmigt (Genehmigungsnummer: 24/3/09). Für einen Flusskammerversuch wurden einem Probanden $20 \mathrm{ml}$ Blut abgenommen. In die 20-ml-Spritze wurde $1 \mathrm{ml}$ Heparin vorgelegt, um die Blutgerinnung zu hemmen. Die Isolierung der Lymphozyten erfolgte unter der Sterilbank. Das frisch entnommene Blut wurde mit der gleichen Menge HBSS versetzt. In 2 Reaktionsröhrchen wurden jeweils $10 \mathrm{ml}$ Ficoll-Paque Plus vorgelegt und mit dem Blut vorsichtig überschichtet. Anschließend wurden die beiden Röhrchen für $25 \mathrm{~min}$ bei $1600 \mathrm{rpm}$ ohne Bremse zentrifugiert. Bei diesem Schritt ist es essentiell, die Bremse der Zentrifuge auszustellen, um den Aufbau eines Gradienten zu ermöglichen. Da Lymphozyten eine geringere Dichte als andere Zellen im Blut haben, bilden sie eine milchig-trübe Schicht auf der Ficoll-Phase, während die übrigen Zellen auf den Boden des Reaktionsröhrchens sinken (Abb. 5). 
Im Anschluss an die Zentrifugation konnte der Serum-Überstand abgenommen und verworfen werden. Nun wurden die Lymphozyten vorsichtig mit einer Pipette abgenommen und auf 2 Röhrchen aufgeteilt. Die Röhrchen wurden mit HBSS aufgefüllt und für 10 min bei 1800 rpm zentrifugiert. Nachdem der Überstand verworfen wurde, folgte der erste Schritt der CFDA-SE-Färbung. Mit Hilfe des Fluoreszenzfarbstoffs CFDA-SE (Carboxyfluoresceindiacetat-succinimidyl-ester) wurden die Lymphozyten angefärbt und konnten unter dem Mikroskop leichter von den Endothelzellen abgegrenzt werden. Die Aufnahmen der gefärbten Lymphozyten wurden im FITC-Kanal gemacht. Für die Färbung wurde CFDA-SE bis zu einer Endkonzentration von $2 \mu \mathrm{M}$ mit HBSS gemischt. In dieser Lösung wurden die Lymphozyten resuspendiert. Anschließend folgte eine Inkubation der Zellen für 15 min bei $37^{\circ} \mathrm{C}$ und eine Zentrifugation für $10 \mathrm{~min}$ bei $1100 \mathrm{rpm}$. Im Anschluss wurde der Überstand verworfen und die Lymphozyten erneut in HBSS resuspendiert und für $30 \mathrm{~min}$ bei Raumtemperatur inkubiert. Es folgte eine Zentrifugation für $10 \mathrm{~min}$ bei $1100 \mathrm{rpm}$. Nachdem der Überstand abpipettiert wurde, wurden die Zellsedimente resuspendiert, miteinander vereint und anschließend in ein Reaktionsröhrchen überführt. Das Röhrchen wurde mit HBSS aufgefüllt und ein letztes Mal für 10 min bei 1100 rpm zentrifugiert. Das Zellsediment wurde in $1 \mathrm{ml}$ HBSS resuspendiert und die Zellzahl mit Hilfe einer Neubauer-Zählkammer bestimmt. Anschließend wurde die Zellzahl mit Hilfe von HBSS auf $2 \times 10^{6}$ Zellen/ml eingestellt. Der Zellsuspension wurde $\mathrm{CaCl}_{2}$-Lösung bis zu einer Endkonzentration von $2 \mathrm{mM}$ zugesetzt. Für das Flusskammerexperiment wurde die Lymphozytensuspension in 1-ml-Spritzen aufgezogen.

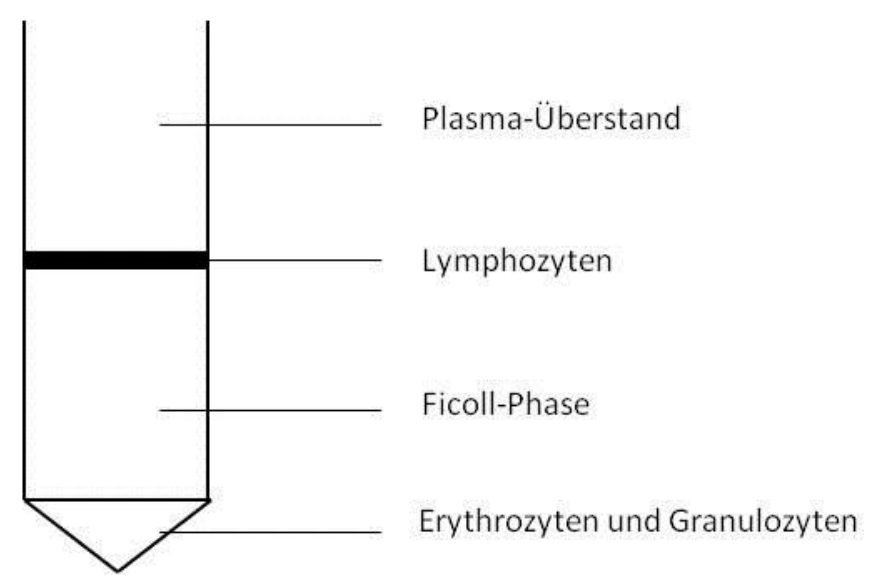

Abb. 5 Bei der Lymphozytenisolierung sammeln sich die Lymphozyten aufgrund ihrer geringeren Dichte auf der Ficoll-Phase. Erythrozyten und Granulozyten haben die höchste Dichte und sammeln sich nach der Zetrifugation am Boden des Röhrchens. 


\subsubsection{Durchführung eines Flusskammerexperiments}

Zu Beginn wurde jeweils ein mit HUVEC beschichteter Thermanox ${ }^{\mathrm{TM}}$-Objektträger aus der Petrischale genommen und in die Flusskammer gelegt. Dabei musste stets darauf geachtet werden, sämtliche Luftblasen aus der Kammer zu entfernen, da Luftblasen einen gleichmäßigen laminaren Fluss behindern. Nach jedem Wechsel des beschichteten Objektträgers wurde das Schlauchsystem mit einem Waschpuffer bestehend aus $50 \mathrm{ml} \mathrm{HBSS}$ $+100 \mu \mathrm{l} 2 \mathrm{mM} \mathrm{CaCl}$-Lösung durchgespült, um einen Verschluss des englumigen Schlauchsystems durch anhaftende Lymphozyten zu verhindern. Nachdem die Flusskammer mit dem eingelegten und festgeschraubten Objektträger auf einem inversen Phasenkontrast-Mikroskop montiert worden war, wurde die Spritze mit der Lymphozytensuspension an den zuführenden Schlauch angesteckt und in einen Perfusor eingeklemmt. Mit Hilfe des Perfusors war es möglich, die Lymphozyten in einer genau vorgegebenen Flussrate über den Objektträger fließen zu lassen. Für dieses Experiment wurde die schon in anderen Arbeiten verwendete Flussrate von 1,12 ml/h $(1.04$ dyn/cm2) gewählt. Bei höheren Flussraten kam es zur Ablösung der Endothelzellen. Als nächstes wurde am Mikroskop die 10fache Vergrößerung eingestellt und der Objektträgertisch so justiert, dass etwa 1/16 der Flusskammeraussparung sichtbar war. Nun wurde der Perfusor angestellt. Sobald in der Flusskammer die ersten Lymphozyten durch das Mikroskop zu erkennen waren, begann die Zeitmessung. Nach 10 min wurde der Fluss angehalten und die auf den Endothelzellen festhaftenden Lymphozyten in 16 Sichtfeldern nach einem festgelegten (standardisierten) Schema ausgezählt (Abb. 6).

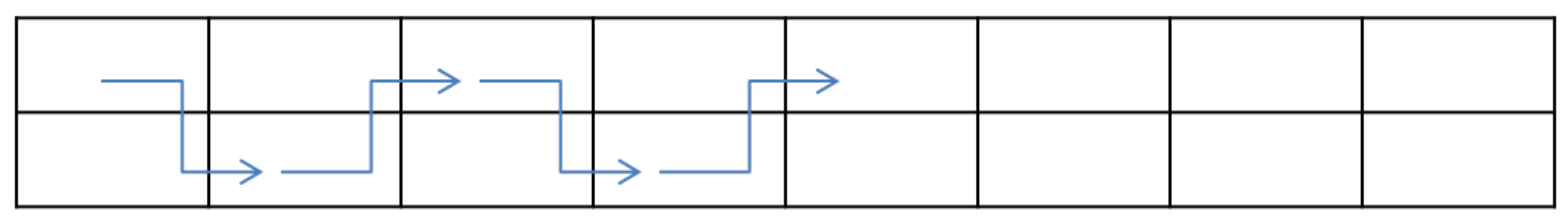

Abb. 6 Die Graphik zeigt das standardisierte Schema für die Auszählung der adhärenten Lymphozyten. Der Objektträger wurde in 16 Felder aufgeteilt, die nacheinander ausgezählt wurden. 
Während des Flusses wurde bereits die Anzahl der rollenden Lymphozyten in einem Sichtfeld bestimmt. Da die Lymphozyten mit CFDA-SE angefärbt waren, wurden die Aufnahmen im FITC-Kanal gemacht. Die Auswertung der Bilder erfolgte mit dem Programm MetaMorph (Molecular Devices).

\subsubsection{Statistische Auswertung}

Für die statistische Auswertung wurde der ungepaarte t-Test verwendet, wobei p-Werte von $p \leq 0,05(*)$ als statistisch signifikant, $p \leq 0,01\left(^{* *}\right)$ als hochsignifikant und $p \leq 0,001\left({ }^{* *}\right)$ als höchstsignifikant gewertet wurden. Zur Abschätzung des statistischen Mittels wurde der Mittelwert und zur Abschätzung des statistischen Fehlers die Standardabweichung (SD) verwendet. Alle statistischen Tests waren zweiseitig. 


\subsection{Material}

\subsubsection{Verbrauchsmaterialien}

\begin{tabular}{|l|l|}
\hline Verbrauchsmaterialien & Bezugsquelle \\
\hline „Chamber slides“ für die Immunfluoreszenz & BD, Franklin Lakes, NJ, USA \\
\hline Flusskammer & Plano, Wetzlar, Deutschland \\
\hline Reaktionsgefäße, 0,5 ml, 1,5 ml, $2 \mathrm{ml}$ & Eppendorf, Hamburg, Deutschland \\
\hline Reaktionsröhrchen für die & BD, Franklin Lakes, NJ, USA \\
\hline Rurchflusszytometrie & $\begin{array}{l}\text { Greiner Bio One, Frickenhausen, } \\
\text { Deutschland }\end{array}$ \\
\hline Glaspipetten $150 \mathrm{~mm} / 230 \mathrm{~mm}$ & WU Mainz, Bamberg, Deutschland \\
\hline Infusions-Set mit Flügelkanüle & Servoprax, Wesel, Deutschland \\
\hline Kulturflaschen $25 \mathrm{~cm}^{2}, 75 \mathrm{~cm}{ }^{2}$ & $\begin{array}{l}\text { Greiner Bio One, Frickenhausen, } \\
\text { Deutschland }\end{array}$ \\
\hline PCR-Reaktionsgefäße $\mathrm{ml}, 50 \mathrm{ml}$ & Biozym, Hessisch Oldendorf, Deutschland \\
\hline Petrischalen & $\begin{array}{l}\text { Greiner Bio One, Frickenhausen, } \\
\text { Deutschland }\end{array}$ \\
\hline Pipettenspitzen & Eppendorf, Hamburg, Deutschland \\
\hline Serologische Pipette $5 \mathrm{ml}, 10 \mathrm{ml}, 25 \mathrm{ml}$ & $\begin{array}{l}\text { Sarstedt, Nümbrecht, Deutschland } \\
\text { Spritze } 20 \mathrm{ml}, 1 \mathrm{ml}\end{array}$ \\
\hline
\end{tabular}

\subsubsection{Gebrauchsfertige Reaktionssysteme}

\begin{tabular}{|l|l|}
\hline Reaktionssysteme & Bezugsquelle \\
\hline E.Z.N.A. ${ }^{\circledR}$ Total RNA Kit I & Omega Bio-Tek, Norcross, GA, USA \\
\hline First Strand cDNA Synthesis Kit & Fermentas, St. Leon-Rot, Deutschland \\
\hline peqGOLD Taq DNA Polymerase & Peqlab, Erlangen, Deutschland \\
\hline RNase-Free DNase Set & Omega Bio-Tek, Norcross, GA, USA \\
\hline Venor $^{\circledR}$ GeM Mycoplasma PCR Detection Kit & Minerva Biolabs, Berlin, Deutschland \\
\hline
\end{tabular}




\subsubsection{Größenstandard}

\begin{tabular}{|l|l|}
\hline Größenstandard & Bezugsquelle \\
\hline GeneRuler $^{\mathrm{TM}} 100 \mathrm{bp}$ Ladder & Fermentas, St. Leon-Rot, Deutschland \\
\hline
\end{tabular}

\subsubsection{Geräte}

\begin{tabular}{|c|c|}
\hline Geräte & Bezugsquelle \\
\hline Absaugsystem Vacusafe comfort & $\begin{array}{l}\text { IBS Integra Biosciences, Fernwald, } \\
\text { Deutschland }\end{array}$ \\
\hline Brutschrank HERAcell 150 & Thermo Fisher Scientific, Waltham, MA, USA \\
\hline Durchflusszytometer FACSCanto II & BD, Franklin Lakes, NJ, USA \\
\hline Fluoreszenzmikroskop Axio Imager M1 & Zeiss, Oberkochen, Deutschland \\
\hline Flusskammer & $\begin{array}{l}\text { Individuelle Anfertigung durch } \\
\text { wissenschaftliche Werkstätte }\end{array}$ \\
\hline Gel Imager U : Genius & Syngene, Frederick, MD, USA \\
\hline Gelkammer & Bio-Rad, Hercules, CA, USA \\
\hline Inverses Mikroskop, Axiovert 200 & Zeiss, Oberkochen, Deutschland \\
\hline Mikrozentrifuge Galaxy Mini & VWR, West Chester, PA, USA \\
\hline Photometer Genesys 10 Bio & Thermo Fisher Scientific, Waltham, MA, USA \\
\hline Photometereinsatz TrayCell & Hellma Analytics, Müllheim, Deutschland \\
\hline Pipetten & Eppendorf, Hamburg, Deutschland \\
\hline $\begin{array}{l}\text { Power Pack P25 (Spannungsquelle für die } \\
\text { Elektrophorese) }\end{array}$ & Biometra, Göttingen, Deutschland \\
\hline Präzisionswaage & Acculab Sartorius, Göttingen, Deutschland \\
\hline PCR Mastercycler & Eppendorf, Hamburg, Deutschland \\
\hline pH-Meter HI 9321 & Hanna Instruments, Woonsocket, RI, USA \\
\hline Pipettierhilfe Pipetboy acu & $\begin{array}{l}\text { IBS Integra Biosciences, Fernwald, } \\
\text { Deutschland }\end{array}$ \\
\hline Reinstwassersystem arium ${ }^{\circledR} 611 \mathrm{VF}$ & Sartorius, Göttingen, Deutschland \\
\hline Spritzenpumpe & WPI, Sarasota, FL, USA \\
\hline
\end{tabular}




\begin{tabular}{|l|l|}
\hline Vortex Mixer L-46 & Labinco, Breda, Niederlande \\
\hline Wasserbad & Memmert, Schwabach, Deutschland \\
\hline Thermomixer comfort & Eppendorf, Hamburg, Deutschland \\
\hline Tischzentrifuge & Thermo Fisher Scientific, Waltham, MA, USA \\
\hline Zentrifuge & Thermo Fisher Scientific, Waltham, MA, USA \\
\hline
\end{tabular}

\subsubsection{Chemikalien}

\begin{tabular}{|c|c|}
\hline Chemikalien & Bezugsquelle \\
\hline Borsäure & Roth, Karlsruhe, Deutschland \\
\hline Calciumchlorid-Dihydrat & Roth, Karlsruhe, Deutschland \\
\hline CFDA-SE & Invitrogen, Carlsbad, CA, USA \\
\hline Dimethylfumarat & Sigma-Aldrich, St. Louis, MO, USA \\
\hline DMSO (Dimethylsulfoxid) & Sigma-Aldrich, St. Louis, MO, USA \\
\hline dNTP Set & Fermentas, St. Leon-Rot, Deutschland \\
\hline EBM (endothelial cell basal medium) & PromoCell, Heidelberg, Deutschland \\
\hline EGM (endothelial cell growth medium) & PromoCell, Heidelberg, Deutschland \\
\hline $\begin{array}{l}\text { EGM-MV (endothelial cell growth medium } \\
\text { for microvascular vessel) }\end{array}$ & PromoCell, Heidelberg, Deutschland \\
\hline Ethanol & Roth, Karlsruhe, Deutschland \\
\hline EDTA & GIBCO $^{\circledR}$ Invitrogen, Carlsbad, CA, USA \\
\hline Ficoll-Paque Plus & GE Healthcare, Freiburg, Deutschland \\
\hline FCS (fetal calf serum) & PAA, Pasching, Austria \\
\hline GelRed $^{\mathrm{TM}}$ & Biotium, Hayward, CA, USA \\
\hline HBSS (Hank's Buffered Salt Solution) & GIBCO Invitrogen, Darmstadt, Deutschland \\
\hline Heparin & Sigma-Aldrich, St. Louis, MO, USA \\
\hline Humanes AB-Serum & Sigma-Aldrich, St. Louis, MO, USA \\
\hline Loading dye (Gelelektrophorese) & Fermentas, St. Leon-Rot, Deutschland \\
\hline Methanol & Roth, Karlsruhe, Deutschland \\
\hline Monomethylfumarat & Sigma-Aldrich, St. Louis, MO, USA \\
\hline Mounting Medium & Dako, Glostrup, Denmark \\
\hline
\end{tabular}




\begin{tabular}{|l|l|}
\hline TNF $\alpha$ & ImmunoTools, Friesoythe, Deutschland \\
\hline Trypsin-EDTA & PAA, Pasching, Austria \\
\hline PBS (phosphate buffered saline) & PAA, Pasching, Austria \\
\hline Tris & Merck, Darmstadt, Deutschland \\
\hline Trypanblau & Sigma-Aldrich, St. Louis, MO, USA \\
\hline 2-Mercaptoethanol & Roth, Karlsruhe, Deutschland \\
\hline
\end{tabular}

\subsubsection{Puffer/Lösungen}

10fach TBE-Puffer

$108 \mathrm{~g}$ Tris

55 g Borsäure

$40 \mathrm{ml} \mathrm{0,5} \mathrm{M}$ EDTA pH 8,0

$1000 \mathrm{ml}$ Aqua Bidest

\subsubsection{Antikörper}

\begin{tabular}{|l|l|l|l|}
\hline Antikörper & $\begin{array}{l}\text { Ursprungsspezies } \\
\text { und Isotyp }\end{array}$ & Verdünnung & Hersteller \\
\hline Anti-CD54 & Maus, IgG & $1: 100$ & $\begin{array}{l}\text { Dako, Glostrup, } \\
\text { Denmark }\end{array}$ \\
\hline Anti-CD62E & IgG, Clone CRL2515 & $1: 100$ & $\begin{array}{l}\text { ATCC, Manassas, VA, } \\
\text { USA }\end{array}$ \\
\hline Anti-CD106 & Maus, IgG & $1: 100$ & $\begin{array}{l}\text { ImmunoTools GmbH, } \\
\text { Friesoythe, } \\
\text { Deutschland }\end{array}$ \\
\hline Anti-mouse F(ab) ${ }_{2}$ PE & Kaninchen, F(ab) 2 & $1: 30$ & $\begin{array}{l}\text { ImmunoTools GmbH, } \\
\text { Friesoythe, } \\
\text { Deutschland }\end{array}$ \\
\hline $\begin{array}{l}\text { Anti-mouse F(ab) }{ }_{2} \\
\text { FITC }\end{array}$ & Ziege, F(ab) ${ }_{2}$ & $1: 100$ & $\begin{array}{l}\text { Dako, Glostrup, } \\
\text { Denmark, } \\
\text { Deutschland }\end{array}$ \\
\hline PE-Isotyp & Maus, IgG & $1: 100$ & $\begin{array}{l}\text { ImmunoTools GmbH, } \\
\text { Friesoythe, } \\
\text { Deutschland }\end{array}$ \\
\hline FITC-Isotyp & Maus, IgG & $1: 100$ & $\begin{array}{l}\text { ImmunoTools GmbH, } \\
\text { Friesoythe, } \\
\text { Deutschland }\end{array}$ \\
\hline
\end{tabular}




\subsubsection{Zellen}

\begin{tabular}{|l|l|}
\hline Zellen & Bezugsquelle \\
\hline $\begin{array}{l}\text { HUVEC (human umbilical vein endothelial } \\
\text { cells) }\end{array}$ & Cambrex, Vervier, Belgien \\
\hline $\begin{array}{l}\text { HPEC-A2 (immortalized human placental } \\
\text { microvascular endothelial cells) }\end{array}$ & $\begin{array}{l}\text { Generiert wie beschrieben (Schütz et al. } \\
\text { 1997) }\end{array}$ \\
\hline
\end{tabular}

\subsubsection{Software}

\begin{tabular}{|l|l|}
\hline Software & Bezugsquelle \\
\hline AxioVision 4.7.1 & Zeiss, Oberkochen, Deutschland \\
\hline MetaMorph 6.3r2 & Visitron Systems, Puchheim, Deutschland \\
\hline
\end{tabular}




\section{Ergebnisse}

\subsection{Wirkung von FAE auf mRNA-Ebene}

\subsubsection{Wirkung von DMF und MMF auf die Zytokintranskription}

Chronisch entzündliche Hauterkrankungen gehen mit einem Anstieg von proinflammatorischen Zytokinen und einer vermehrten Expression von endothelialen Adhäsionsproteinen einher. Mit Hilfe der RT-PCR wurde die Transkription verschiedener Zytokine, Rezeptoren und Adhäsionsproteine untersucht und der Einfluss der Fumarsäureestern DMF und MMF auf die Transkription analysiert. Untersucht wurde die mRNA der Zytokine IL-6, IL-8, MCP-1, CXCL1, der Matrixmetalloproteinase MMP2, des vaskulären endothelialen Wachstumsfaktors (VEGF), der beiden Rezeptoren VEGFR1 und VEGFR2 und der Adhäsionsproteine E-Selektin, P-Selektin, ICAM-1, VCAM-1, CD31 und CD144. Die mRNA von HUVEC und HPEC-A2, zwei humanen Endothelzellreihen, wurde für das Experiment verwendet. Bei HUVEC handelt es sich um primäre Zellen, bei HPEC-A2 um eine immortalisierte Zelllinie. Die Zellen wurden vor der mRNA-Gewinnung mit TNFa aktiviert und mit DMF oder MMF in sechs verschiedenen Konzentrationen (5, 15, 25, 50, 100 oder $200 \mu \mathrm{M}$ ) behandelt. Unstimulierte (kein TNF $\alpha$ ) und unbehandelte (keine FAE) Zellen dienten als Kontrolle. Als interne Kontrolle diente die GAPDH-PCR. Das Gen zur Synthese der Glycerinaldehyd-3-phosphat-Dehydrogenase (GAPDH) wird konstitutiv exprimiert und so sollten alle Proben die gleiche Menge an GAPDH-mRNA aufweisen.

Die Interleukine IL-6 und IL-8 dienen bei Entzündungen als Botenstoffe des Immunsystems. HUVEC exprimierten IL-8-mRNA unverändert auch nach der Behandlung mit DMF in Konzentrationen zwischen 5 und $100 \mu \mathrm{M}$, erst bei $200 \mu \mathrm{M}$ DMF zeigte sich eine deutlich reduzierte Transkription. Die Menge an IL-6-mRNA hingegen sank schon bei Konzentrationen von $25 \mu \mathrm{M}$ DMF ab, war bei $100 \mu \mathrm{M}$ nur noch sehr gering und bei $200 \mu \mathrm{M}$ nicht mehr zu detektieren. In HPEC-A2 war die Reduktion von IL-6 etwas schwächer ausgeprägt als in HUVEC und wurde erst bei $100 \mu \mathrm{M}$ sichtbar, wohingegen die Menge der IL-8-mRNA in HPEC-A2 schon bei $100 \mu \mathrm{M}$ stark abgeschwächt war und das Transkriptionsniveau der nicht stimulierten Kontrolle erreichte. MMF zeigte in den beiden untersuchten Zellreihen sowohl bei IL-6 als auch bei IL-8 keine Wirkung (Abb. 7). 
Ähnlich wie IL-8 verhielt sich nach Behandlung mit DMF und MMF auch das Chemokin CXCL1, welches eine wichtige Rolle bei der Rekrutierung von Entzündungszellen spielt. Eine leicht abgeschwächte mRNA-Bande zeigte sich in der RT-PCR nach Behandlung von HUVEC mit $100 \mu \mathrm{M}$ DMF, eine starke Herunterregulation der CXCL1-mRNA in HUVEC nach $200 \mu \mathrm{M}$ DMF, in HPEC-A2 nach 100 oder 200 MM DMF. Die mRNA-Synthese des Chemokins MCP-1 (monocyte chemotactic protein-1) sprach nur geringfügig auf die Behandlung mit DMF an. Eine leichte Abnahme der mRNA-Menge wurde in beiden Endothelzellreihen bei Konzentrationen von 100 oder $200 \mu \mathrm{M}$ sichtbar. Die Behandlung mit MMF hatte auf die Transkription von CXCL1 und MCP-1 keine Auswirkungen (Abb. 7).

Die mRNA-Spiegel von MMP2 blieben sowohl nach der Behandlung mit DMF als auch mit MMF konstant. 


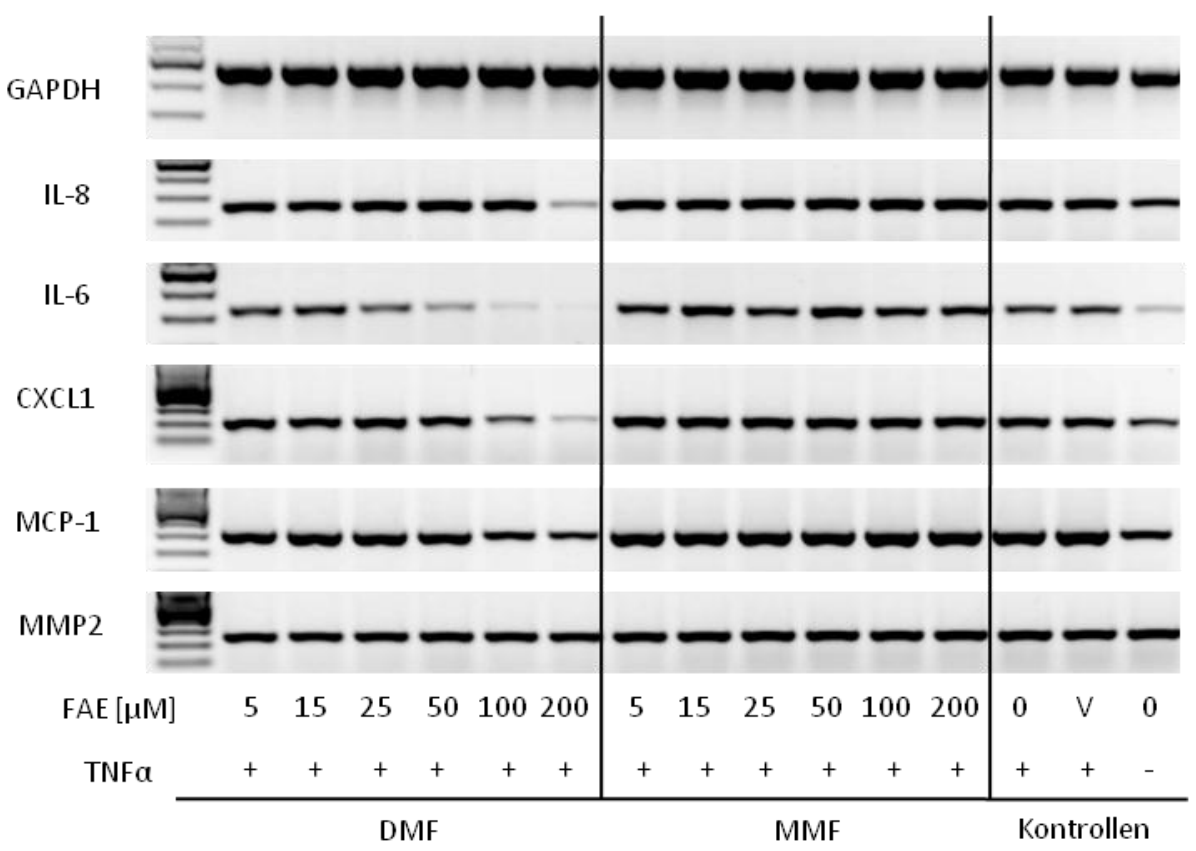

HPEC-A2

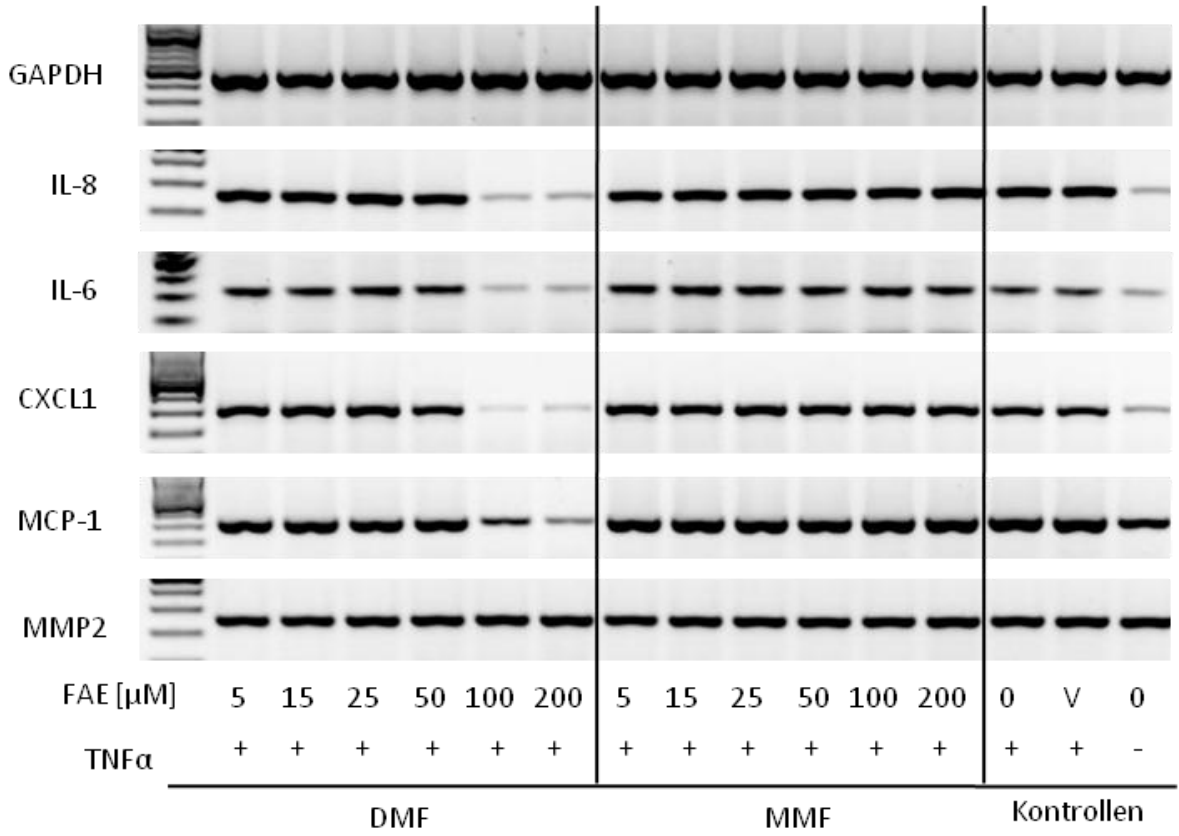

Abb. 7 Die mRNA wurde mit Hilfe der semiquantitativen RT-PCR untersucht. Die humanen Endothelzellinien HUVEC (oberes Schema) und HPEC-A2 (unteres Schema) wurden mit DMF und MMF in den angegebenen Konzentrationen behandelt und mit TNF $\alpha(25 \mathrm{ng} / \mathrm{ml})$ stimuliert. Die Kontrollen wurden entweder nicht behandelt, nur mit TNF $\alpha$ oder mit TNF $\alpha$ und dem Lösungsmittel DMSO (V) behandelt. DMF in höheren Konzentrationen zeigt eine inhibitorische Wirkung auf die Transkription der Zytokine IL-8, IL-6, CXCL1 und MCP-1. Eine Behandlung der Zellen mit MMF hingegen zeigt keinen Effekt. 


\subsubsection{Wirkung von DMF und MMF auf die VEGF-Transkription}

Der vaskuläre endotheliale Wachstumsfaktor (VEGF) stimuliert die Teilung und Migration von Endothelzellen. Die Menge an VEGF-mRNA nahm sowohl in HUVEC als auch in HPEC-A2 mit steigender DMF-Konzentration zu (Abb. 8). Während die PCR-Bande bei einer DMFKonzentration von $5 \mu \mathrm{M}$ noch relativ schwach ausgeprägt war, zeigte sich bei $50 \mu \mathrm{M}$ schon eine deutlich gesteigerte mRNA-Menge. Die stärkste Transkription ließ sich nach einer Behandlung der Zellen mit $200 \mu \mathrm{M}$ DMF beobachten. Dieser Effekt zeigte sich bei drei unabhängig voneinander durchgeführten Versuchsdurchläufen. Die Behandlung der Zellen mit MMF zeigte keine vergleichbare Wirkung, hier blieben die mRNA-Banden annähernd konstant. Auf die Transkription der beiden Rezeptoren VEGFR1 und VEGFR2 hatte die Behandlung mit den zu untersuchenden FAE keine erkennbare Auswirkung. Bei VEGFR1 waren zwar deutlich stärkere mRNA-Banden zu sehen als bei VEGFR2, beide Rezeptoren zeigten aber jeweils konstante mRNA-Mengen in einer PCR. 
HUVEC

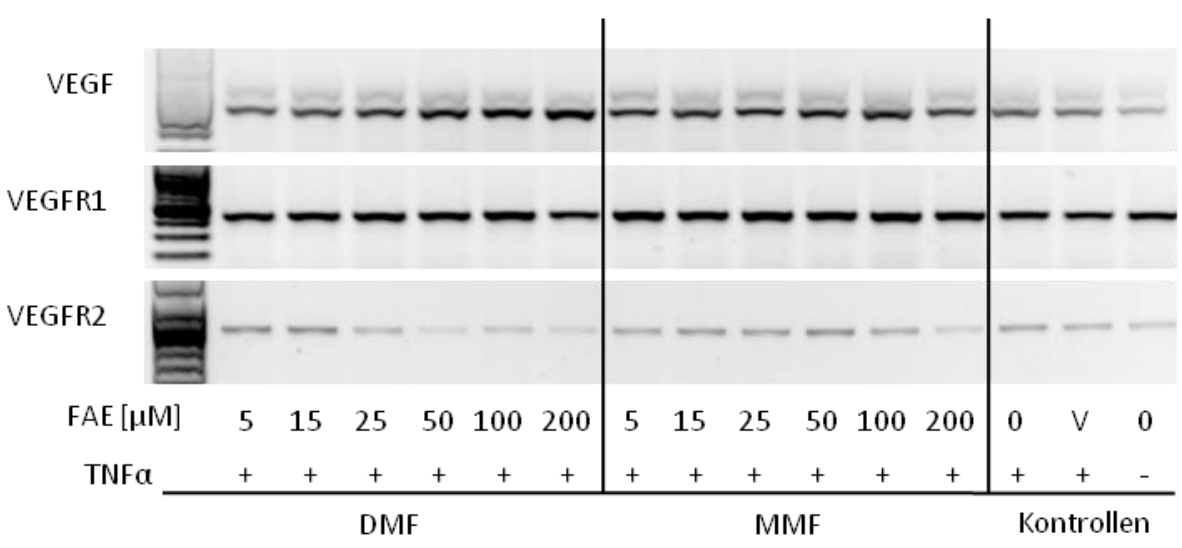

HPEC-A2

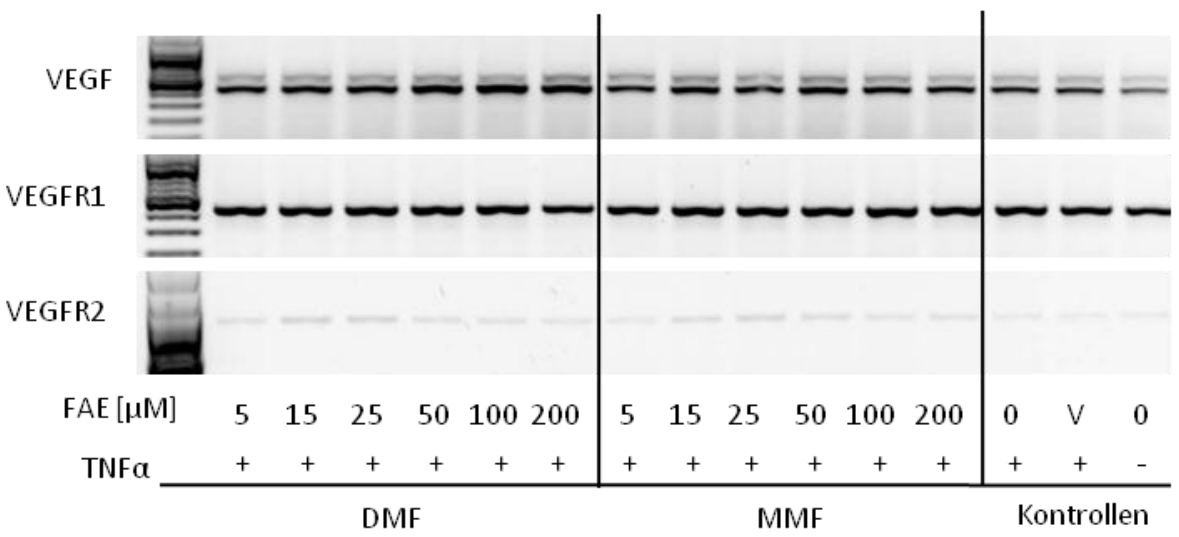

Abb. 8 Die Transkription von VEGF und seinen beiden Rezeptoren VEGFR1 und VEGFR2 wurde mit Hilfe der RT-PCR analysiert. Die humanen Endothelzelllinien HUVEC (oberes Schema) und HPEC-A2 (unteres Schema) wurden mit DMF oder MMF behandelt und mit TNFa $(25 \mathrm{ng} / \mathrm{ml})$ stimuliert. Mit steigender DMF-Konzentration nimmt auch die Menge an VEGFmRNA zu, MMF zeigt keinen Effekt. Die mRNA-Banden der beiden Rezeptoren werden durch die Behandlung mit FAE nicht beeinflusst. 


\subsubsection{Wirkung von DMF und MMF auf die Adhäsionsproteintranskription}

Die Adhäsionsproteine ICAM-1, VCAM-1 und E-Selektin werden auf Endothelzellen exprimiert und spielen eine wichtige Rolle in der Pathogenese chronisch entzündlicher Hauterkrankungen. Für die Infiltration von Lymphozyten in die Haut sind sie unerlässlich. E-Selektin wird nur auf aktivierten Endothelzellen exprimiert, daher zeigten sich in den PCR-Untersuchungen bei den unstimulierten Zellen keine Banden. Mit TNF $\alpha$ stimulierte HUVEC exprimierten E-Selektin-mRNA auch noch nach Behandlung mit 5, 15 oder $25 \mu \mathrm{M}$ DMF. Bei einer Konzentration von $50 \mu \mathrm{M}$ DMF war die Transkription bereits stark abgeschwächt und bei 100 oder $200 \mu \mathrm{M}$ waren keine Banden mehr sichtbar. Bei HPEC-A2 begann die Herunterregulation der mRNA-Menge bereits bei $15 \mu \mathrm{M}$ DMF. Bei $25 \mu \mathrm{M}$ war die E-Selektin-mRNA noch nachweisbar, wohingegen bei Konzentrationen von 50, 100 oder 200 $\mu \mathrm{M}$ DMF keine Banden mehr zu detektieren waren (Abb. 9).

Bei den Adhäsionsproteinen VCAM-1 und ICAM-1 zeigte sich auf mRNA-Ebene ein ähnliches Bild (Abb. 9). Auch VCAM-1-mRNA war in HUVEC nach Behandlung mit 5, 15 oder $25 \mu \mathrm{M}$ DMF in annähernd gleichbleibender Signalstärke nachweisbar. Eine schwach reduzierte mRNA-Menge war bereits bei $50 \mu \mathrm{M}$ sichtbar, stark herunterreguliert wurde die Transkription durch die Behandlung der Zellen mit 100 oder $200 \mu \mathrm{M}$ DMF. In HPEC-A2 rief die Behandlung mit DMF eine ähnliche Wirkung hervor, lediglich die Bande bei $50 \mu \mathrm{M} D M F$ war schwächer ausgeprägt. Auch ICAM-1-mRNA wurde in HUVEC noch exprimiert, nachdem die Zellen mit 5, 15 oder $25 \mu \mathrm{M}$ DMF behandelt worden waren. Wie bei der E-Selektin-PCR zeigte sich bei $50 \mu \mathrm{M}$ nur noch eine sehr schwache Bande. Auch bei Konzentrationen von 100 oder $200 \mu \mathrm{M}$ waren noch schwache Banden erkennbar. Bei HPEC-A2 zeigte sich eine stark reduzierte Menge von ICAM-1-mRNA bei 50, 100 oder 200 MM DMF. Zudem war eine abgeschwächte Bande bei 25 MM DMF zu sehen. MMF beeinflusste die Transkription von E-Selektin, ICAM-1 und VCAM-1 nicht.

Auch P-Selektin, ein weiteres endotheliales Adhäsionsprotein, wurde näher untersucht. Die P-Selektin-Transkription war durch TNF $\alpha$-Stimulation nicht induzierbar, daher zeigten auch die stimulierten Zellen keine stärkeren PCR-Banden als die unstimulierte Kontrolle. Die DMFund MMF-Behandlung hatte sowohl bei HUVEC als auch bei HPEC-A2 keine sichtbare Auswirkung auf die Menge der P-Selektin-mRNA. 
Das Oberflächenprotein CD31 (PECAM-1) wird bei Entzündungen auf Endothelzellen verstärkt exprimiert und unterstützt die Aktivierung neutrophiler Granulozyten. Es konnte bei den PCR-Untersuchungen in sämtlichen Proben nachgewiesen werden, die Zugabe von DMF oder MMF führte zu keinen Veränderungen seiner Transkription. Ebenso verhielt es sich bei den durchgeführten PCR-Untersuchungen für das Protein CD144 (VE-Cadherin). CD144 spielt als Cadherin eine wichtige Rolle bei endothelialen Zell-Zell-Kontakten. Auch hier führte die Behandlung mit DMF oder MMF nicht zu einer Veränderung in der Expression des CD144-Genprodukts. 
HUVEC

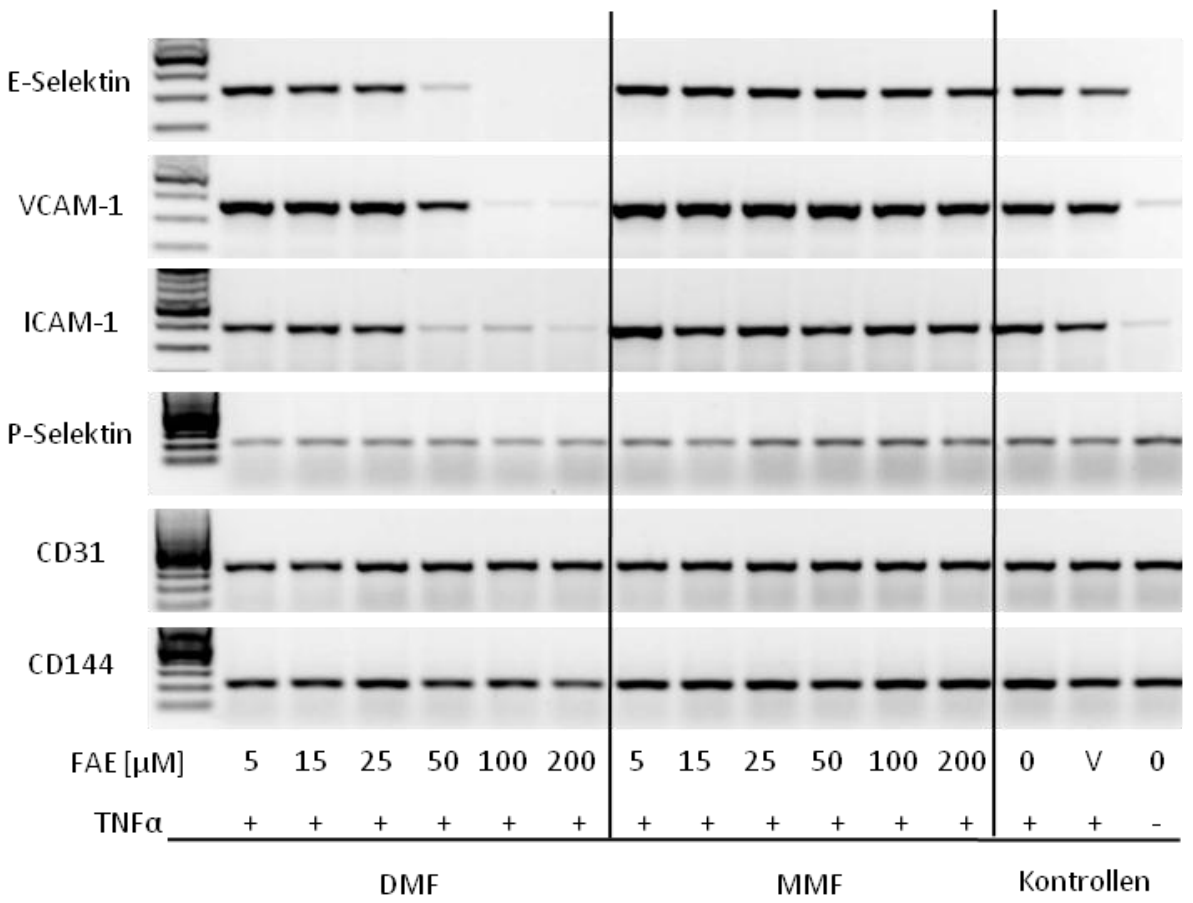

HPEC-A2

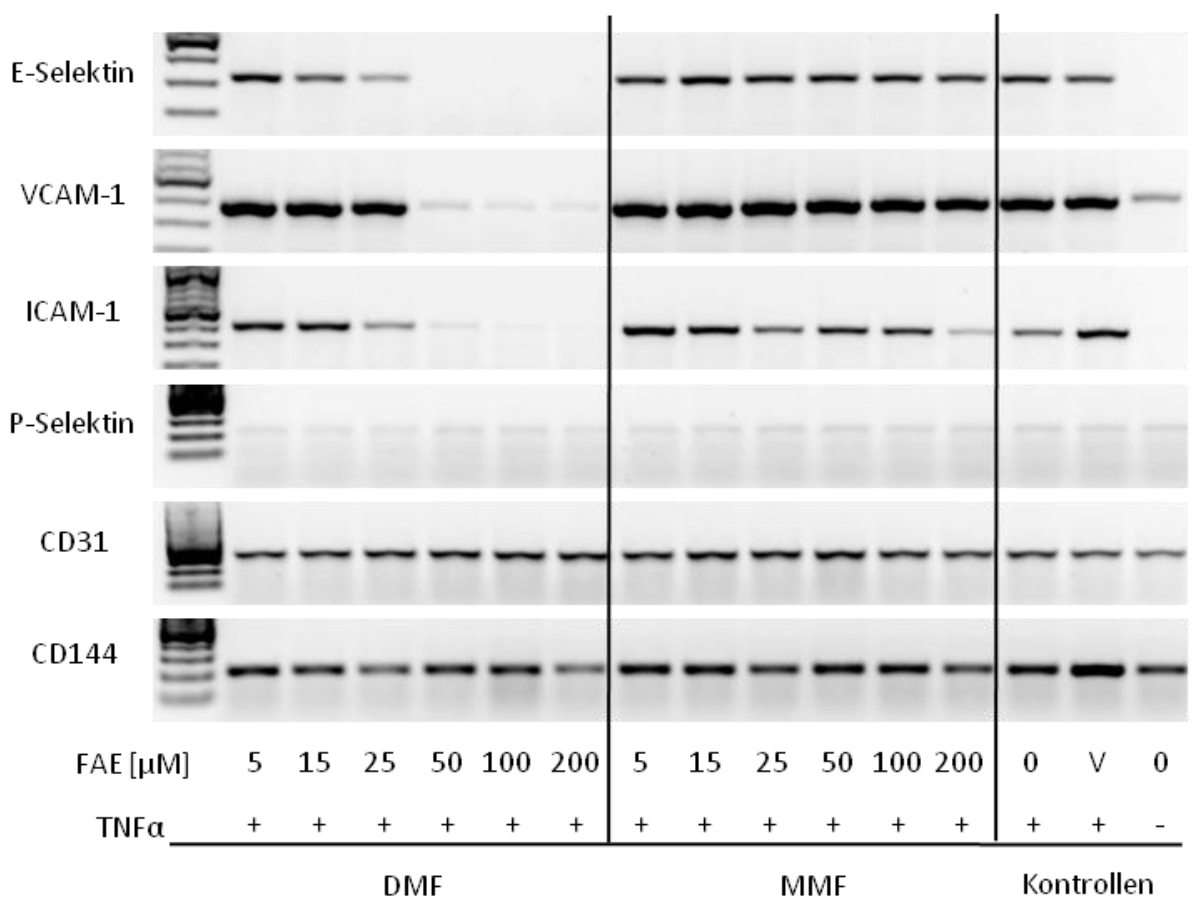

Abb. 9 Die mRNA-Expression wurde mit Hilfe der semiquantitativen RT-PCR bestimmt. DMF, nicht aber MMF, inhibiert in höheren Konzentrationen die Expression der Adhäsionsproteine E-Selektin, VCAM-1 und ICAM-1 in den humanen Endothelzelllinien HUVEC (oberes Schema) und HPEC-A2 (unteres Schema). Die mRNA-Expression von P-Selektin, CD31 und CD144 wird durch die Behandlung mit FAE nicht beeinflusst. 


\subsection{Wirkung von FAE auf Proteinebene}

Der Kontakt zwischen Lymphozyten und den Adhäsionsproteinen der Endothelzellen stellt den initialen Schritt der Lymphozyteninfiltration in die Haut dar. Eine besondere Rolle spielen hier die Proteine E-Selektin, VCAM-1 und ICAM-1. E-Selektin vermittelt die erste lockere Anhaftung, VCAM-1 und ICAM-1 die darauffolgende feste Adhäsion. Funktionell ist es wichtig, dass nach der Regulation der Gentranskription, die durch PCR-Untersuchungen nachgewiesen wurde, die entsprechenden Genprodukte (Proteine) auch orthotop exprimiert werden. Der Nachweis regulatorischer Veränderungen war daher auch auf Proteinebene notwendig.

Schon in den PCR-Untersuchungen zeigte sich eine supprimierende Wirkung des Fumarsäureesters DMF auf die Transkription der Adhäsionsproteine E-Selektin, VCAM-1 und ICAM-1. Um diesen Effekt genauer zu untersuchen und Wirkungen der FAE auf die Oberflächenexpression der Proteine zu analysieren, wurden durchflusszytometrische Messungen durchgeführt. Die Messungen wurden nur an HUVEC durchgeführt, da eine frühere Studie unserer Arbeitsgruppe bereits gezeigt hat, dass E-Selektin auf der Zelloberfläche von HPEC-A2 nicht exprimiert wird (Oostingh et al. 2007). Gemessen wurde sowohl die mittlere Fluoreszenzintensität (MFI) als auch der prozentuale Anteil an exprimierenden Zellen. Die Durchflusszytometrie wurde dreimal durchgeführt und die Durchschnittswerte der drei Messungen errechnet.

In einem ersten Versuch wurden HUVEC nur mit TNFa (25 ng/ml) stimuliert und die Oberflächenexpression von E-Selektin, VCAM-1 und ICAM-1 auf stimulierten und unstimulierten Zellen wurde verglichen. Die Messung zeigte, dass die Expression aller drei Adhäsionsproteine durch TNF $\alpha$ induzierbar ist. Die Zahl der positiven Zellen ließ sich bei E-Selektin um den Faktor 32,2, bei VCAM-1 um den Faktor 18 und bei ICAM-1 um den Faktor 2,5 steigern. Weiterhin zeigte sich, dass E-Selektin und VCAM-1 auf unstimulierten Zellen kaum oder gar nicht exprimiert werden. Die Anzahl der positiven Zellen betrug hier 2 bzw. 1,1\%. ICAM-1 hingegen war mit 34,6\% positiven Zellen auch auf unstimulierten HUVEC messbar. Dieses Protein wird in geringem Umfang von ruhenden Endothelzellen konstitutiv exprimiert (Rothlein et al. 1986). 


\subsubsection{Einfluss von DMF und MMF auf die Expression von E-Selektin}

In der nächsten Versuchsreihe wurden HUVEC $1 \mathrm{~h}$ vor der TNF $\alpha$-Stimulation mit DMF und MMF in fünf verschiedenen Konzentrationen (5, 15, 25, 50 oder $200 \mu \mathrm{M})$ behandelt. HUVEC zeigten nach Stimulation mit TNF $\alpha$ in Bezug auf die E-Selektin-Expression eine durchschnittliche MFI von 3.528. Die Behandlung der Zellen mit DMF in ansteigenden Konzentrationen führte zu einem kontinuierlichen Abfall der MFI. Nach der Behandlung mit $15 \mu \mathrm{M}$ DMF zeigte sich bereits ein Absinken auf 2.443. Die Behandlung mit 50 bzw. $200 \mu \mathrm{M}$ DMF führte zu einem signifikanten Abfall der MFI-Werte auf 542 bzw. $247(p<0,01)$. Die Zugabe von MMF führte nicht zu einer signifikanten Reduktion der E-Selektin-Expression. Es zeigten sich konstant hohe Werte mit einer MFI von durchschnittlich 4.379 nach Behandlung mit $200 \mu \mathrm{M}$ MMF (Abb. 10). Auch die Anzahl der positiven Zellen, d.h. der Zellen, die E-Selektin exprimieren, sank mit steigender DMF-Konzentration kontinuierlich ab. Während die Zahl der positiven Zellen nach TNF $\alpha$ Stimulation 73\% betrug, führte die Behandlung mit $15 \mu \mathrm{M}$ DMF bereits zu einem Abfall auf 64\%. Eine signifikante Abnahme ließ sich durch die Zugabe von $50 \mu \mathrm{M}$ DMF erreichen. Hier sank die Anzahl der E-Selektin-exprimierenden Zellen auf $19 \%$, was einer Reduktion um 74\% entspricht $(p<0,001)$. Auch die Inkubation mit $200 \mu \mathrm{M}$ DMF führte zu einer signifikanten Abnahme um 90\% auf 7\% positive Zellen $(p<0,001)$. Die MMF-Behandlung zeigte keine signifikante Wirkung. Während E-Selektin nach der Stimulation mit TNFa auf der Oberfläche von 73\% der HUVEC nachweisbar war, waren es nach der Behandlung mit 5, 15, 25 oder 50 MM MMF im Durchschnitt jeweils noch 72\%, nach der Zugabe von $200 \mu \mathrm{M}$ MMF noch 70\% (Abb. 10). 


\section{E-Selektin}
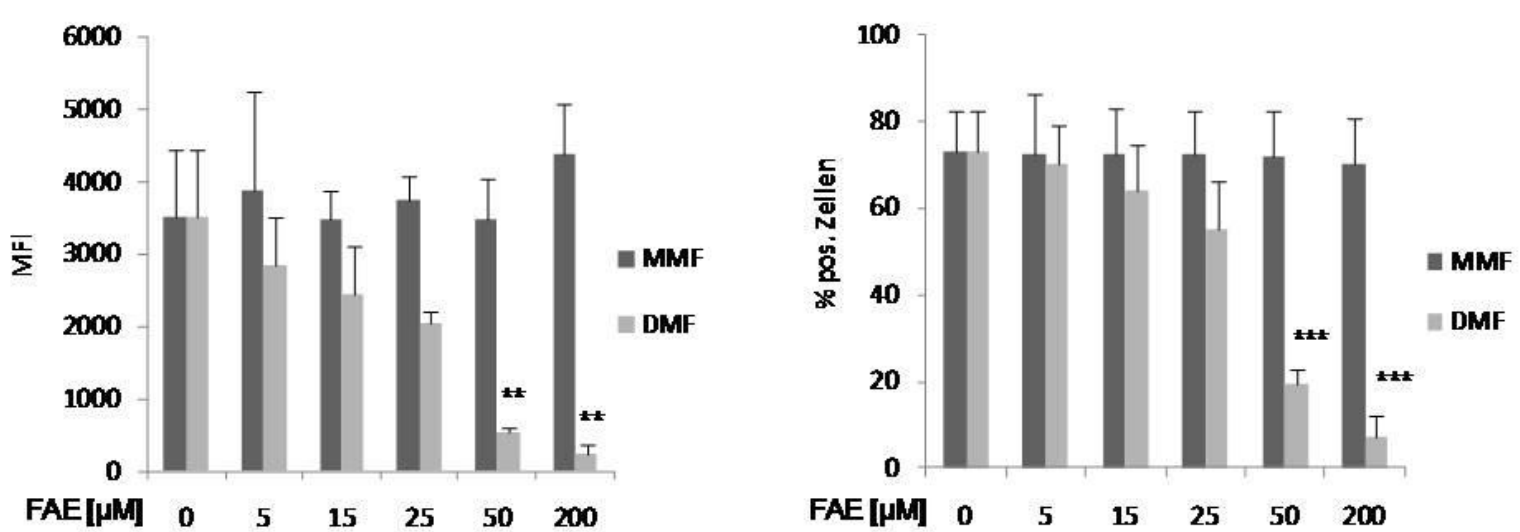

Abb. 10 Die Proteinexpression von E-Selektin auf der Zelloberfläche von HUVEC wurde mit Hilfe der Durchflusszytometrie bestimmt. Die mittlere Fluoreszenzintensität (MFI, linkes Schema) und die Anzahl der positiven Zellen in \% (rechtes Schema) wurden gemessen. HUVEC wurden entweder mit DMF oder MMF in den angegeben Konzentrationen behandelt und mit TNF $\alpha(25 \mathrm{ng} / \mathrm{ml})$ aktiviert. Angegeben sind Mittelwerte (+ Standardabweichung) aus drei unabhängigen Versuchen. * $p<0,05 ; * * p<0,01 ; * * p<0,001$ im Vergleich zu der unbehandelten und stimulierten Kontrolle.

Eine weitere Untersuchung der E-Selektin-Expression erfolgte mit Hilfe der Immunfluoreszenzfärbung von HUVEC. Die Zellen wurden wie schon bei der PCR und den durchflusszytometrischen Messungen mit DMF oder MMF (50 oder $200 \mu \mathrm{M}$ ) behandelt und anschließend mit TNFa (25 ng/ml) stimuliert. Als Kontrolle diente sowohl eine unbehandelte und unstimulierte als auch eine unbehandelte und stimulierte Probe.

In der E-Selektin-Färbung zeigte sich erwartungsgemäß kein Signal in der unbehandelten und unstimulierten Kontrolle. Die TNFa-Stimulation führte zur Expression von E-Selektin auf der Zelloberfläche von HUVEC und einem starken Signal in der Immunfluoreszenzfärbung. Daran änderte sich bei MMF-Behandlung nichts. Die Zugabe von $50 \mu \mathrm{M}$ DMF führte dagegen zu einer deutlichen Abnahme der E-Selektin-Expression, nach Inkubation mit $200 \mu \mathrm{M}$ wurde das Expressionsniveau der unstimulierten Kontrolle erreicht (Abb. 11). 

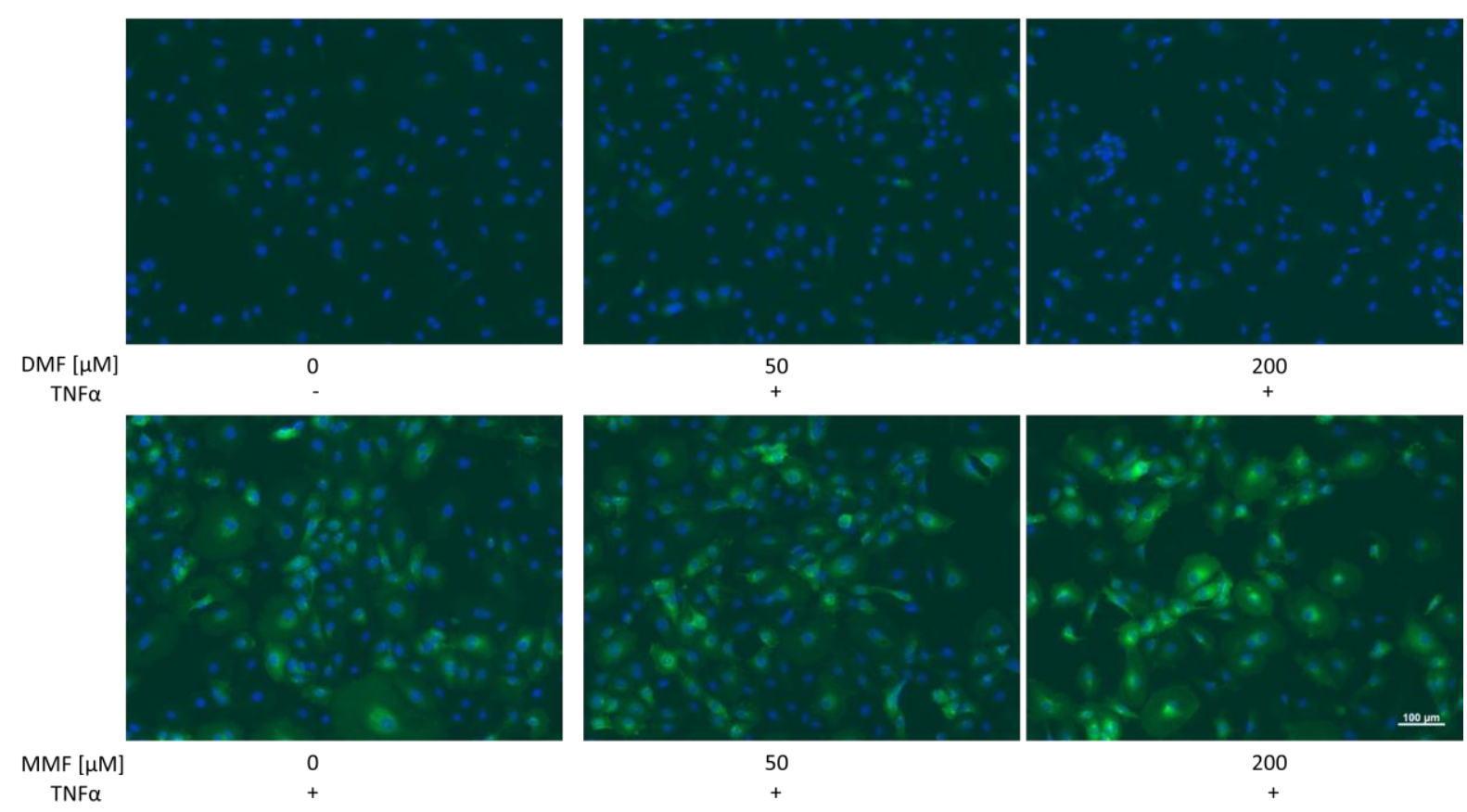

50

200

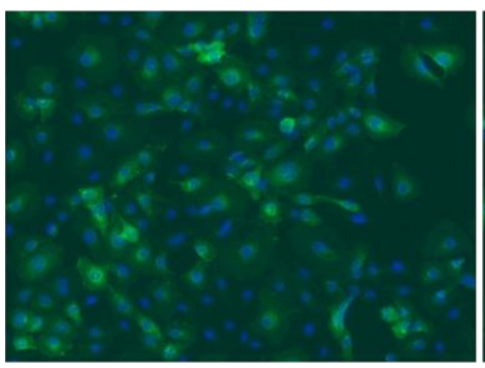

50

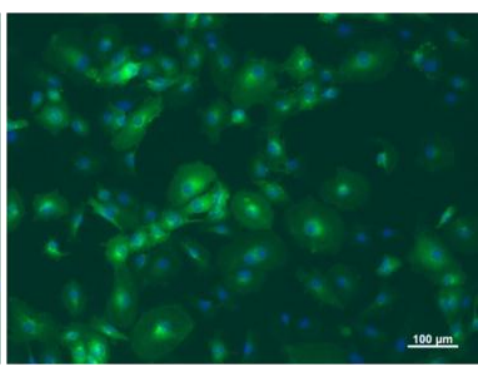

200

E-Selektin (20x)
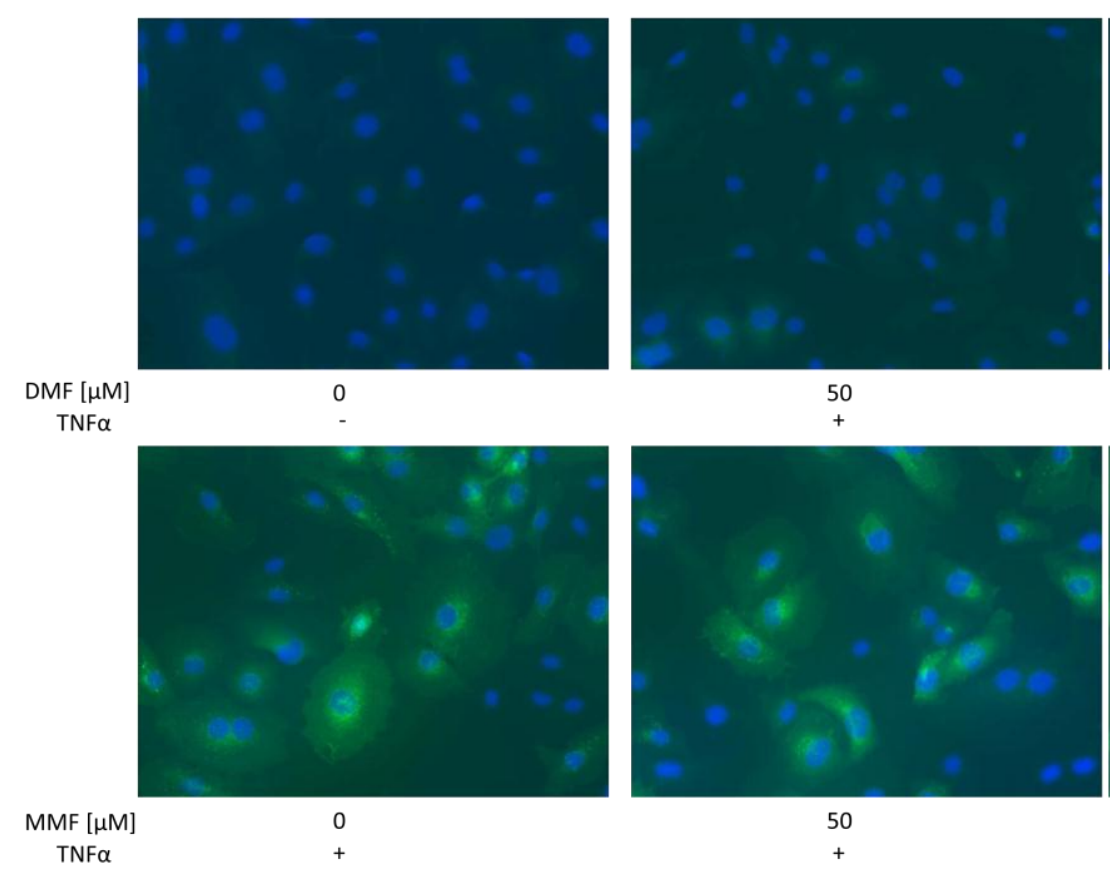

50

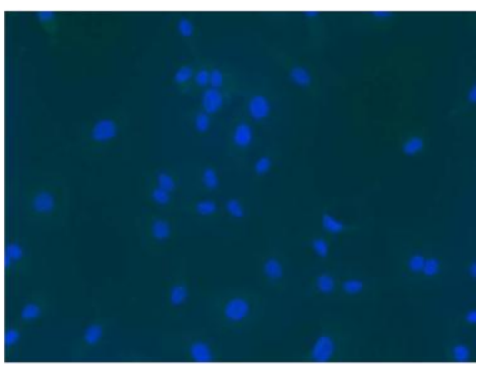

200
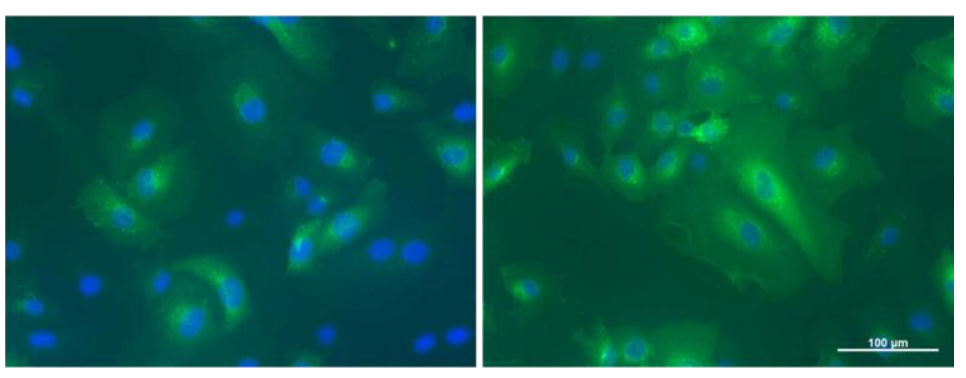

200

50

Abb. 11 Die Expression von E-Selektin auf der Oberfläche von HUVEC wurde mit Immunfluoreszenzfärbungen untersucht. HUVEC wurden mit DMF oder MMF in den beiden angegebenen Konzentrationen behandelt und mit TNF $\alpha(25 \mathrm{ng} / \mathrm{ml})$ aktiviert. Die Behandlung mit 50 oder 200 MM DMF führte zu einer deutlichen Abschwächung des Signals. Unbehandelte und unstimulierte bzw. unbehandelte und stimulierte Endothelzellen dienten als Kontrolle. Die Bilder wurden mit einer zehnfachen (oberes Schema) und mit einer zwanzigfachen (unteres Schema) Vergrößerung aufgenommen. Alle Aufnahmen erfolgten mit einer Belichtungszeit von 350 ms. Der Maßstab zeigt $100 \mu \mathrm{m}$. Die Zellkerne wurden mit DAPI angefärbt. 


\subsubsection{Einfluss von DMF und MMF auf die Expression von VCAM-1}

In Bezug auf die VCAM-1-Expression zeigten HUVEC nach TNF $\alpha$-Stimulation im Durchschnitt eine MFI von 3.636. Auch die Expression von VCAM-1 nahm mit steigender DMFKonzentration kontinuierlich ab. Nach der Inkubation mit $15 \mu \mathrm{M}$ DMF konnte ein Abfall der MFI auf 2.711 beobachtet werden. Die Zugabe von 50 oder $200 \mu \mathrm{M}$ führte zu einem signifikanten Rückgang der VCAM-1-Expression auf 609 und $689(p<0,05)$. Durch die Behandlung der Zellen mit MMF konnte keine vergleichbare Reduktion der VCAM-1-Expression erzielt werden. Während bei der unbehandelten Kontrolle eine MFI von 3.636 gemessen werden konnte, führte die Zugabe von $200 \mu \mathrm{M}$ MMF lediglich zu einem leichten Abfall auf 2.492 (Abb. 12). Bei der Analyse der positiven Zellen zeigte sich erneut ein ähnliches Bild wie bei der Untersuchung der MFI. Nach Stimulation mit TNF $\alpha$ exprimierten durchschnittlich 74\% der HUVEC VCAM-1. Durch die Zugabe von $25 \mu \mathrm{M}$ DMF konnte eine Reduktion auf 52\% erreicht werden. Deutlich sichtbar wurde die Wirkung von DMF nach der Behandlung mit 50 oder $200 \mu \mathrm{M}$, hier ließ sich VCAM-1 noch auf der Oberfläche von 22\% bzw. 10\% der Zellen nachweisen, was einer Abnahme der Zellzahl um 70,3\% bzw. 86,5\% entspricht $(p<0,01)$. Im Anschluss an die MMF-Behandlung schwankte die Zahl der positiven Zellen lediglich zwischen 72\% nach Zugabe von $15 \mu \mathrm{M}$ und 63\% nach $200 \mu \mathrm{M}$ MMF (Abb. 12)

\section{VCAM-1}
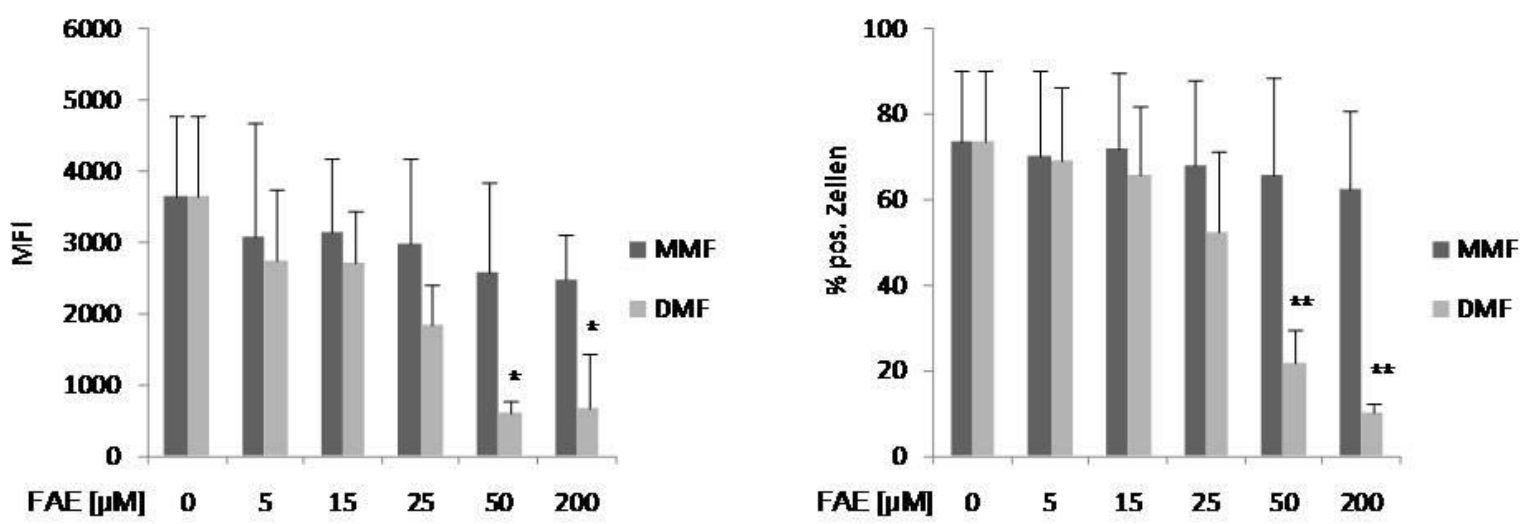

Abb. 12 Anhand von durchflusszytometrischen Messungen wurde die Proteinexpression von VCAM-1 auf der Zelloberfläche von HUVEC bestimmt. Die Zellen wurden mit DMF oder MMF behandelt und mit TNF $\alpha$ stimuliert. Analysiert wurde die mittlere Fluoreszenzintensität (MFI, linkes Schema) und die Anzahl der positiven Zellen in \% (rechtes Schema). Angegeben sind Mittelwerte (+ Standardabweichung) aus drei unabhängigen Versuchen. ${ }^{*} p<0,05 ;{ }^{* *} p<0,01 ;{ }^{* *} p<0,001$ im Vergleich zu der unbehandelten und stimulierten Kontrolle. 
Auch die VCAM-1-Expression wurde mit Hilfe der Immunfluoreszenzfärbung noch weiter untersucht.

In der VCAM-1-Färbung zeigte sich eine leichte konstitutive Expression und somit ein schwaches Signal in der unbehandelten und unstimulierten Kontrolle. Ein starkes Signal ließ sich auch hier durch die Stimulation mit TNF $\alpha$ erzielen. Dieses Signal blieb nach der Inkubation mit 50 oder $200 \mu \mathrm{M}$ MMF erhalten. Ein deutlich abgeschwächtes Signal im Vergleich zur stimulierten Kontrolle zeigte sich bereits in der mit $50 \mu \mathrm{M}$ DMF behandelten Probe, eine starke Abnahme der VCAM-1-Expression konnte durch die Zugabe von $200 \mu \mathrm{M}$ DMF erreicht werden (Abb. 13). 


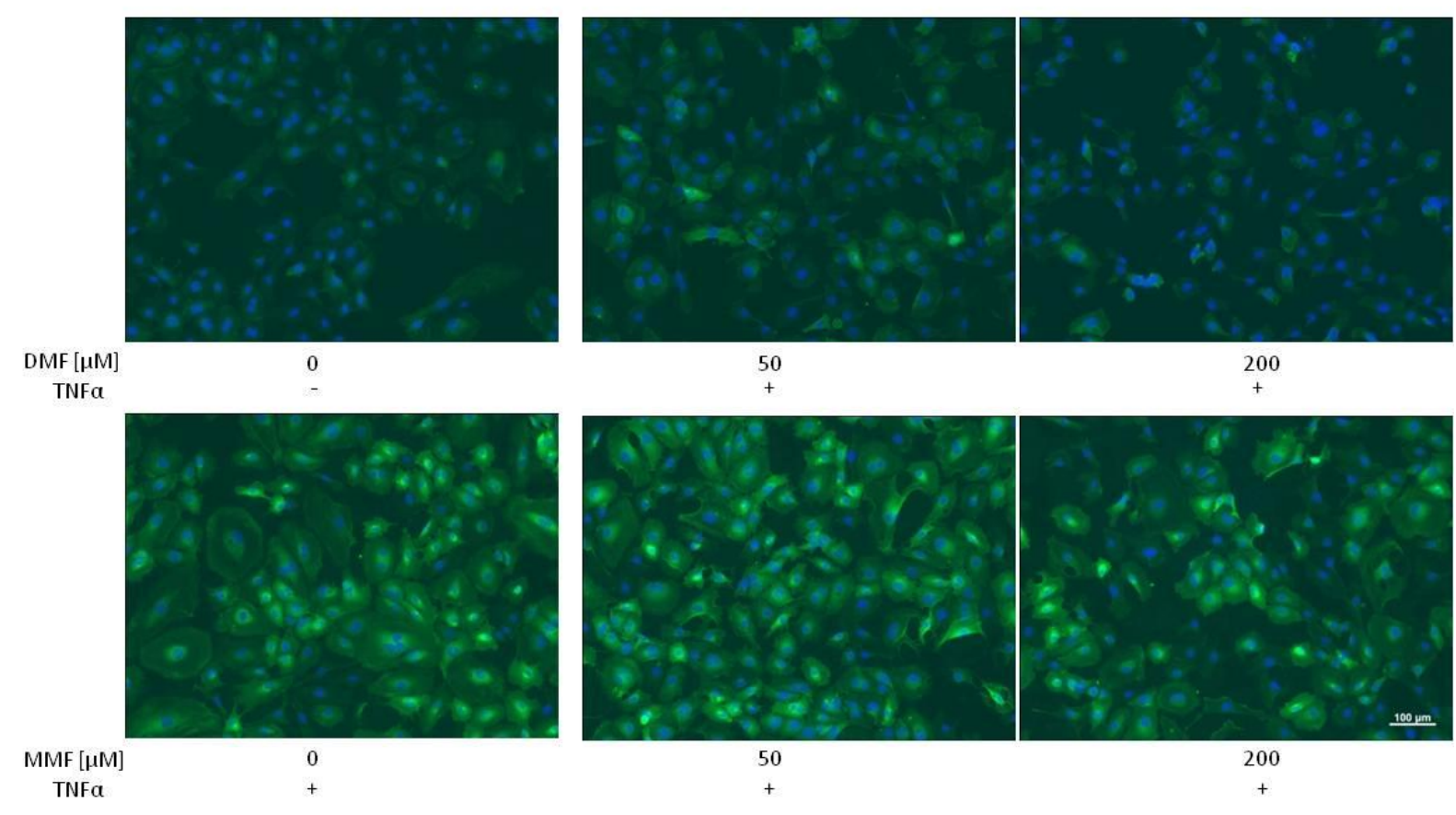

$\operatorname{VCAM}-1(20 \mathrm{x})$

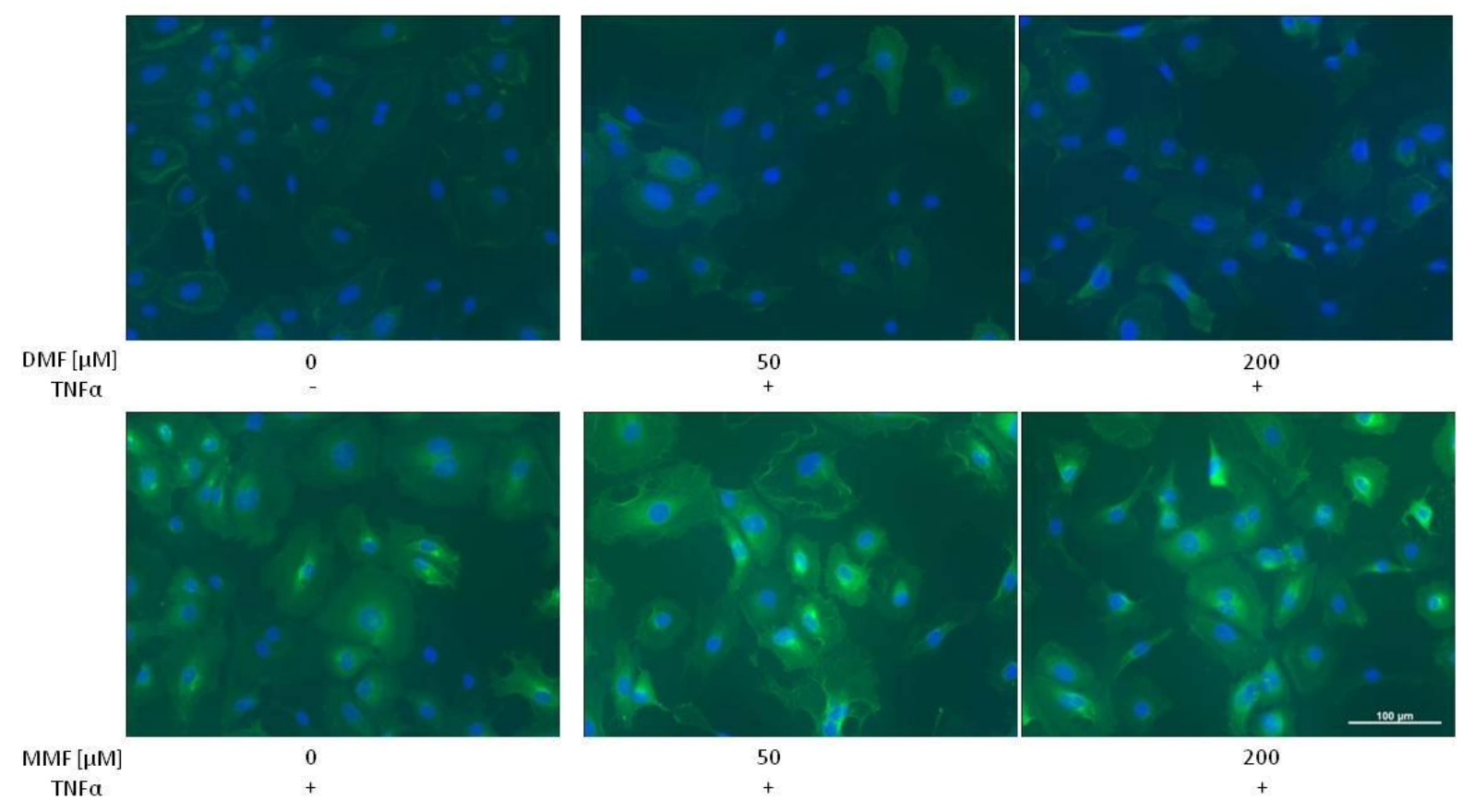

Abb. 13 Mit Hilfe der Immunfluoreszenzfärbung konnte die Expression von VCAM-1 auf der Oberfläche von HUVEC analysiert werden. HUVEC wurden mit DMF oder MMF in den beiden angegebenen Konzentrationen behandelt und mit TNFa $(25 \mathrm{ng} / \mathrm{ml})$ stimuliert. Die Behandlung mit DMF führte zu einer reduzierten VCAM-1-Expression und somit zu einem stark abgeschwächten Signal in der Immunfluoreszenz. Unbehandelte und unstimulierte bzw. unbehandelte und stimulierte Endothelzellen dienen als Kontrolle. Die Bilder wurden mit einer zehnfachen (oberes Schema) und mit einer zwanzigfachen (unteres Schema) Vergrößerung aufgenommen. Die Belichtungszeit betrug bei allen Aufnahmen 350 ms. Der Maßstab zeigt $100 \mu \mathrm{m}$. Die Zellkerne der HUVEC wurden mit DAPI angefärbt. 


\subsubsection{Einfluss von DMF und MMF auf die Expression von ICAM-1}

Wie bereits bei E-Selektin und VCAM-1 beobachtet, nahm auch die ICAM-1-Expression in HUVEC mit ansteigender DMF-Konzentration kontinuierlich ab. Die stimulierte Kontrolle wies eine im Vergleich sehr hohe MFI von 15.018 auf. Mit einer MFI von 14.418 war eine leichte Abnahme schon bei einer Konzentration von $5 \mu \mathrm{M}$ DMF messbar. Bereits die Behandlung mit 15 und $25 \mu \mathrm{M}$ DMF führte zu einer signifikanten Reduktion der ICAM-1-MFI auf 10.317 und $9.973(p<0,01)$. Ebenfalls signifikant war die Abnahme der ICAM-1-Expression nach Behandlung der Zellen mit 50 oder 200 MM DMF. Hier konnte die MFI auf Werte von 3.749 und 991 gesenkt werden $(p<0,001)$. Leicht fluktuierende Werte zeigten sich in der durchflusszytometrischen Messung im Anschluss an die MMF-Behandlung. Die stimulierte und unbehandelte Kontrolle zeigte eine MFI von 15.018, die mit $5 \mu \mathrm{M}$ MMF behandelte Probe eine MFI von 16.129. Die Zugabe von 50 oder $200 \mu \mathrm{M}$ MMF führte zu Werten von 15.048 und 17.013. Auch hier war im Anschluss an die MMF-Behandlung also weder ein Aufwärts- noch ein Abwärtstrend erkennbar (Abb. 14). Weiter ergab die durchflusszytometrische Messung bei der Analyse der ICAM-1-Expression mit 92\% eine sehr hohe Prozentzahl an positiven Zellen in der stimulierten und unbehandelten Probe. Die Behandlung mit 5, 15 oder 25 MM DMF führte mit 94\%, 91\% und 89\% positiven Zellen zu ähnlich hohen Werten. Erst die Proben, die mit 50 oder 200 MM DMF behandelt wurden, zeigten mit $73 \%$ und $46 \%$ eine deutlich reduzierte Zahl an ICAM-1-exprimierenden Zellen. Die Zugabe von MMF zeigte erneut keinen nennenswerten Effekt. Die Zahl der positiven Zellen schwankte zwischen 94\% nach Behandlung mit 5 oder $25 \mu \mathrm{M}$ MMF und $92 \%$ nach Zugabe von $200 \mu \mathrm{M}$ (Abb. 14). 

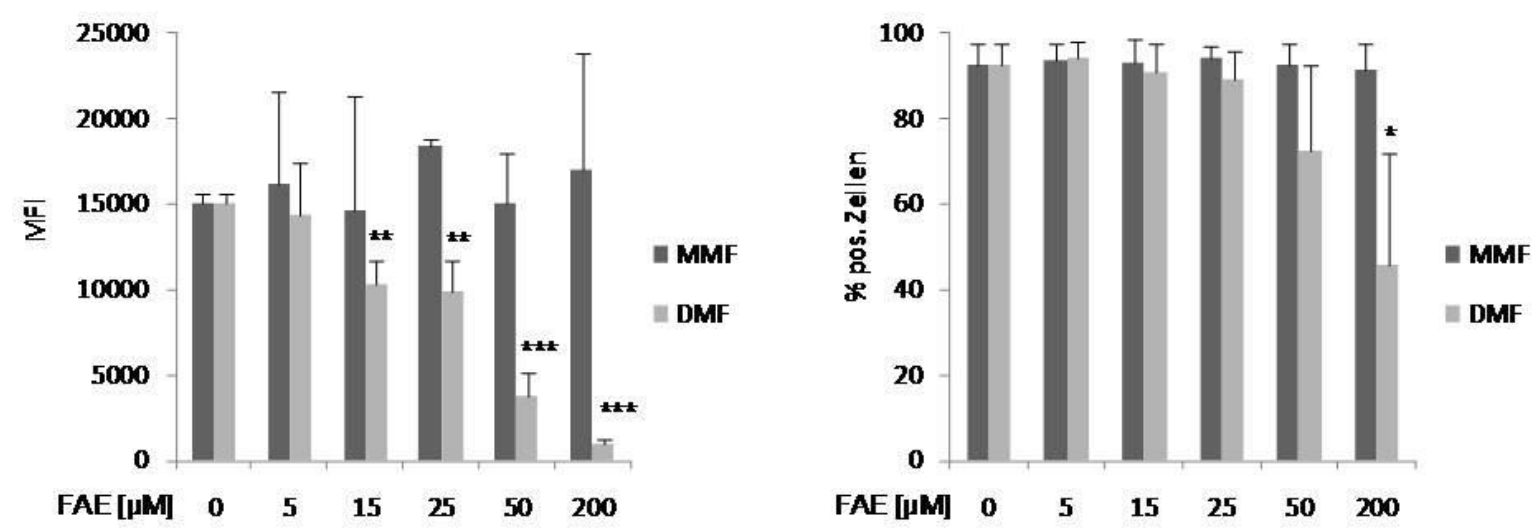

Abb. 14 Die Expression von ICAM-1 auf der Zelloberfläche von HUVEC wurde mit Hilfe der Durchflusszytometrie bestimmt. Die mittlere Fluoreszenzintensität (MFI) und die Anzahl der positiven Zellen in \% wurden gemessen, nachdem HUVEC entweder mit DMF oder MMF in den angegeben Konzentrationen behandelt und mit TNF $\alpha(25 \mathrm{ng} / \mathrm{ml})$ aktiviert wurden. Angegeben sind Mittelwerte (+ Standardabweichung) aus drei unabhängigen Versuchen. ${ }^{*} p<0,05 ;{ }^{* *} p<0,01 ;{ }^{* * *} p<0,001$ im Vergleich zu der unbehandelten und stimulierten Kontrolle.

Eine ICAM-1-Färbung wurde unter Berücksichtigung der Ergebnisse der Durchflusszytometrie nicht durchgeführt. Da sich die Anzahl der ICAM-1-exprimierenden Zellen nur um 50\% senken ließ, waren bei der Immunfluoreszenzfärbung, die für quantitative Auswertungen nur bedingt genutzt werden kann, keine aussagekräftigen Aufnahmen zu erwarten.

Zusammenfassend lässt sich sagen, dass DMF in den durchgeführten durchflusszytometrischen Messungen zu einer signifikanten Abnahme der Oberflächenexpression von E-Selektin, VCAM-1 und ICAM-1 auf HUVEC führte. Die mittlere inhibitorische Konzentration $\left(\mathrm{IC}_{50}\right)$ lag für die drei untersuchten Proteine jeweils zwischen 25 und $50 \mu \mathrm{M}$ DMF. Die Behandlung der Endothelzellen mit MMF rief bei keinem der drei Adhäsionsproteine eine signifikante Änderung in der Expression hervor. 


\subsection{Wirkung der FAE auf die Interaktion von Endothelzellen und Lymphozyten}

Mit Hilfe der PCR, der Durchflusszytometrie und der Immunfluoreszenz konnten bereits inhibitorische Effekte von DMF, nicht aber MMF, bzgl. der Expression von Adhäsionsproteinen auf der Oberfläche von humanen Endothelzellen beobachtet werden. Als nächstes sollte der funktionelle Aspekt der MMF- und DMF-Behandlung genauer untersucht werden. Um den Einfluss der Fumarsäureester auf die Interaktion zwischen Endothelzellen und humanen Lymphozyten untersuchen zu können, wurden Versuche mit einer Flusskammer durchgeführt. Da das Rollen und die feste Adhäsion der Lymphozyten durch verschiedene endotheliale Proteine vermittelt werden, wurden diese beiden konsekutiven funktionellen Aspekte der Lymphozyteninfiltration getrennt voneinander analysiert.

Während der 10-minütigen Perfusionszeit wurden die rollenden Lymphozyten in einem Sichtfeld ausgezählt (Abb. 17). Der Flusskammerversuch wurde viermal durchgeführt und die Durchschnittswerte der vier Messungen errechnet. Es zeigte sich, dass die humanen Lymphozyten nicht auf den unstimulierten Endothelzellen rollen. Hier ergab sich in den vier Versuchsdurchläufen lediglich ein Wert von 0,25 Lymphozyten/Sichtfeld. Ein deutlich anderes Bild zeigte sich nach TNFa-Stimulation der Endothelzellen. Hier rollten durchschnittlich 67,25 Lymphozyten auf den ausgesäten HUVEC. (Diese endotheliale Aktivierung verdeutlicht die zentrale Bedeutung von TNF im psoriatischen Krankheitsprozess, die heute bei modernen Therapien bereits gezielt genutzt wird.) Als nächstes wurden die stimulierten Endothelzellen mit $50 \mu \mathrm{M}$ DMF behandelt. Hier ließ sich ein signifikanter Rückgang der Anzahl an rollenden Lymphozyten beobachten, der Durchschnitt betrug nun noch 9,5 ( $p<0,001$, im Vergleich zu der stimulierten und unbehandelten Probe). Die Behandlung von HUVEC mit $200 \mu \mathrm{M}$ DMF führte zu einer noch stärkeren Abnahme der Interaktion zwischen Lymphozyten und Endothelzellen. Der Durchschnitt betrug lediglich noch 1,25 Lymphozyten/Sichtfeld $(p<0,001)$. Die Inkubation der Objektträger mit $50 \mu \mathrm{M}$ MMF führte zu einem erneuten Anstieg der Anzahl an rollenden Zellen. Hier konnten 65,75 Zellen gezählt werden. Die Behandlung mit $200 \mu \mathrm{M}$ MMF führte wiederum zu einer leichten, jedoch nicht signifikanten Abnahme der Zell-Zell-Interaktion. Hier wurden im Durchschnitt 49 rollende Lymphozyten beobachtet. 
Die Zahl der adhärenten Lymphozyten wurde jeweils im Anschluss an eine 10-minütige Perfusionsperiode bestimmt (Abb. 16, 17). Hier wurde der Mittelwert aus 16 Sichtfeldern und vier Versuchsdurchläufen gebildet. Erwartungsgemäß zeigte sich ein ähnliches Bild wie bei der Analyse der rollenden Lymphozyten. Mit durchschnittlich 0,4 adhärenten Lymphozyten/Sichtfeld ließ sich fast keine Interaktion zwischen unstimulierten HUVEC und den Blutzellen beobachten. Durch die Stimulation mit TNF $\alpha$ ließ sich die Zahl der fest anhaftenden Lymphozyten auf durchschnittlich 28,3 steigern. Zu einer signifikanten Abnahme der Anzahl an adhärenten Lymphozyten um 88\% auf 5 Lymphozyten/Sichtfeld, im Vergleich zu der stimulierten und unbehandelten Probe, führte die Behandlung mit $50 \mu \mathrm{M}$ DMF $(p<0,01)$. Die Zugabe von $200 \mu \mathrm{M}$ DMF reduzierte die Anzahl der anhaftenden Blutzellen um $98,8 \%$ auf 0,4 Lymphozyten/Sichtfeld $(p<0,01)$. Auch bei der Analyse der adhärenten Lymphozyten zeigte die MMF-Behandlung keine signifikante Wirkung. Die Zugabe von $50 \mu \mathrm{M}$ MMF führte zu einer durchschnittlichen Anzahl von 28,7 adhärenten Zellen, die Inkubation mit $200 \mu \mathrm{M}$ zu 23,6 adhärenten Lymphozyten/Sichtfeld. 

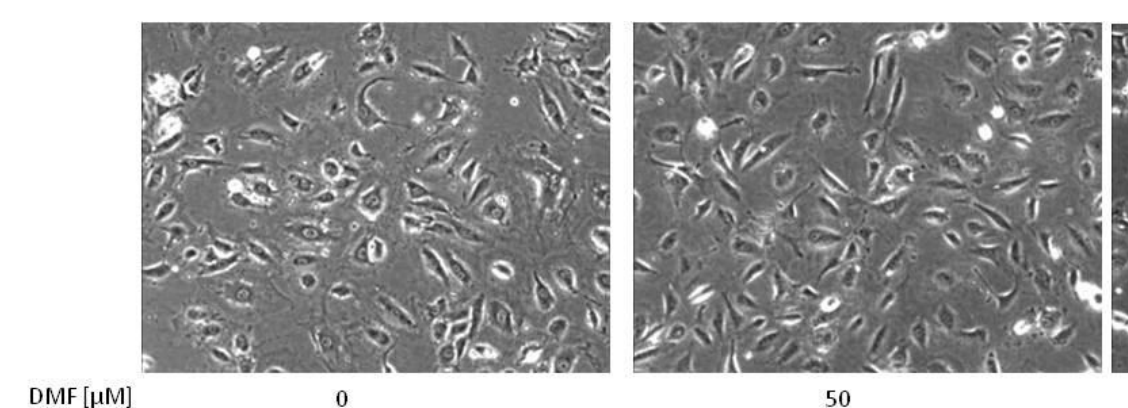

TNFa

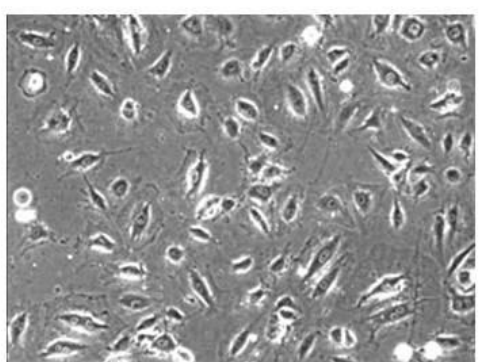

$\mathrm{MMF}[\mu \mathrm{M}]$

TNFa
50

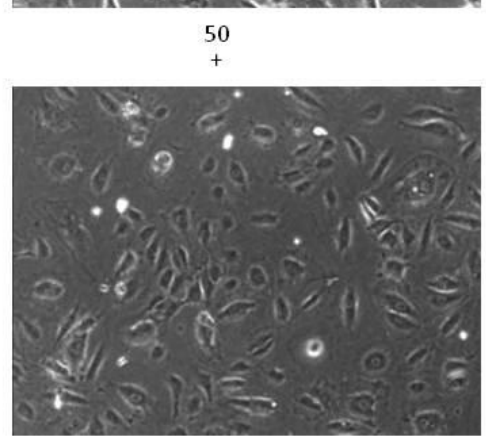

50

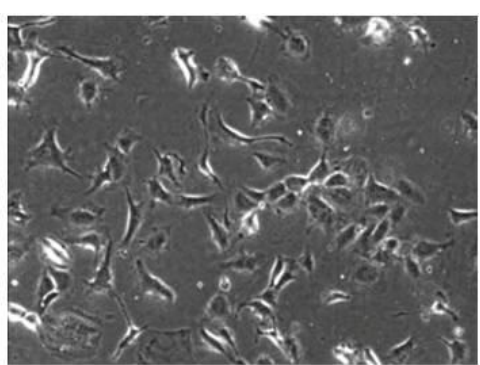

200

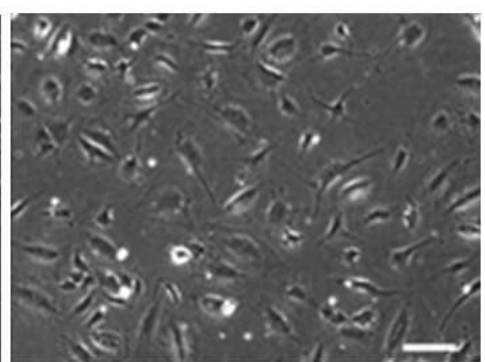

200

Abb. 11 HUVEC wurden für die Flusskammerversuche in einer festgelegten Zellzahl auf Thermanox ${ }^{\mathrm{TM}}$-Objektträger ausgesät, mit 50 oder $200 \mu \mathrm{M}$ DMF oder MMF behandelt und mit TNF $\alpha$ aktiviert $(25 \mathrm{ng} / \mathrm{ml})$. Die Aufnahmen wurden mit einer zehnfachen Vergrößerung aufgenommen und zeigen HUVEC vor dem Beginn der Lymphozytenperfusion. Der Maßstab zeigt $100 \mu \mathrm{m}$.

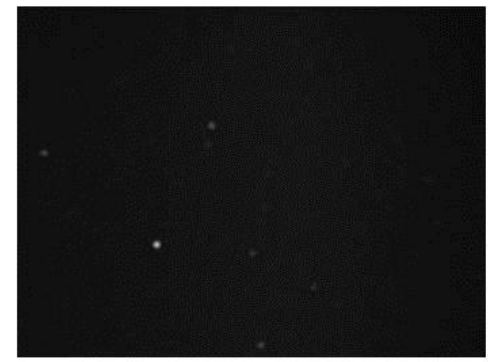

DMF $[\mu \mathrm{M}]$
TNFa

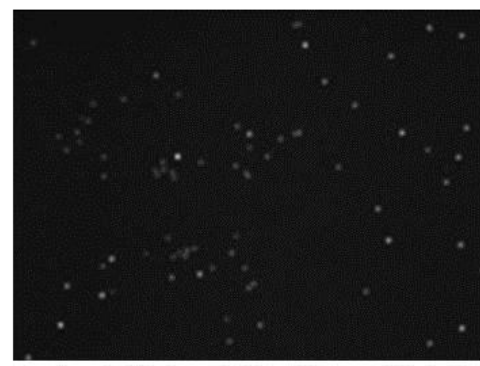

MMF $[\mu \mathrm{M}]$

TNFa

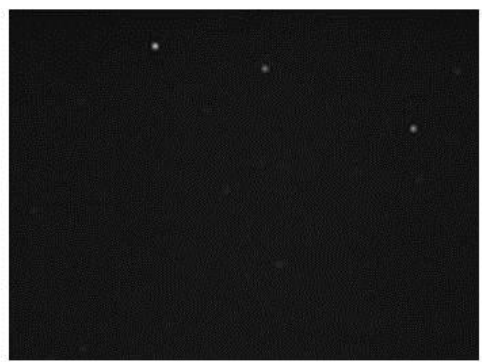

50

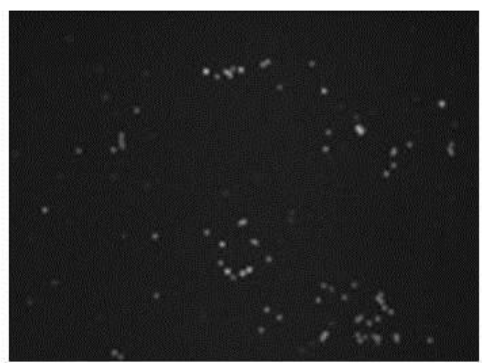

50

50
+

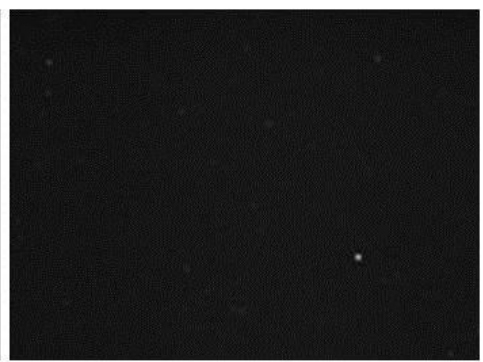

200

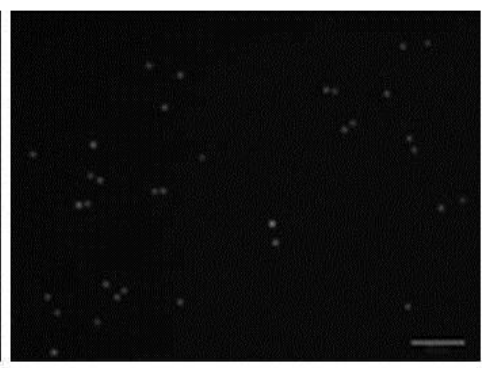

200

Abb. 12 Die Aufnahmen zeigen adhärente, mit CFDA-SE angefärbte Lymphozyten nach einer Perfusionszeit von 10 min. Im Anschluss an die Perfusion wurden 16 Aufnahmen gemacht und die adhärenten Lymphozyten ausgezählt. Die Lymphozyten hafteten lediglich auf aktivierten HUVEC, die mit MMF oder nicht mit FAE behandelt wurden. Die Aufnahmen wurden mit einer zehnfachen Vergrößerung aufgenommen, der Maßstab zeigt $100 \mu \mathrm{m}$. 

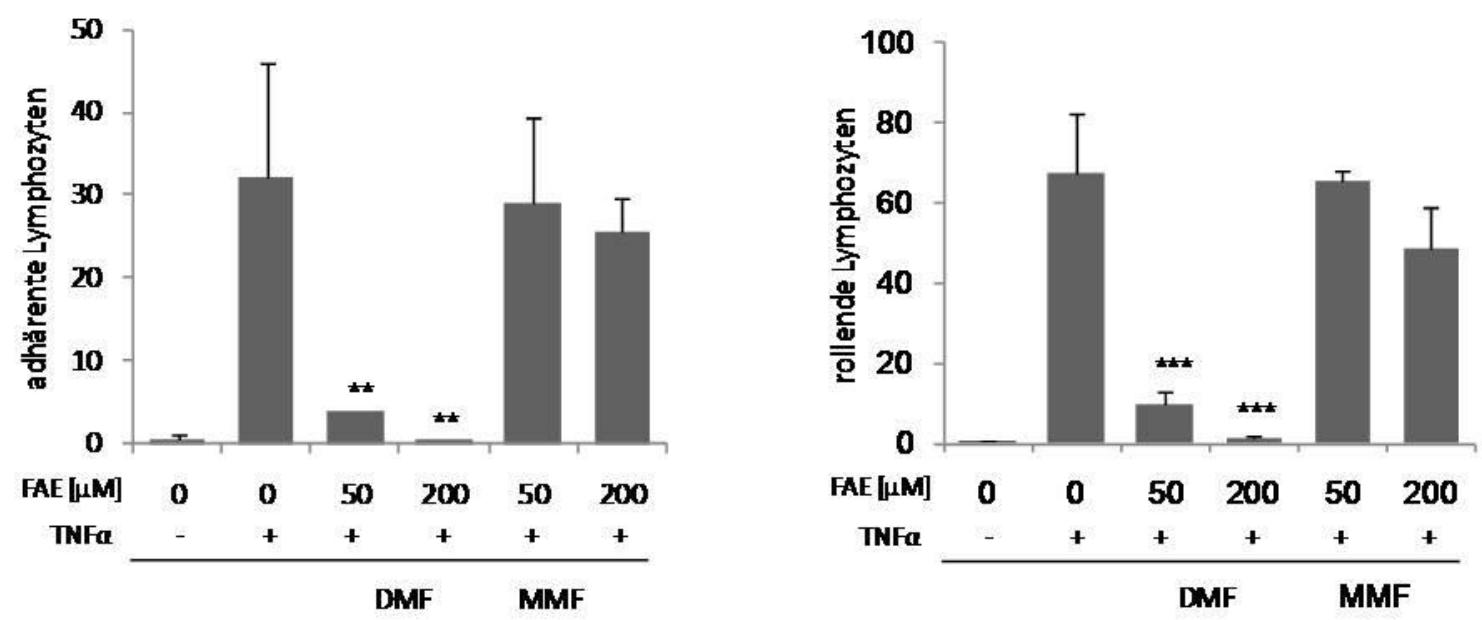

Abb. 13 HUVEC wurden mit DMF oder MMF in Konzentrationen von 50 oder $200 \mu \mathrm{M}$ behandelt und mit TNF $\alpha$ (25 ng/ml) stimuliert. Mit Hilfe einer Flusskammer wurden die Interaktionen von HUVEC und humanen Lymphozyten analysiert. Im Anschluss an eine 10-minütige Perfusionsphase wurden die adhärenten Lymphozyten auf den Thermanox ${ }^{\mathrm{TM}}$-Objektträgern ausgezählt (linkes Schema). Während der Perfusion wurden die rollenden Lymphozyten in einem Sichtfeld bestimmt (rechtes Schema). Die Diagramme zeigen Mittelwerte (+Standardabweichung) aus vier unabhängigen Versuchen. ${ }^{*} p<0,05$; ** $p<0,01 ; * * p<0,001 \mathrm{im}$ Vergleich zu der unbehandelten und stimulierten Kontrolle. 


\section{Diskussion}

\section{1 Übersicht}

Fumarsäureester werden bereits seit vielen Jahren erfolgreich in der Therapie der mittelschweren und schweren Psoriasis eingesetzt. Dennoch herrscht immer noch keine Einigkeit darüber, welcher Inhaltsstoff in Fumaderm ${ }^{\circledR}$ für den antipsoriatischen Effekt des Medikaments hauptsächlich verantwortlich ist. Darüber hinaus scheinen die bisher bekannten Wirkungen sehr pleiotrop zu sein. Mit Hilfe von in-vitro- und in-vivoExperimenten konnten verschiedene Effekte von DMF auf Endothelzellen, T-Lymphozyten, Keratinozyten, Monozyten, PBMC und dendritische Zellen nachgewiesen werden. Studien haben allerdings ergeben, dass die Halbwertszeit von DMF im Vollblut lediglich 6 min beträgt (Litjens et al. 2004a) und DMF nach oraler Aufnahme im Blut von gesunden Probanden nicht nachweisbar ist (Litjens et al. 2004c). Es folgte die Hypothese, dass DMF lediglich als Vorstufe für den eigentlichen Wirkstoff MMF dient und im Körper durch Hydrolyse zügig in MMF umgewandelt wird (Litjens et al. 2004a). In neuesten Studien gelang es nun aber, einen Metaboliten von DMF im Urin von Psoriasis-Patienten nachzuweisen. Hierbei handelt es sich um N-acetyl-S-(1,2-dimethoxycarbonylethyl)cystein (NAC-DMS). NAC-DMS geht aus einer Reaktion von Glutathion (GSH) mit DMF hervor (Rostami-Yazdi et al. 2009). Die Studienergebnisse sprechen dafür, dass DMF im Anschluss an die Resorption im Darm in Zellen des Blutes aufgenommen und dort an das ubiquitär vorkommende GSH gebunden wird.

Um die Wirkung der Fumarsäureester DMF und MMF auf humane Endothelzellen zu untersuchen, wurden die beiden Substanzen über eine weite Konzentrationsspanne an primären, makrovaskulären (HUVEC) und immortalisierten, mikrovaskulären (HPEC-A2) Endothelzellen getestet. Zudem wurde die Wirkung der Fumarsäureester auf die Interaktion von HUVEC und humanen Lymphozyten analysiert. 


\subsection{DMF inhibiert die Expression der Adhäsionsproteine E-Selektin, ICAM-1 und VCAM-1}

Die lockere Adhäsion von Lymphozyten an das Endothel und das anschließende Rollen der Lymphozyten entlang der Gefäßwand stellen die ersten Schritte der Lymphozyteninfiltration ins Gewebe dar. Der initiale Zell-Zell-Kontakt wird durch Selektine vermittelt, die darauffolgende festere Adhäsion überwiegend durch VCAM-1 und ICAM-1 aus der Immunglobulin-Superfamilie (Schön und Ludwig 2005). Die Expression der Proteine E-Selektin, ICAM-1 und VCAM-1 auf der Zelloberfläche von HUVEC ist durch Stimulation der Zellen mit TNF $\alpha$ induzierbar. Alle drei Proteine werden transkriptionell reguliert und nach Aktivierung der Endothelzellen durch Entzündungsmediatoren verstärkt auf der Zelloberfläche exprimiert.

In unserer Untersuchung zeigte sich eine signifikant inhibitorische Wirkung von DMF, jedoch nicht MMF, auf die Expression der drei Adhäsionsproteine E-Selektin, VCAM-1 und ICAM-1. Dieser supprimierende Effekt war in den humanen Endothelzellen sowohl auf mRNA- als auch auf Proteinebene nachweisbar.

E-Selektin spielt in der Pathogenese der Psoriasis eine wichtige Rolle. Psoriatische Plaques sind durch verstärkte E-Selektin-Expression in den papillären Gefäßen und den Gefäßen der oberen retikulären Dermis gekennzeichnet (Rohde et al. 1992). Zudem wird die Expression von E-Selektin auf der endothelialen Zelloberfläche länger aufrechterhalten als in den dermalen Gefäßen gesunder Haut (Groves et al. 1991). Da E-Selektin für das initiale Rollen der Lymphozyten entlang der Gefäßwand essentiell ist, liegt der Schluss nahe, dass die Behandlung mit DMF über die verminderte Anzahl an E-Selektin-Molekülen auf der Zelloberfläche zu einer reduzierten Interaktion zwischen Endothelzellen und Lymphozyten führt. Das Rollen der Lymphozyten entlang der Gefäßwände ist eine Voraussetzung für die darauffolgende Adhäsion. Somit führt eine verminderte Zahl an rollenden Zellen auch zu einer reduzierten Anzahl an adhärenten und infiltrierenden Zellen.

In einer klinischen Studie konnte allerdings gezeigt werden, dass ein gegen E-Selektin gerichteter monoklonaler Antikörper in der Therapie der Psoriasis nicht wirksam ist (Bhushan et al. 2002). Dieses Ergebnis ist dadurch zu erklären, dass die blockierte Funktion von E-Selektin durch andere Rezeptoren, beispielsweise P-Selektin oder VLA-4, die ebenfalls das Rollen von Lymphozyten entlang der Gefäßwand vermitteln können, kompensiert wird 
(Boehncke und Schön 2003). Die gezielte Inhibition nur eines Rezeptors ist hier wahrscheinlich zu selektiv, um eine kollektiv vermittelte Funktion in therapeutisch relevantem Ausmaß zu hemmen. Da sich beispielsweise P-Selektin und E-Selektin in ihren Funktionen nicht nur ergänzen, sondern auch überschneiden, kann der Ausfall eines Adhäsionsproteins bis zu einem gewissen Grad durch die gesteigerte Expression des anderen Proteins kompensiert werden (Jung et al. 1999).

Bei einem Entzündungsgeschehen werden sowohl E-Selektin als auch P-Selektin verstärkt auf aktivierten Endothelzellen exprimiert. Die beiden Proteine unterscheiden sich jedoch durch ihren Regulationsmechanismus und die zu ihrer Expression führenden Faktoren. E-Selektin wird nach Aktivierung der Zellen durch Entzündungsmediatoren wie TNF $\alpha$, IL-1 $\beta$ oder LPS, transkriptionell reguliert, wohingegen P-Selektin intrazellulär in Vesikeln (Weibel-PaladeKörperchen) gespeichert und nach Stimulation mit Thrombin oder Histamin an die Zelloberfläche transportiert wird (Cleator et al. 2006).

Die Expression von P-Selektin-mRNA ließ sich durch Behandlung der Endothelzellen mit TNF $\alpha$ nicht steigern. Auch die Behandlung mit DMF und MMF führte zu keiner Veränderung in der basalen mRNA-Expression. DMF zeigte also unter den gegebenen Versuchsbedingungen keine Wirkung auf die Transkription von P-Selektin. Es bleibt aber zu klären, ob DMF einen Effekt auf die im Falle einer Entzündung gesteigerte P-Selektin-Expression ausübt. Dafür müssten HUVEC in einem in-vitro-Versuch vor der DMF-Behandlung nicht mit TNF $\alpha$, sondern mit Histamin oder Thrombin aktiviert werden. Dennoch lässt sich festhalten, dass E-Selektin in der Pathogenese der Psoriasis eine wichtige Stellung einnimmt und DMF die E-SelektinExpression auf der Zelloberfläche von HUVEC supprimiert. Das ebenfalls am Rollen beteiligte VCAM-1 wird ebenfalls durch DMF reduziert.

Bei der Analyse der ICAM-1- und VCAM-1-Expression zeigte sich ein ähnliches Bild wie bei E-Selektin. Während MMF keinen Effekt auf die mRNA- und die Proteinexpression zeigte, war bei DMF in Bezug auf beide Proteine ein signifikant supprimierender Effekt nachweisbar. Auch hier liegt erneut der Schluss nahe, dass DMF durch die Reduktion der ICAM-1- und VCAM-1-Expression auf der Oberfläche von Endothelzellen in den Prozess der Lymphozytenadhäsion eingreift. Studien belegen die Relevanz dieser beiden Proteine, die während der Entstehung von psoriatischen Läsionen auf Endothelzellen überexprimiert werden (Wetzel et al. 2006). 


\subsubsection{DMF interferiert mit der Wirkung des Transkriptionsfaktors NF-kB}

Für E-Selektin konnte bereits gezeigt werden, dass DMF die TNF $\alpha$-induzierte E-SelektinExpression durch Interaktion mit dem Transkriptionsfaktor NF-kB inhibiert (Loewe et al. 2001). Bei NF-kB handelt es sich um eine Gruppe von fünf verschiedenen Proteinen, von denen jeweils zwei in unterschiedlichen Kombinationen aneinander binden und auf diese Weise Dimere bilden können. Die häufigste Form repräsentiert das Heterodimer p50/p65.

NF-KB ist von großer Bedeutung bei der Regulation einer Immunantwort und der Entstehung von Entzündungen. In der Epidermis gesunder Haut ist NF-KB in aktiver Form im Zellkern kaum nachweisbar. In nicht betroffener Haut von Psoriasis-Patienten hingegen konnte die aktivierte Untereinheit p65 in Keratinozyten in leicht erhöhter Konzentration nachgewiesen werden. Eine deutlich gesteigerte Konzentration von p65 ließ sich in den Zellkernen der Epidermis psoriatischer Plaques detektieren (Lizzul et al. 2005).

In HUVEC verhindert DMF die Translokation der NF-kB-Untereinheit p65 in den Zellkern (Loewe et al. 2002) und moduliert so die Regulation der unter NF-KB-Kontrolle stehenden Gene. Neben E-Selektin stehen auch ICAM-1 und VCAM-1 unter der Kontrolle von NF-KB. Studien haben gezeigt, dass das NF-KB Heterodimer p50/p65 an die Promotorregion des VCAM-1-Gens bindet und so den Transkriptionsvorgang aktiviert (Collins et al. 1995). Einem komplexeren Regulationsmechanismus unterliegt hingegen das ICAM-1-Gen. Zwar bindet NF-KB in aktivierten Endothelzellen auch an die Promotorregion von ICAM-1, die Transkription des Gens wird aber zusätzlich durch die Interaktion von NF-kB mit anderen Transkriptionsfaktoren reguliert (Roebuck and Finnegan 1999). Die Expression von ICAM-1 und VCAM-1 wird in komplexer Weise zell- und stimulusabhängig reguliert. Dennoch führen die Tatsachen, dass NF-KB an der Expression der beiden Proteine beteiligt ist und DMF die Translokation von NF-кB in den Zellkern von Endothelzellen verhindert, zu der Annahme, dass die Abnahme der VCAM-1- und ICAM-1-Expression nach DMF-Behandlung zumindest teilweise auf Interaktionen zwischen DMF und den Transkriptionsmechanismen zurückzuführen ist.

Für DMF in hohen Konzentrationen konnte zuvor eine proapoptotische Wirkung nachgewiesen werden (Loewe et al. 2006). Möglich wäre daher auch eine Abnahme der gemessenen Adhäsionsproteine durch eine erhöhte Apoptoserate der Zellen. Allerdings zeigt sich bei einigen PCRs, z.B. bei MMP2, PECAM-1 und P-Selektin, auch bei $200 \mu M$ DMF, noch 
eine konstante mRNA-Expression, was eher gegen eine gesteigerte Apoptose sprechen würde. Auch neueste Studien führen antiangiogene Effekte einer DMF-Behandlung auf eine verstärkte Apoptoserate zurück. DMF in einer Konzentration von $100 \mu \mathrm{M}$ führte hier zu einer gestörten Ausdifferenzierung, Migration und Proliferation von Endothelzellen (GarciaCaballero et al. 2011). Allerdings wurden die Zellen $14 \mathrm{~h}$ mit DMF inkubiert, was einer verhältnismäßig langen DMF-Exposition entspricht. Eine genaue Aussage über eine mögliche proapoptotische Wirkung von DMF auf Endothelzellen, unter den gegebenen Versuchsbedingungen, lässt sich also nur durch eine gezielte Untersuchung der Apoptoseraten treffen.

\subsection{Wirkung von DMF auf die Adhäsionsproteine VE-Cadherin und PECAM-1}

Der nächste Schritt der Lymphozyteninfiltration ins Gewebe ist, nach dem lymphozytären Rollen und der festen Adhäsion an die Endothelzellen, die Transmigration der Lymphozyten durch den Endothelzellverbund. Adhärente Lymphozyten verlassen die Zirkulation, indem sie die Gefäßinnenwand zwischen den Endothelzellen hindurch passieren (Muller 2001). Adhäsionsproteine, die an den lateralen Zellgrenzen der Endothelzellen lokalisiert sind, u.a. PECAM-1 (CD31) und VE-Cadherin (CD144), sind an diesem Prozess beteiligt.

In verschiedenen Studien konnte gezeigt werden, dass PECAM-1 eine wichtige Rolle bei der Transmigration von Leukozyten spielt und die Blockade von PECAM-1 durch selektive Antikörper in vivo und in vitro zu einer Reduktion der Leukozytentransmigration führt (Muller et al. 1993; Bogen et al. 1994).

VE-Cadherin hingegen ist an der Aufrechterhaltung der Integrität des Endothels beteiligt. In Untersuchungen führte ein Antikörper gegen VE-Cadherin zu einer verstärkten Durchlässigkeit des Endothels für Leukozyten (Gotsch et al. 1997). Um die Wirkung von DMF und MMF auf die Expression von PECAM-1 und VE-Cadherin zu analysieren, wurde die Transkription der Gene untersucht. Nach Stimulation der Endothelzellen mit TNF $\alpha$ zeigte sich keine gesteigerte mRNA-Expression und auch die Behandlung mit DMF und MMF für fünf Stunden führte zu keiner veränderten Transkription der untersuchten Gene. Eine Wirkung von DMF auf die Proteine PECAM-1 und VE-Cadherin war in der PCR unter den 
vorherrschenden Versuchsbedingungen zwar nicht erkennbar, ausschließen lässt sich ein Effekt auf die Transmigration von Leukozyten dennoch nicht. Da der Prozess der Leukozytentransmigration durch eine Vielzahl an Molekülen vermittelt wird und der genaue Ablauf noch nicht aufgeklärt wurde, ist ein Eingreifen von DMF an anderer Stelle möglich. Denkbar wäre auch eine veränderte mRNA-Expression nach längeren Inkubationszeiten mit den Fumarsäureestern.

\subsection{DMF inhibiert die Interaktion von Endothelzellen und Lymphozyten}

Mit Hilfe einer Flusskammer konnten die Effekte einer FAE-Behandlung auch funktionell untersucht werden. Die Behandlung von HUVEC mit DMF führte, vermutlich durch die reduzierte Expression von Adhäsionsproteinen auf der Zelloberfläche, zu einer deutlichen Abnahme der Interaktion zwischen Endothelzellen und Lymphozyten. In vivo konnte bereits gezeigt werden, dass die Behandlung von aktivierten T-Lymphozyten mit DMF über eine Herunterregulation von Adhäsionsproteinen auf der Lymphozytenoberfläche zu einer reduzierten Anzahl rollender T-Zellen führt (Rubant et al. 2008).

In unserer Flusskammeruntersuchung führte die Inkubation von HUVEC mit $50 \mu \mathrm{M}$ DMF bereits zu einer signifikanten Reduktion sowohl des Rollens der Lymphozyten auf den Endothelzellen als auch der Adhäsion. Das Niveau der unstimulierten und unbehandelten Kontrolle wurde durch die Behandlung mit $200 \mu \mathrm{M}$ DMF erreicht. Die Inkubation der Zellen mit MMF bis zu einer Konzentration von $200 \mu \mathrm{M}$ führte nicht zu einer signifikanten Reduktion der Zell-Zell-Interaktionen.

Sowohl die Ergebnisse der Durchflusszytometrie als auch der Flusskammeruntersuchung unterstützen die Hypothese, dass DMF, in Bezug auf die Psoriasisbehandlung, den Hauptwirkstoff unter den Fumarsäureestern darstellt. Es ist anzunehmen, dass DMF seine antipsoriatische Wirkung zumindest teilweise durch Suppression der Expression von Adhäsionsproteinen auf Endothelzellen ausübt, wodurch er zu einer reduzierten funktionellen Interaktion von Endothelzellen und Lymphozyten kommt. Durch die verminderte Anzahl an Adhäsionsproteinen auf der Zelloberfläche wird die Einwanderung von Leukozyten in die Haut supprimiert und die Bildung von entzündlichen Infiltraten 
verhindert. DMF interferiert somit mit einem zentralen pathophysiologischen Mechanismus der Entzündung.

Unlängst veröffentlichte Studien zeigen, dass DMF die Tendenz aufweist, Zellen zu penetrieren und dort Reaktionen mit Glutathion (GSH) einzugehen (Schmidt et al. 2007). Glutathion wirkt als Antioxidans und ist in fast allen Zellen des Körpers enthalten. In-vitro-Versuche konnten bereits zeigen, dass DMF und GSH unter physiologischen Bedingungen kovalente Bindungen eingehen (Held et al. 1988). Die Abnahme der GSHKonzentration in Zellen führte in Untersuchungen ebenfalls zu antiinflammatorischen Effekten (Lehmann et al. 2007; Horikawa et al. 2002). NAC-DMS, ein Produkt, das aus der Reaktion von DMF mit GSH hervorgeht, ist im Urin von Psoriasis-Patienten nachweisbar (Rostami-Yazdi et al. 2009). Dieser Fund könnte erklären, warum DMF nach oraler Einnahme im Blut nicht nachweisbar ist.

\subsection{DMF inhibiert die Transkription proinflammatorischer Zytokine}

Die Chemokine IL-6, IL-8, MCP-1 und CXCL1 werden von Endothelzellen im Falle einer Entzündungsreaktion sezerniert und spielen eine wichtige Rolle bei der Entstehung und Aufrechterhaltung von Entzündungen. Auf mRNA-Ebene zeigte DMF eine inhibitorische Wirkung auf die Transkription dieser proinflammatorischen Chemokine. DMF führt in HUVEC ab einer Konzentration von $25 \mu \mathrm{M}$ und in HPEC-A2 ab $100 \mu \mathrm{M}$ zu einer Abnahme der Expression von IL-6-mRNA. IL-6 übt seine proinflammatorische Wirkung u.a. dadurch aus, dass es in der Leber die Bildung von Akute-Phase-Proteinen stimuliert (Le et al. 1989), zusammen mit anderen Chemokinen Fieber induziert (Helle et al. 1988) und bei der Aktivierung von B- und T-Lymphozyten mitwirkt (Heinrich et al. 1990). Da Psoriasis-Patienten erhöhte Serumspiegel von IL-6 aufweisen, ist die Abnahme der IL-6-mRNA nach Behandlung mit DMF besonders interessant. In anderen Untersuchungen wurde ein Zusammenhang zwischen der IL-6-Konzentration im Serum und dem Ansprechen auf die Psoriasistherapie festgestellt (Zalewska et al. 2006). Bei erfolgreicher Therapie sank sowohl der IL-6-Spiegel als auch die Konzentration von IL-8 im Blut ab.

IL-8 ist ein weiteres proinflammatorisches Interleukin, welches bei Psoriasis-Patienten im Blut ebenfalls erhöht ist. Auch in der Haut dieser Patienten lassen sich erhöhte IL-8-Spiegel 
nachweisen (Kapp 1993). IL-8 wirkt proangiogen auf Endothelzellen (Konstantinova et al. 1996). Außerdem übt es eine chemotaktische Wirkung auf neutrophile Granulozyten, eine weitere Zellpopulation in psoriatischen Infiltraten, aus und gilt daher als wichtiger Mediator bei der Entstehung von Munro-Mikroabszessen. In Bezug auf IL-8 führt DMF in einer Konzentration von $200 \mu \mathrm{M}$ zu einer Abnahme der mRNA-Expression. Der Einfluss von DMF auf die Transkription von IL-6 und IL-8 könnte einen Teil zu der antipsoriatischen Wirkung von Fumaderm ${ }^{\circledR}$ beitragen. Beide Interleukine kommen im Blut von Psoriasis-Patienten in erhöhten Konzentrationen vor und wirken auf Entzündungszellen, die in der Pathogenese der Psoriasis eine wichtige Rolle spielen. Die Abnahme der IL-8- und IL-6-Konzentration im Serum durch die Behandlung mit DMF könnte zu einem verminderten chemotaktischen Reiz und somit zu einer reduzierten Zahl an einwandernden Entzündungszellen führen. Bei anderen Krankheitsbildern, wie z.B. der rheumatoiden Arthritis, macht man sich die Wirkung von IL-6-Rezeptor-Inhibitoren bereits zu Nutze (Emery et al. 2008). Allerdings sind die DMFKonzentrationen, bei denen sich unter den angewendeten Versuchsbedingungen eine Wirkung auf die Expression der IL-6- und IL-8-mRNA zeigt, sehr hoch und werden vermutlich nach Einnahme von Fumaderm ${ }^{\circledR}$ im Körper nicht erreicht. Interessant ist daher die Frage, ob sich eine Reduktion der Interleukinexpression bei längerer Inkubationszeit bereits bei geringeren FAE-Konzentrationen zeigt.

CXCL1, ein weiteres Chemokin, das von Endothelzellen sezerniert wird, wirkt chemotaktisch auf neutrophile Granulozyten und fördert so ebenfalls die Einwanderung von Zellen in das Entzündungsgebiet (Moser et al. 1990). Auch in psoriatischen Läsionen konnte CXCL1 nachgewiesen werden (Schröder et al. 1992). Die Expression von CXCL1-mRNA wurde sowohl in HUVEC als auch in HPEC-A2 durch DMF in Konzentrationen von 100 oder $200 \mu \mathrm{M}$ deutlich reduziert.

In den untersuchten Endothelzellreihen führten 100 oder $200 \mu$ M DMF außerdem zu einer Reduktion der Expression von MCP-1-mRNA. MCP-1 spielt eine wichtige Rolle bei der Rekrutierung von Monozyten. Diese Zellen wandern, aktiviert durch Chemokine, in die Haut ein und differenzieren sich dort zu Makrophagen (Vestergaard et al. 2004).

Somit sind auch CXCL1 und MCP-1 an der Zellrekrutierung beteiligt und wirken auf wichtige Entzündungszellen ein. Wie bereits bei der IL-6- und IL-8-PCR beobachtet, wird aber auch die MCP-1 und CXCL1-mRNA-Expression bei fünfstündiger FAE-Inkubation erst durch sehr hohe DMF-Konzentrationen supprimiert. 
Keine erkennbare Wirkung zeigte DMF auf die Transkription von MMP2. MatrixMetalloproteinasen sind Endopeptidasen, die am Abbau und der Umgestaltung von extrazellulärer Matrix beteiligt sind. Die Expression von MMP2-mRNA ließ sich durch Stimulation der Endothelzellen mit TNF $\alpha$ nicht induzieren. Frühere Untersuchungen zeigten bereits ein mäßiges Ansprechen der MMP2-Expression auf die Behandlung mit Chemokinen und Wachstumsfaktoren (Fleischmajer et al. 2000). Die Epidermis von Psoriasis-Patienten weist zwar eine gesteigerte Konzentration von MMP2 auf, allerdings erfolgt die Produktion hier überwiegend durch Keratinozyten und nicht durch Endothelzellen (Fleischmajer et al. 2000). Welche Rolle MMP2 in der Pathogenese der Psoriasis spielt, ist noch nicht erforscht. Allerdings bleibt zu erwähnen, dass in MMP2-defizienten Mäusen sowohl die Zellproliferation als auch die Angiogenese, beides wichtige Charakteristika der Psoriasis, reduziert sind (Itoh et al. 1998). Eine Mitbeteiligung der Matrixmetalloproteinasen an vaskulären Veränderungen in psoriatischen Läsionen scheint somit wahrscheinlich. Interessant wäre daher eine Untersuchung, die sich mit der Auswirkung einer DMF-Behandlung auf die MMP2-Sekretion in Keratinozyten beschäftigt.

\subsection{DMF führt zu einem Anstieg der VEGF-Konzentration auf mRNA-Ebene}

VEGF ist ein wichtiger angiogenetischer Faktor und unterstützt das Überleben, die Proliferation und die Migration von Endothelzellen. Zudem wirkt VEGF als proinflammatorisches Zytokin, erhöht die endotheliale Permeabilität und induziert die Expression von Adhäsionsproteinen. VEGF stellt daher ein mögliches Bindeglied zwischen Entzündung und Angiogenese dar.

In Hautbiopsien von Psoriasis-Patienten konnte eine gesteigerte VEGF-mRNA-Expression in der Epidermis von psoriatischen Läsionen nachgewiesen werden, die beiden Rezeptoren VEGFR1 und VEGFR2 wurden verstärkt in den kleinen dermalen Gefäßen exprimiert (Detmar et al. 1994). In unserer Untersuchung nahm die VEGF-mRNA-Menge mit steigender DMFKonzentration leicht zu. Da von einer antipsoriatisch wirkenden Substanz wie DMF eher ein negativer Effekt auf die Angiogenese zu erwarten war, war das Ergebnis der VEGF-PCR überraschend. In einer Untersuchung mit VEGF-transgenen Mäusen konnte gezeigt werden, dass es in den Hautgefäßen der Tiere im Vergleich zu Wildtyp-Mäusen zu vermehrtem Rollen 
und gesteigerter Adhäsion von Leukozyten kommt. Die Anzahl der Interaktionen zwischen Leukozyten und Endothelzellen konnte durch die Zugabe von Antikörpern gegen E-Selektin und P-Selektin jedoch auf das Normalniveau gesenkt werden (Detmar et al. 1998). Die in-vivo-Versuche bestätigen die Ergebnisse eines in-vitro-Experiments, in dem gezeigt wurde, dass HUVEC nach Stimulation mit VEGF verstärkt die Adhäsionsproteine ICAM-1, VCAM-1 und E-Selektin exprimieren (Melder et al. 1996). In einer kürzlich publizierten Studie mit JunB/c-Jun-defizienten Mäusen, die einen psoriasiformen Phänotyp aufweisen, konnte durch Antikörper-vermittelte Blockade (G6-31) von VEGF die chronisch-entzündliche Hauterkrankung gebessert werden (Schönthaler et al. 2009). In einer anderen neuen Studie konnte durch anti-angiogene Gentherapie, die ebenfalls zur Besserung psoriatischer Hautveränderungen im Tiermodell führte, auch die VEGF-Expression reduziert werden (Zibert et al. 2011).

In unseren Versuchen zeigte sich zwar eine erhöhte VEGF-Konzentration auf Transkriptionsebene, eine Aussage über die Proteinexpression lässt sich dadurch allerdings noch nicht treffen. In der funktionellen Untersuchung zeigte sich zumindest weder ein vermehrtes Rollen der Lymphozyten noch eine gesteigerte Adhäsion. Möglich ist auch, dass der Effekt von VEGF nur sehr schwach ausgeprägt ist und durch die starke Wirkung von DMF auf die Adhäsionsproteinexpression überdeckt wird. Möglicherweise interferieren aber auch beide Wirkmechanismen miteinander. Die VEGF-stimulierte Expression von ICAM-1, VCAM-1 und E-Selektin wird durch Aktivierung des Transkriptionsfaktors NF-kB hervorgerufen (Kim et al. 2001). NF-KB spielt auch bei der Suppression der Adhäsionsproteine durch DMF eine entscheidende Rolle. DMF verhindert die Translokation von NF-kB in den Zellkern und inhibiert so die Transkription der zugehörigen Gene. Somit ist eine verstärkte Transkription, wie sie durch VEGF-Stimulation hervorgerufen wird, nicht mehr möglich. Zudem zeigte sich auf mRNA-Ebene keine gesteigerte Expression der Rezeptoren VEGFR1 und VEGFR2, über die VEGF seine Wirkung ausübt. Die fehlende Hochregulation der VEGF-Rezeptoren könnte somit ebenfalls dazu beitragen, dass trotz gesteigerter VEGF-Konzentrationen kein Effekt erkennbar war. In neuesten Studien führte eine DMF-Behandlung von HUVEC sogar zu einer reduzierten Expression von VEGFR2, vermutlich durch die Interaktion von DMF mit dem Transkriptionsfaktor Sp1 (Meissner et al. 2011). Dieses Ergebnis führte zu der Annahme, dass der anti-angiogene Effekt einer DMF-Behandlung zumindest teilweise auf die Herunterregulation des VEGF-Rezeptors zurückzuführen sei. 
Des Weiteren zeigten Versuche mit VEGF-transgenen Mäusen, dass erhöhte VEGF-Spiegel in der Haut der Tiere zu einem psoriasisähnlichen Phänotyp mit hyperpermeablen und hyperplastischen Gefäßen führen (Xia et al. 2003). Über welchen Wirkmechanismus VEGF zu der gesteigerten endothelialen Permeabilität führt, ist nicht bekannt. In den zahlreichen in-vivo- und in-vitro-Versuchen wird jedoch deutlich, dass VEGF eine Schlüsselrolle bei der Entstehung von vaskulären Veränderungen einnimmt.

Weiter konnte gezeigt werden, dass VEGF die Expression der proinflammatorischen Zytokine IL-6 und IL-8 in Endothelzellen fördert (Hao et al. 2009). IL-8 ist in der Lage, die VEGFProduktion in Endothelzellen zu stimulieren und VEGF wiederum fördert autokrin die Expression von VEGFR2 (Martin et al. 2009). Somit entsteht ein Signalweg, über den VEGF seine eigene Wirkung verstärken und eine Entzündung kontinuierlich gefördert werden kann. Die Vermutung liegt nahe, dass auch dieser Signalweg durch die Behandlung mit DMF unterbrochen wird. Zwar zeigte sich nach Behandlung der Endothelzellen mit DMF eine verstärkte VEGF-Transkription, die Transkription von IL-8 hingegen wurde supprimiert und auch in Bezug auf die Expression von VEGFR2-mRNA zeigte sich kein Anstieg. Denkbar wäre, dass DMF den Signalweg durch die bereits auf mRNA-Ebene beobachtete Suppression der IL-8-Expression inhibiert oder der Induktion von VEGFR2 entgegenwirkt.

VEGF übt seine zahlreichen Wirkungen über eine Vielzahl an verschiedenen, teilweise bekannten und teilweise noch nicht verstandenen Mechanismen aus. DMF beeinflusst die Expression von VEGF in Endothelzellen. Welche Folgen sich daraus ergeben, bleibt noch zu klären. 


\section{Zusammenfassung}

Die Psoriasis ist eine gutartige, chronisch schubweise verlaufende systemische Autoimmunerkrankung mit meist scharf begrenzten erythematosquamösen Plaques an der Haut. Verschiedene Sonderformen sowie psoriatische Arthritiden sind ebenfalls bekannt. Histologisch treten lymphozytäre Infiltrate in Dermis und Epidermis auf. Um aus dem Blutstrom in die Haut einwandern zu können, müssen die Lymphozyten die endotheliale Barriere überqueren. Für den Zell-Zell-Kontakt sind auf Seiten der Endothelzellen besonders die Selektine für das anfängliche Rollen und die Proteine VCAM-1 und ICAM-1 für die darauf folgende feste Adhäsion von Bedeutung.

Die vorliegende Arbeit hatte zum Ziel, den Einfluss der Fumarsäureester (FAE) Dimethylfumarat und Monomethylfumarat auf die Expression der genannten Adhäsionsproteine auf der Oberfläche von humanen Endothelzellen zu untersuchen. Des Weiteren sollte der Effekt einer FAE-Behandlung auf die Interaktion von Endothelzellen und Lymphozyten analysiert werden.

Mit verschiedenen Methoden konnte gezeigt werden, dass DMF, Bestandteil des PsoriasisMedikaments Fumaderm ${ }^{\circledR}$, zahlreiche Wirkungen in Endothelzellen hervorruft. Es inhibiert die Transkription verschiedener proinflammatorischer Zytokine. Die Expression der Adhäsionsproteine E-Selektin, VCAM-1 und ICAM-1 auf der Endothelzelloberfläche wird durch Inkubation der Zellen mit DMF deutlich herunterreguliert. Dies wird begleitet von einer reduzierten funktionellen Interaktion von Endothelzellen und Lymphozyten. DMF interferiert somit mit einem zentralen pathophysiologischen Mechanismus der Entzündung. Das Wissen über die immunmodulatorischen Wirkungen von DMF könnte dazu beitragen, das Einsatzgebiet der FAE zu erweitern. Auch Patienten mit anderen chronisch entzündlichen Erkrankungen könnten eventuell von einer Therapie mit FAE profitieren. Die Ergebnisse der vorliegenden Arbeit können einen Teil dazu beitragen, den Wirkmechanismus der FAE weiter aufzuklären. 


\section{Literaturverzeichnis}

Akman A, Yilmaz E, Mutlu H, Ozdogan M (2009): Complete remission of psoriasis following bevacizumab therapy for colon cancer. Clin Exp Dermatol 34, 202-4

Altmeyer PJ, Matthes U, Pawlak F, Hoffmann K, Frosch P J, Ruppert P, Wassilew SW, Horn T, Kreysel HW, Lutz G et al. (1994): Antipsoriatic effect of fumaric acid derivatives. Results of a multicenter double-blind study in 100 patients. J Am Acad Dermatol $\underline{30}$, 977-81

Amherd-Hoekstra A, Naher H, Lorenz HM, Enk AH (2010): Psoriatic arthritis: a review. J Dtsch Dermatol Ges $\underline{8}, 332-9$

Austin LM, Ozawa M, Kikuchi T, Walters IB, Krueger JG (1999): The majority of epidermal T cells in Psoriasis vulgaris lesions can produce type 1 cytokines, interferon-gamma, interleukin-2, and tumor necrosis factor-alpha, defining TC1 (cytotoxic T lymphocyte) and TH1 effector populations: a type 1 differentiation bias is also measured in circulating blood T cells in psoriatic patients. J Invest Dermatol $\underline{113}, 752-9$

Bhushan M, Bleiker TO, Ballsdon AE, Allen MH, Sopwith M, Robinson MK, Clarke C, Weller RP, Graham-Brown RA, Keefe M et al. (2002): Anti-E-selectin is ineffective in the treatment of psoriasis: a randomized trial. Br J Dermatol 146, 824-31

Boehncke WH, Schön MP (2003): Interfering with leukocyte rolling - a promising therapeutic approach in inflammatory skin disorders? Trends Pharmacol Sci 24; 49-52

Boehncke WH, Friedrich M, Mrowietz U, Reich K, Rosenbach T, Sticherling M, Thaçi D (2003): Stellenwert von Biologics in der Psoriasis-Therapie: Ein Konsensus-Papier der Arbeitsgruppe Psoriasis, Arbeitsgemeinschaft dermatologische Forschung. J Dtsch Dermatol Ges $\underline{1}$, 620-8

Boehncke WH, Boehncke S, Schön MP (2010): Managing comorbid disease in patients with psoriasis. BMJ $\underline{340}, 200-3$ 
Bogen S, Pak J, Garifallou M, Deng X, Muller WA (1994): Monoclonal antibody to murine PECAM-1 (CD31) blocks acute inflammation in vivo. J Exp Med 179, 1059-64

Bowcock AM (2005): The genetics of psoriasis and autoimmunity. Annu Rev Genomics Hum 6, 93-122

Boyman O, Hefti, HP, Conrad C, Nickoloff BJ, Suter M, Nestle FO (2004): Spontaneous development of psoriasis in a new animal model shows an essential role for resident $T$ cells and tumor necrosis factor-alpha. J Exp Med 199, 731-6

Braverman IM, Yen A (1977): Ultrastructure of the capillary loops in the dermal papillae of psoriasis. J Invest Dermatol $\underline{68}$, 53-60

Cleator JH, Zhu WQ, Vaughan DE, Hamm HE (2006): Differential regulation of endothelial exocytosis of P-selectin and von Willebrand factor by protease-activated receptors and cAMP. Blood $107,2736-44$

Collins T, Read MA, Neish AS, Whitley MZ, Thanos D, Maniatis T (1995): Transcriptional regulation of endothelial cell adhesion molecules: NF-kappa B and cytokine-inducible enhancers. FASEB J $\underline{9}, 899-909$

Creamer D, Allen MH, Sousa A, Poston R, Barker JN (1997): Localization of endothelial proliferation and microvascular expansion in active plaque psoriasis. $\mathrm{Br} J$ Dermatol $\underline{136}$, 85965

de Jong R. Bezemer AC, Zomerdijk TP, van de Pouw-Kraan T, Ottenhoff TH, Nibbering PH (1996): Selective stimulation of T helper 2 cytokine responses by the anti-psoriasis agent monomethylfumarate. Eur J Immunol 26, 2067-74

Detmar M, Brown LF, Claffey KP, Yeo KT, Kocher O, Jackman RW, Berse B, Dvorak HF (1994): Overexpression of vascular permeability factor/vascular endothelial growth factor and its receptors in psoriasis. J Exp Med $\underline{180}$ 1141-6 
Detmar M, Brown LF, Schön MP, Elicker BM, Velasco P, Richard L, Fukumura D, Monsky W, Claffey KP, Jain RK (1998): Increased microvascular density and enhanced leukocyte rolling and adhesion in the skin of VEGF transgenic mice. J Invest Dermatol 111, 1-6

Elias PM, Arbiser J, Brown BE, Rossiter H, Man MQ, Cerimele F, Crumrine D, Gunathilake R, Choi EH, Uchida Y et al. (2008): Epidermal vascular endothelial growth factor production is required for permeability barrier homeostasis, dermal angiogenesis, and the development of epidermal hyperplasia: implications for the pathogenesis of psoriasis. Am J Pathol $\underline{173}$, 68999

Emery P, Keystone E, Tony HP, Cantagrel A, van Vollenhoven R, Sanchez A, Alecock E, Lee J, Kremer J (2008): IL-6 receptor inhibition with tocilizumab improves treatment outcomes in patients with rheumatoid arthritis refractory to anti-tumour necrosis factor biologicals: results from a 24-week multicentre randomised placebo-controlled trial. Ann Rheum Dis $\underline{67}$, $1516-23$

Eyerich S, Onken AT, Weidinger S, Franke A, Nasorri F, Pennino D, Grosber M, Pfab F, Schmidt-Weber CB, Mempel M et al. (2011): Mutual antagonism of T cells causing psoriasis and atopic eczema. N Engl J Med $\underline{365}, 231-8$

Farber EM (1972): The genetics of psoriasis. Calif Med $\underline{116}, 46$

Ferrara N, Davis-Smyth T (1997): The biology of vascular endothelial growth factor. Endocr $\operatorname{Rev} \underline{18}, 4-25$

Fleischmajer R, Kuroda K, Hazan R, Gordon RE, Lebwohl MG, Sapadin AN, Unda F, lehara N, Yamada $Y$ (2000): Basement membrane alterations in psoriasis are accompanied by epidermal overexpression of MMP-2 and its inhibitor TIMP-2. J Invest Dermatol $\underline{115}$, 771-7

Garcia-Caballero M, Mari-Beffa M, Medina MA, Quesada AR (2011): Dimethylfumarate inhibits angiogenesis in vitro and in vivo: a possible role for its antipsoriatic effect? J Invest Dermatol $\underline{131}, 1347-55$ 
Gotsch U, Borges E, Bosse R, Boggemeyer E, Simon M, Mossmann H, Vestweber D (1997): VE-cadherin antibody accelerates neutrophil recruitment in vivo. J Cell Sci $\underline{110}, 583-8$

Gottlieb SL, Gilleaudeau P, Johnson R, Estes L, Woodworth TG, Gottlieb AB, Krueger JG (1995): Response of psoriasis to a lymphocyte-selective toxin (DAB389IL-2) suggests a primary immune, but not keratinocyte, pathogenic basis. Nat Med $1,442-7$

Griffiths CE, Strober BE, van de Kerkhof P, HO V, Fidelus-Gort R, Yeilding N, Guzzo C, Xia Y, Zhou B, Li S et al. (2010): Comparison of ustekinumab and etanercept for moderate-tosevere psoriasis. N Engl J Med $\underline{362}, 118-28$

Groves RW, Allen MH, Barker JN, Haskard DO, MacDonald DM (1991): Endothelial leucocyte adhesion molecule-1 (ELAM-1) expression in cutaneous inflammation. Br J Dermatol $\underline{124}$, $117-23$

Hao Q, Wang L, Tang H (2009): Vascular endothelial growth factor induces protein kinase Ddependent production of proinflammatory cytokines in endothelial cells. Am J Physiol Cell Physiol 296, C821-7

Harrington LE, Hatton RD, Mangan PR, Turner H, Murphy TL, Murphy KM, Weaver CT (2005): Interleukin 17-producing CD4+ effector T cells develop via a lineage distinct from the $T$ helper type 1 and 2 lineages. Nat Immunol $\underline{6}, 1123-1132$

Heinrich PC, Castell JV, Andus T (1990): Interleukin-6 and the acute phase response. Biochem J $\underline{265}, 621-36$

Held KD, Epp ER, Clark EP, Biaglow JE (1988): Effect of dimethyl fumarate on the radiation sensitivity of mammalian cells in vitro. Radiat Res $\underline{115}$, 495-502

Helle M, Brakenhoff JP, De Groot, Aarden LA (1988): Interleukin 6 is involved in interleukin 1induced activities. Eur J Immunol $\underline{18}$, 957-9 
Henseler T, Christophers E (1985): Psoriasis of early and late onset: characterization of two types of psoriasis vulgaris. J Am Acad Dermatol $\underline{13}$, 450-6

Heydendael VM, Spuls PI, Opmeer BC, de Borgie CA, Reitsma JB, Goldschmidt WF, Bossuyt PM, Bos JD, De Rie MA (2003): Methotrexate versus cyclosporine in moderate-to-severe chronic plaque psoriasis. N Engl J Med $\underline{349}, 658-65$

Homey B, Alenius H, Muller A, Soto H, Bowman EP, Yuan W, McEvoy L, Lauerma Al, Assmann T, Bunemann E et al. (2002): CCL27-CCR10 interactions regulate T cell-mediated skin inflammation. Nat Med $\underline{8}, 157-65$

Horikawa S, Yoneya R, Nagashima Y, Hagiwara K, Ozasa H (2002): Prior induction of heme oxygenase-1 with glutathione depletor ameliorates the renal ischemia and reperfusion injury in the rat. FEBS Lett $\underline{510}, 221-4$

Itoh T, Tanioka M, Yoshida H, Yoshioka T, Nishimoto H, Itohara S (1998): Reduced angiogenesis and tumor progression in gelatinase A-deficient mice. Cancer Res $\underline{58}, 1048-51$

Jung U, Ley K (1999): Mice lacking two or all three selectins demonstrate overlapping and distinct functions for each selectin. J Immunol 162, 6755-62

Kansas GS (1996): Selectins and their ligands: current concepts and controversies. Blood $\underline{88}$, 3259-87

Kapp A (1993): The role of cytokines in the psoriatic inflammation. J Dermatol Sci $\underline{5}, 133-42$

Kim I, Moon SO, Kim SH, Kim HJ, Koh YS, Koh GY (2001):Vascular endothelial growth factor expression of intercellular adhesion molecule 1 (ICAM-1), vascular cell adhesion molecule 1 (VCAM-1), and E-selectin through nuclear factor-kappa B activation in endothelial cells. J Biol Chem $\underline{276}, 7614-20$ 
Kolbach DN, Nieboer C (1992): Fumaric acid therapy in psoriasis: results and side effects of 2 years of treatment. J Am Acad Dermatol 27, 769-71

Konstantinova NV, Duong DM, Remenyik E, Hazarika P, Chuang A, Duvic M (1996): Interleukin-8 is induced in skin equivalents and is highest in those derived from psoriatic fibroblasts. J Invest Dermatol 107, 615-21

Konter U, Kellner I, Klein E, Kaufmann R, Mielke V, Sterry W (1989): Adhesion molecule mapping in normal human skin. Arch Dermatol Res 281, 454-62

Kupper TS (2003): Immunologic targets in psoriasis. N Engl J Med 349: 1987-90

Le JM, Vilcek J (1989): Interleukin 6: a multifunctional cytokine regulating immune reactions and the acute phase protein response. Lab Invest $\underline{61}, 588-602$

Lebwohl M (2003): Psoriasis. Lancet 361, 1197-204

Lehmann JC, Listopad JJ, Rentzsch CU, Igney FH, von Bonin A, Hennekes HH, Asadullah K, Docke WD (2007): Dimethylfumarate induces immunosuppression via glutathione depletion and subsequent induction of heme oxygenase 1. J Invest Dermatol $\underline{127}$, 835-45

Leonardi CL, Powers JL, Matheson RT, Goffe BS, Zitnik R, Wang A, Gottlieb AB (2003): Etanercept as monotherapy in patients with psoriasis. N Engl J Med 349, 2014-22

Lew W, Bowcock AM, Krueger JG (2004): Psoriasis vulgaris: cutaneous lymphoid tissue supports T-cell activation and "Type 1" inflammatory gene expression. Trends Immunol $\underline{25}$, 295-305

Litjens NH, van Strijen E, van Gulpen C, Mattie H, van Dissel JT, Thio HB, Nibbering PH (2004a): In vitro pharmacokinetics of anti-psoriatic fumaric acid esters. BMC Pharmacol $\underline{4}$, 22-28 
Litjens NH, Rademaker M, Ravensbergen, Rea D, van der Plas MJ, Thio B, Walding a, van Dissel JT, Nibbering PH (2004b): Monomethylfumarate affects polarization of monocytederived dendritic cells resulting in down-regulated Th1 lymphocyte responses. Eur J Immunol $\underline{34}, 565-75$

Litjens NH, Burggraaf J, van Strijen E, van Gulpen C, Mattie H, Schoemaker RC, van Dissel JT, Thio HB, Nibbering PH (2004c): Pharmacokinetics of oral fumarates in healthy subjects. Br J Clin Pharmacol $\underline{58}, 429-32$

Litjens NH, Rademaker M, Ravensbergen B, Thio HB, van Dissel JT, Nibbering PH (2006): Effects of monomethylfumarate on dendritic cell differentiation. $\mathrm{Br} J$ Dermatol 154, 211-7

Lizzul PF, Aphale A, Malaviya R, Sun Y, Masud S, Dombrovskiy V, Gottlieb AB (2005): Differential expression of phosphorylated NF-kappaB/RelA in normal and psoriatic epidermis and downregulation of NF-kappaB in response to treatment with etanercept. J Invest Dermatol $\underline{124}, 1275-83$

Loewe R, Pillinger M, de Martin R, Mrowietz U, Groger M, Holnthoner W, Wolff K, Wiegrebe W, Jirovsky D, Petzelbauer P (2001): Dimethylfumarate inhibits tumor-necrosis-factorinduced CD62E expression in an NF-kappa B-dependent manner. J Invest Dermatol 117, $1363-8$

Loewe R, Holnthoner W, Groger M, Pillinger M, Gruber F, Mechtcheriakova D, Hofer E, Wolff K, Petzelbauer P (2002): Dimethylfumarate inhibits TNF-induced nuclear entry of NF-kappa B/p65 in human endothelial cells. J Immunol $168,4781-7$

Loewe R, Valero T, Kremling S, Pratscher B, Kunstfeld R, Pehamberger H, Petzelbauer P (2006): Dimethylfumarate impairs melanoma growth and metastasis. Cancer Res $\underline{66}, 11888-$ 96 
Mallon E, Bunce M, Wojnarowska F, Welsh (1997): HLA-CW*0602 is a susceptibility factor in type I psoriasis, and evidence Ala-73 is increased in male type I psoriatics. J Invest Dermatol $109,183-6$

Martin D, Galisteo R, Gutkind JS (2009): CXCL8/IL8 stimulates vascular endothelial growth factor (VEGF) expression and the autocrine activation of VEGFR2 in endothelial cells by activating NFkappaB through the CBM (Carma3/Bcl10/Malt1) complex. J Biol Chem $\underline{284}$, 6038-42

Mason J, Mason AR, Cork MJ (2002): Topical preparations for the treatment of psoriasis: a systematic review. Br J Dermatol 146, 351-64

Meissner M, Doll M, Hrgovic I, Reichenbach G, König V, Hailemariam-Jahn T, Gille J, Kaufmann J (2011): Suppression of VEGFR2 Expression in Human Endothelial Cells by Dimethylfumarate Treatment: Evidence for Anti-Angiogenic Action. J Invest Dermatol 131, $1356-64$

Melder RJ, Koenig GC, Witwer BP, Safabakhsh N, Mann LL, Jain RK (1996): During angiogenesis, vascular endothelial growth factor and basic fibroblast growth factor regulate natural killer cell adhesion to tumor endothelium. Nat Med 2, 992-7

Micali G, Lacarrubba F, Musumeci ML, Massimino D, Nasca MR (2010): Cutaneous vascular patterns in psoriasis. Int J Dermatol; $\underline{49}, 249-56$

Michel G, Mirmohammadsadegh A, Olasz E, Jarzebska-Deussen B, Muschen A, Kemeny L, Abts HF, Ruzicka T (1997): Demonstration and functional analysis of IL-10 receptors in human epidermal cells: decreased expression in psoriatic skin, down-modulation by IL-8, and up-regulation by an antipsoriatic glucocorticosteroid in normal cultured keratinocytes. J Immunol 159, 6291-7

Morris A, Rogers M, Fischer G, Williams K (2001): Childhood psoriasis: a clinical review of 1262 cases. Pediatr Dermatol $\underline{18}, 188-98$ 
Moser B, Clark-Lewis I, Zwahlen R, Baggiolini M (1990): Neutrophil-activating properties of the melanoma growth-stimulatory activity. J Exp Med 171, 1797-802

Mrowietz U, Christophers E, Altmeyer P (1998): Treatment of psoriasis with fumaric acid esters: results of a prospective multicentre study. German Multicentre Study. Br J Dermatol $1998 ; \underline{138}, 456-60$

Mrowietz U, Rostami-Yazdi M, Neureither M, Reich K (2009): 15 years of fumaderm: fumaric acid esters for the systemic treatment of moderately severe and severe psoriasis vulgaris. J Dtsch Dermatol Ges $\underline{7}$ Suppl 2, 3-16

Mueller W, Herrmann B (1979): Cyclosporin A for psoriasis. N. Engl. J. Med $\underline{301}, 555$

Muller WA (2001): Migration of leukocytes across endothelial junctions: some concepts and controversies. Microcirculation $\underline{8}, 181-93$

Muller WA, WeigI SA, Deng X, Phillips DM (1993): PECAM-1 is required for transendothelial migration of leukocytes. J Exp Med $\underline{178}, 449-60$

Nast A, Boehncke WH, Mrowietz U, Ockenfels HM, Philipp S, Reich K, Rosenbach T, Sammain A, Schlaeger M, Sebastian M et al. (2011): S3-Leitlinie zur Therapie der Psoriasis vulgaris Update 2011. J Dtsch Dermatol Ges $\underline{9}$, 1-104

Nieboer C, de Hoop D, van Loenen AC, Langendijk PN, van Dijk E (1989): Systemic therapy with fumaric acid derivates: new possibilities in the treatment of psoriasis. J Am Acad Dermatol $\underline{20}, 601-8$

Nieboer C, de Hoop D, Langendijk PN, van Loenen AC, Gubbels J (1990): Fumaric acid therapy in psoriasis: a double-blind comparison between fumaric acid compound therapy and monotherapy with dimethylfumaric acid ester. Dermatologica 181, 33-7 
Nielsen HJ, Christensen IJ, Svendsen MN, Hansen U, Werther K, Brunner N, Petersen LJ, Kristensen JK (2002): Elevated plasma levels of vascular endothelial growth factor and plasminogen activator inhibitor-1 decrease during improvement of psoriasis. Inflamm Res $\underline{51}, 563-7$

Ockenfels HM, Schultewolter T, Ockenfels G, Funk R, Goos M (1998): The antipsoriatic agent dimethylfumarate immunomodulates T-cell cytokine secretion and inhibits cytokines of the psoriatic cytokine network. Br J Dermatol 139, 390-5

Oostingh GJ, Schlickum S, Friedl P, Schön MP (2007): Impaired induction of adhesion molecule expression in immortalized endothelial cells leads to functional defects in dynamic interactions with lymphocytes. J Invest Dermatol $\underline{127}$, 2253-8

Pang ML, Murase JE, Koo J (2008): An updated review of acitretin--a systemic retinoid for the treatment of psoriasis. Expert Opin Drug Metab Toxicol $\underline{4}$, 953-64

Reynolds NJ, Al-Daraji WI (2002): Calcineurin inhibitors and sirolimus: mechanisms of action and applications in dermatology. Clin Exp Dermatol 27, 555-61

Robert C, Kupper TS (1999): Inflammatory skin diseases, T cells, and immune surveillance. N Engl J Med 341, 1817-28

Roebuck KA, Finnegan A (1999): Regulation of intercellular adhesion molecule-1 (CD54) gene expression. J Leukoc Biol $\underline{66}$, 876-88

Rohde D, Schluter-Wigger W, Mielke V, von den Driesch P, von Gaudecker B, Sterry W (1992): Infiltration of both T cells and neutrophils in the skin is accompanied by the expression of endothelial leukocyte adhesion molecule-1 (ELAM-1): an immunohistochemical and ultrastructural study. J Invest Dermatol $\underline{98}, 794-9$ 
Rostami-Yazdi M, Clement B, Schmidt TJ, Schinor D, Mrowietz U (2009): Detection of metabolites of fumaric acid esters in human urine: implications for their mode of action. $J$ Invest Dermatol $\underline{129}, 231-4$

Rostami-Yazdi M, Clement B, Mrowietz U (2010): Pharmacokinetics of anti-psoriatic fumaric acid esters in psoriasis patients. Arch Dermatol Res 302, 531-8

Rothlein R, Dustin ML, Marlin SD, Springer TA (1986): A human intercellular adhesion molecule (ICAM-1) distinct from LFA-1. J Immunol 137, 1270-4

Rubant SA, Ludwig RJ, Diehl S, Hardt K, Kaufmann R, Pfeilschifter JM, Boehncke WH (2008): Dimethylfumarate reduces leukocyte rolling in vivo through modulation of adhesion molecule expression. J Invest Dermatol $\underline{128}, 326-31$

Schmidt TJ, Ak M, Mrowietz U (2007): Reactivity of dimethyl fumarate and methylhydrogen fumarate towards glutathione and $\mathrm{N}$-acetyl-L-cysteine-preparation of S-substituted thiosuccinic acid esters. Bioorg Med Chem $\underline{15}$, 333-42

Schön, MP, Boehncke WH (2005): Psoriasis. N Engl J Med 352; 1899-912

Schön MP, Ludwig RJ (2005): Lymphocyte trafficking to inflamed skin--molecular mechanisms and implications for therapeutic target molecules. Expert Opin Ther Targets $\underline{9}$, 225-43

Schön MP, Detmar M, Parker CM (1997): Murine psoriasis-like disorder induced by naive CD4+ T cells. Nat Med $\underline{3}, 183-8$

Schön MP, Krahn T, Schön M, Rodriguez ML, Antonicek H, Schult JE, Ludwig RJ, Zollner TM, Bischoff E, Bremm KD et al. (2002): Efomycine M, a new specific inhibitor of selectin, impairs leukocyte adhesion and alleviates cutaneous inflammation. Nat Med $\underline{8}, 366-72$ 
Schön MP, Zollner TM, Boehncke WH (2003): The molecular basis of lymphocyte recruitment to the skin: clues for pathogenesis and selective therapies of inflammatory disorders. J Invest Dermatol $\underline{121}, 951-62$

Schönthaler HB, Huggenberger R, Wculek SK, Detmar M, Wagner EF (2009): Systemic antiVEGF treatment strongly reduces skin inflammation in a mouse model of psoriasis. Proc Natl Acad Sci USA 106; 21264-21269

Schopf RE, Aust H, Knop J (2002): Treatment of psoriasis with the chimeric monoclonal antibody against tumor necrosis factor alpha, infliximab. J Am Acad Dermatol 4ㅌ, 886-91

Schröder JM, Gregory H, Young J, Christophers E (1992): Neutrophil-activating proteins in psoriasis. J Invest Dermatol $\underline{98}, 241-7$

Schütz M, Teifel M, Friedl P (1997): Establishment of a human placental endothelial cell line with extended life span after transfection with SV 40 T-antigens. Eur J Cell Biol $\underline{74}$, 315-20

Stadnyk AW (1994): Cytokine production by epithelial cells. FASEB J $\underline{8}, 1041-7$

Steinman $L$ (2007): A brief history of $T(H) 17$, the first major revision in the $T(H) 1 / T(H) 2$ hypothesis of T cell-mediated tissue damage. Nat Med 13, 139-145.

Tedder TF, Steeber DA, Chen A, Engel P (1995): The selectins: vascular adhesion molecules. FASEB J $\underline{9}, 866-73$

Thio HB, Zomerdijk TP, Oudshoorn C, Kempenaar J, Nibbering PH, Van der Schroeff JG, Ponec M (1994): Fumaric acid derivatives evoke a transient increase in intracellular free calcium concentration and inhibit the proliferation of human keratinocytes. Br J Dermatol 131, 85661

Thomas KA (1996): Vascular endothelial growth factor, a potent and selective angiogenic agent. J Biol Chem 271, 603-6 
Todderud G, Nair X, Lee D, Alford J, Davern L, Stanley P, Bachand C, Lapointe P, Marinier A, Martel A et al. (1997): BMS-190394, a selectin inhibitor, prevents rat cutaneous inflammatory reactions. J Pharmacol Exp Ther 282, 1298-304

Treumer F, Zhu K, Glaser R, Mrowietz U (2003): Dimethylfumarate is a potent inducer of apoptosis in human T cells. J Invest Dermatol $\underline{121}, 1383-8$

Vestergaard C, Just H, Baumgartner Nielsen J, Thestrup-Pedersen K, Deleuran M (2004): Expression of CCR2 on monocytes and macrophages in chronically inflamed skin in atopic dermatitis and psoriasis. Acta Derm Venereol $\underline{84}, 353-8$

Wetzel A, Wetzig T, Haustein UF, Sticherling M, Anderegg U, Simon JC, Saalbach A (2006): Increased neutrophil adherence in psoriasis: role of the human endothelial cell receptor Thy1 (CD90). J Invest Dermatol $\underline{126}, 441-52$

Wrone-Smith T, Nickoloff BJ (1996): Dermal injection of immunocytes induces psoriasis. J Clin Invest $98,1878-87$

Xia YP, Li B, Hylton D, Detmar M, Yancopoulos GD, Rudge JS (2003): Transgenic delivery of VEGF to mouse skin leads to an inflammatory condition resembling human psoriasis. Blood $102,161-8$

Young HS, Summers AM, Bhushan M, Brenchley PE, Griffiths CE (2004): Single-nucleotide polymorphisms of vascular endothelial growth factor in psoriasis of early onset. J Invest Dermatol 122, 209-15

Zalewska A, Glowacka E, Wyczolkowska J, Tchorzewski H, Narbutt J, Sysa-Jedrzejowska A (2006): Interleukin 6 and 8 levels in plasma and fibroblast cultures in psoriasis. Mediators Inflamm 2006, 1-6

Zhu K, Mrowietz U (2001): Inhibition of dendritic cell differentiation by fumaric acid esters. J Invest Dermatol 116, 203-8 
Zibert JR, Wallbrecht K, Schön M, Mir LM, Jacobsen GK, Trochon-Joseph V, Bouquet C, Villadsen LS, Cadossi R, Skov L, Schön MP (2011): Halting angiogenesis by non-viral somatic gene therapy alleviates psoriasis and murine psoriasiform skin lesions. J Clin Invest $\underline{121}, 410-$ 421

Zollner TM, Asadullah K (2003): Selectin and selectin ligand binding: a bittersweet attraction. J Clin Invest 112, 980-3 


\section{Publikation}

Teile dieser Arbeit wurden veröffentlicht:

Wallbrecht K*, Drick N*, Hund AC, Schön MP (2011): Downregulation of endothelial adhesion molecules by dimethylfumarate, but not monomethylfumarate, and impairment of dynamic lymphocyte-endothelial cell interactions. Exp Dermatol 20, 980-5

* geteilte Erstautorenschaft 


\section{Danksagung}

Herrn Prof. Dr. M. P. Schön danke ich für die Bereitstellung des Themas, seine Diskussionsbereitschaft und die freundliche Unterstützung und Betreuung.

Frau K. Zachmann danke ich für ihre Hilfsbereitschaft, mit der sie mir bei Fragen und beim Erlernen neuer Methoden zur Seite stand.

Dankbar bin ich Tillmann Schill, der mir so manches Mal mit Rat und Tat zur Seite stand und immer bemüht war, alle meine Fragen zu beantworten.

Des Weiteren danke ich Nadin Pletz, Verena Lorenz und Philine Schneider für die motivierende und zugleich entspannte Atmosphäre und für viele schöne, lehrreiche und auch spaßige Stunden im Labor.

Mein besonderer Dank gilt Frau Dr. Wallbrecht, die mir mit ihrer Diskussionsbereitschaft, ihren Anregungen und Lösungsvorschlägen bei der Erstellung dieser Arbeit immer hilfreich und unterstützend zur Seite stand. Sowohl ihr außerordentliches Engagement als auch ihr Interesse an meinem Fortschritt und ihre endlose Geduld trugen maßgeblich zum Gelingen dieser Arbeit bei. 


\section{Lebenslauf}

Am 21. Dezember 1985 wurde ich als Tochter von Herbert Drick und Maria Hackling-Drick, geb. Hackling, in Berlin geboren.

Von 1992 bis 1998 besuchte ich die Schweizerhof-Grundschule und ab 1998 das SchadowGymnasium in Berlin-Zehlendorf. Die 2. Hälfte des 11. Schuljahres verbrachte ich an der North Montgomery High School in Crawfordsville, Indiana in den USA. Im Juni 2005 erlangte ich die allgemeine Hochschulreife.

Zum Wintersemester 2005/2006 begann ich das Studium der Humanmedizin an der GeorgAugust-Universität zu Göttingen. Im Herbst 2007 legte ich den ersten Abschnitt der Ärztlichen Prüfung ab. Zu Beginn des Jahres 2009 begann ich in der Abteilung Dermatologie, Venerologie und Allergologie der Universitätsmedizin Göttingen meine Dissertation zum Erwerb des Doktorgrades der Humanmedizin. Im Februar 2011 begann ich mein Praktisches Jahr mit dem Chirurgie-Tertial, welches ich zu gleichen Teilen im Evangelischen Krankenhaus Oldenburg und an der Mount Sinai School of Medicine, New York absolvierte. Das Tertial für Innere Medizin leistete ich am Emil-von-Behring Krankenhaus in Berlin-Zehlendorf ab. Zurzeit absolviere ich mein drittes Tertial in meinem Wahlfach Dermatologie an der Uniklinik Göttingen. 